\title{
Combination inhaled steroid and long-acting beta2-agonist in addition to tiotropium versus tiotropium or combination alone for chronic obstructive pulmonary disease (Review)
}

Rojas-Reyes MX, García Morales OM, Dennis RJ, Karner C

Rojas-Reyes MX, García Morales OM, Dennis RJ, Karner C.

Combination inhaled steroid and long-acting beta 2 -agonist in addition to tiotropium versus tiotropium or combination alone for chronic obstructive pulmonary disease.

Cochrane Database of Systematic Reviews 2016, Issue 6. Art. No.: CD008532.

DOI: 10.1002/14651858.CD008532.pub3.

\section{www.cochranelibrary.com}


TABLE OF CONTENTS

HEADER

ABSTRACT

PLAIN LANGUAGE SUMMARY

SUMMARY OF FINDINGS

BACKGROUND

OBJECTIVES

METHODS

RESULTS

Figure 1.

Figure 2.

Figure 3.

Figure 4.

Figure 5.

Figure 6.

DISCUSSION

AUTHORS' CONCLUSIONS

ACKNOWLEDGEMENTS

REFERENCES

CHARACTERISTICS OF STUDIES

DATA AND ANALYSES

Analysis 1.1. Comparison 1 Tiotropium + LABA/ICS combination versus tiotropium + placebo, Outcome 1 Mortality (all-cause).

Analysis 1.2. Comparison 1 Tiotropium + LABA/ICS combination versus tiotropium + placebo, Outcome 2 Hospital admission (all causes).

Analysis 1.3. Comparison 1 Tiotropium + LABA/ICS combination versus tiotropium + placebo, Outcome 3 Exacerbation. .........

Analysis 1.4. Comparison 1 Tiotropium + LABA/ICS combination versus tiotropium + placebo, Outcome 4 Quality of life up to 6 months (SGRQ).

Analysis 1.5. Comparison 1 Tiotropium + LABA/ICS combination versus tiotropium + placebo, Outcome 5 Sensitivity analysis - QoL up to 6 months (SGRQ).

Analysis 1.6. Comparison 1 Tiotropium + LABA/ICS combination versus tiotropium + placebo, Outcome 6 FEV1 pre-dose. ...... Analysis 1.7. Comparison 1 Tiotropium + LABA/ICS combination versus tiotropium + placebo, Outcome 7 Serious adverse events all reported (non-fatal).

Analysis 1.8. Comparison 1 Tiotropium + LABA/ICS combination versus tiotropium + placebo, Outcome 8 Pneumonia. ........... Analysis 1.9. Comparison 1 Tiotropium + LABA/ICS combination versus tiotropium + placebo, Outcome 9 Sensitivity analysis - SAE all reported (non-fatal).

Analysis 1.10. Comparison 1 Tiotropium + LABA/ICS combination versus tiotropium + placebo, Outcome 10 Adverse event. .... Analysis 2.1. Comparison 2 Tiotropium + LABA/ICS combination vs LABA/ICS combination + placebo, Outcome 1 FEV1 GIV. .... Analysis 2.2. Comparison 2 Tiotropium + LABA/ICS combination vs LABA/ICS combination + placebo, Outcome 2 Adverse event.

Analysis 2.3. Comparison 2 Tiotropium + LABA/ICS combination vs LABA/ICS combination + placebo, Outcome 3 FEV1. ......... ADDITIONAL TABLES

APPENDICES

FEEDBACK

WHAT'S NEW

HISTORY

CONTRIBUTIONS OF AUTHORS

DECLARATIONS OF INTEREST

SOURCES OF SUPPORT

DIFFERENCES BETWEEN PROTOCOL AND REVIEW

INDEX TERMS

1

1

2

3

5

6

6

8

10

13

15

16

16

17

18

20

20

21

24

35

36

36

37

37

38

38

38

39

39

40

40

40

41

Combination inhaled steroid and long-acting beta ${ }_{2}$-agonist in addition to tiotropium versus tiotropium or combination alone for chronic 
[Intervention Review]

\title{
Combination inhaled steroid and long-acting beta2-agonist in addition to tiotropium versus tiotropium or combination alone for chronic obstructive pulmonary disease
}

\author{
Maria Ximena Rojas-Reyes¹, Olga M García Morales², Rodolfo J Dennis ${ }^{1,3}$, Charlotta Karner4 \\ 1Department of Clinical Epidemiology and Biostatistics, Faculty of Medicine, Pontificia Universidad Javeriana, Bogotá, Colombia. \\ 2Department of Internal Medicine, Faculty of Medicine, Pontificia Universidad Javeriana, Bogotá, Colombia. ${ }^{3}$ Research Department, \\ Fundacion Cardioinfantil Instituto de Cardiologia, Bogota, Colombia. ${ }^{4}$ BMJ-TAG, BMJ, London, UK
}

Contact address: Maria Ximena Rojas-Reyes, Department of Clinical Epidemiology and Biostatistics, Faculty of Medicine, Pontificia Universidad Javeriana, Cr. 7 \#40-62, 2nd floor, Bogotá, DC, Colombia.mxrojas@gmail.com, mxrojas@javeriana.edu.co.

Editorial group: Cochrane Airways Group.

Publication status and date: Edited (no change to conclusions), comment added to review, published in Issue 6, 2017.

Citation: Rojas-Reyes MX, García Morales OM, Dennis RJ, Karner C. Combination inhaled steroid and long-acting beta 2 -agonist in addition to tiotropium versus tiotropium or combination alone for chronic obstructive pulmonary disease. Cochrane Database of Systematic Reviews 2016, Issue 6. Art. No.: CD008532. DOI: 10.1002/14651858.CD008532.pub3.

Copyright @ 2017 The Cochrane Collaboration. Published by John Wiley \& Sons, Ltd.

\section{A B S T R A C T}

\section{Background}

The long-acting bronchodilator tiotropium and single-inhaler combination therapy of inhaled corticosteroids and long-acting beta ${ }^{-}$ agonists (ICS/LABA) are commonly used for maintenance treatment of patients with chronic obstructive pulmonary disease (COPD). Combining these treatments, which have different mechanisms of action, may be more effective than administering the individual components.

\section{Objectives}

To assess relative effects of the following treatments on markers of exacerbations, symptoms, quality of life and lung function in patients with COPD.

- Tiotropium plus LABA/ICS versus tiotropium.

- Tiotropium plus LABA/ICS versus LABA/ICS.

\section{Search methods}

We searched the Cochrane Airways Group Specialised Register of Trials (April 2015), ClinicalTrials.gov (www.ClinicalTrials.gov), the World Health Organization (WHO) trials portal and reference lists of relevant articles.

\section{Selection criteria}

We included parallel, randomised controlled trials (RCTs) lasting three months or longer conducted to compare ICS and LABA combination therapy in addition to inhaled tiotropium versus tiotropium alone or combination therapy alone.

\section{Data collection and analysis}

We independently assessed trials for inclusion, then extracted data on trial quality and outcome results. We contacted study authors to ask for additional information. We collected trial information on adverse effects. 


\section{Main results}

\section{Tiotropium plus LABA/ICS versus tiotropium}

We included six studies (1902 participants) with low risk of bias that compared tiotropium in addition to inhaled corticosteroid and longacting beta2-agonist combination therapy versus tiotropium alone. We found no statistically significant differences in mortality between treatments (odds ratio (OR) 1.80, 95\% confidence interval (CI) 0.55 to 5.91; two studies; 961 participants) as well as in the all-cause hospitalisations (OR $0.84,95 \% \mathrm{Cl} 0.53$ to 1.33; two studies; 961 participants). The effect on exacerbations was heterogeneous among trials and was not meta-analysed. Health-related quality of life measured by St. George's Respiratory Questionnaire (SGRQ) showed a statistically significant improvement in total scores with use of tiotropium + LABA/ICS compared with tiotropium alone (mean difference (MD) -3.46, $95 \% \mathrm{Cl}-5.05$ to -1.87 ; four studies; 1446 participants). Lung function was significantly different in the combined therapy (tiotropium + LABA/ ICS) group, although average benefit with this therapy was small. None of the included studies included exercise tolerance as an outcome.

A pooled estimate of these studies did not show a statistically significant difference in adverse events (OR $1.16,95 \% \mathrm{Cl} 0.92$ to 1.47 ; four studies; 1363 participants), serious adverse events (OR 0.86, 95\% CI 0.57 to 1.30; four studies; 1758 participants) and pneumonia (Peto OR $1.62,95 \% \mathrm{Cl} 0.54$ to 4.82 ; four studies; 1758 participants).

\section{Tiotropium plus LABA/ICS versus LABA/ICS}

One of the six studies (60 participants) also compared combined therapy (tiotropium + LABA/ICS) versus LABA/ICS therapy alone. This study was affected by lack of power; therefore results did not allow us to draw conclusions for this comparison.

\section{Authors' conclusions}

This review update includes three additional studies and provides new low quality evidence supporting the finding that tiotropium + LABA/ ICS-based therapy improves the disease-specific quality of life. The current evidence is insufficient to support the benefit of tiotropium + LABA/ICS-based therapy for mortality, hospital admission or exacerbations (moderate and low quality evidence). Compared with use of tiotropium alone, tiotropium + LABA/ICS-based therapy does not seem to increase undesirable effects nor serious non-fatal adverse events.

\section{PLAIN LANGUAGE SUMMARY}

\section{Are tiotropium plus combination inhalers better than tiotropium or combination inhalers alone for the treatment of COPD?}

\section{Background}

Chronic obstructive pulmonary disease (COPD) is a lung disease that includes the conditions chronic bronchitis and/or emphysema. COPD is characterised by narrowing of the airways and lung tissue destruction. Symptoms include breathlessness and long-term cough. Symptoms of COPD are treatable, but the condition cannot be reversed or cured. It is usually brought on by airway irritants, such as smoking or inhaled dust.

Inhalers with bronchodilators (which allow the airways in the lungs to relax and expand) and/or anti-inflammatory agents are commonly used to ease symptoms and minimise the long-term decline in health caused by COPD. Examples of these treatments are tiotropium, which is a bronchodilator, and combination inhalers, which contain another type of bronchodilator (long-acting beta-agonists) together with anti-inflammatory agents (steroids). These treatments work in different ways and therefore might be more beneficial if used together.

\section{Study characteristics}

This review found six studies, involving 1902 participants, comparing the long-term efficacy and side effects of tiotropium combined with combination inhalers for treatment of patients with COPD. Not all of the people included in these studies had COPD that was severe enough to be recommended for combined therapy according to current guidelines.

\section{Key results}

Current evidence shows potential benefits of treatment with tiotropium in addition to inhaled corticosteroid and long-acting beta2-agonist combination therapy through increased health-related quality of life and a small improvement in lung function in patients receiving this combined therapy. However, this evidence does not allow us to draw conclusions about the effects of these treatments on mortality, hospitalisation for all causes and exacerbations. The frequency of serious and non-serious adverse events was not increased in either of the two groups.

\section{Quality of the evidence}

Overall, we assessed the evidence presented in this review to be of moderate or low quality, which means we are reasonably confident in some of the findings, but less confident in others. 


\begin{tabular}{|c|c|c|c|c|c|c|c|}
\hline \multirow{12}{*}{ 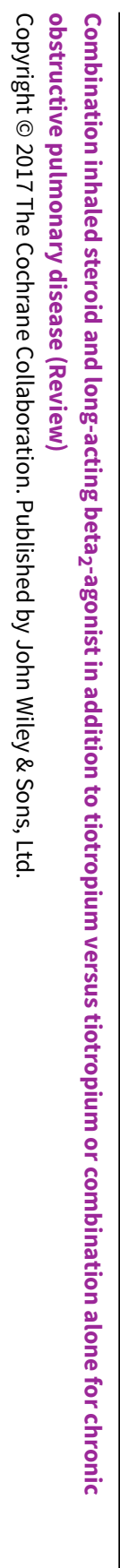 } & \multicolumn{7}{|c|}{$\begin{array}{l}\text { S U M M A R Y O F F I N D I N G S } \\
\text { Summary of findings for the main comparison. Tiotropium + LABA/ICS combination compared with tiotropium for chronic obstructive pulmonary } \\
\text { disease }\end{array}$} \\
\hline & \multicolumn{7}{|c|}{ Tiotropium + LABA/ICS combination compared with tiotropium for chronic obstructive pulmonary disease } \\
\hline & \multicolumn{7}{|c|}{$\begin{array}{l}\text { Patient or population: patients with chronic obstructive pulmonary disease } \\
\text { Settings: ambulatory clinics } \\
\text { Intervention:tiotropium + LABA/ICS combination } \\
\text { Comparison: tiotropium }\end{array}$} \\
\hline & \multirow[t]{2}{*}{ Outcomes } & \multicolumn{2}{|c|}{ Illustrative comparative risks* $(95 \% \mathrm{CI})$} & \multirow{2}{*}{$\begin{array}{l}\text { Relative effect } \\
(95 \% \mathrm{CI})\end{array}$} & \multirow{2}{*}{$\begin{array}{l}\text { Number of par- } \\
\text { ticipants (stud- } \\
\text { ies) }\end{array}$} & \multirow{2}{*}{$\begin{array}{l}\text { Quality of } \\
\text { the evidence } \\
\text { (GRADE) }\end{array}$} & \multirow[t]{2}{*}{ Comments } \\
\hline & & $\begin{array}{l}\text { Assumed risk } \\
\text { Tiotropium }\end{array}$ & $\begin{array}{l}\text { Corresponding risk } \\
\text { Tiotropium + LABA/ICS combination }\end{array}$ & & & & \\
\hline & Mortality (all-cause) & 8 per 1000 & $\begin{array}{l}15 \text { per } 1000 \\
(5 \text { to } 47)\end{array}$ & $\begin{array}{l}\text { OR } 1.80 \\
(0.55 \text { to } 5.91)\end{array}$ & $\begin{array}{l}961 \\
\text { (2 studies) }\end{array}$ & $\begin{array}{l}\oplus \oplus \oplus \ominus \\
\text { Moderatea,b }\end{array}$ & \\
\hline & $\begin{array}{l}\text { Hospital admission (all } \\
\text { causes) }\end{array}$ & 156 per 1000 & $\begin{array}{l}101 \text { per } 1000 \\
(69 \text { to } 145)\end{array}$ & $\begin{array}{l}\text { OR } 0.84 \\
(0.53 \text { to } 1.33)\end{array}$ & $\begin{array}{l}961 \\
\text { (2 studies) }\end{array}$ & $\begin{array}{l}\oplus \oplus \ominus \ominus \\
L_{0} a, b\end{array}$ & \\
\hline & $\begin{array}{l}\text { Exacerbation - at } 12- \\
\text { month follow-up }\end{array}$ & 628 per 1000 & $\begin{array}{l}601 \text { per } 1000 \\
(486 \text { to } 704)\end{array}$ & $\begin{array}{l}\text { OR } 0.89 \\
(0.56 \text { to } 1.41)\end{array}$ & $\begin{array}{l}301 \\
\text { (1 study) }\end{array}$ & $\begin{array}{l}\oplus \oplus \ominus \ominus \\
L_{0} w^{a, b}\end{array}$ & \\
\hline & $\begin{array}{l}\text { Serious adverse events } \\
\text { (non-fatal) }\end{array}$ & 60 per 1000 & $\begin{array}{l}52 \text { per } 1000 \\
(35 \text { to } 76)\end{array}$ & $\begin{array}{l}\text { OR } 0.86 \\
(0.57 \text { to } 1.30)\end{array}$ & $\begin{array}{l}1758 \\
\text { (4 studies) }\end{array}$ & $\begin{array}{l}\oplus \oplus \Theta \Theta \text { a,c } \\
\text { Low }\end{array}$ & \\
\hline & $\begin{array}{l}\text { Quality of life up to } 6 \\
\text { months (SGRQ) }\end{array}$ & & $\begin{array}{l}\text { Mean SGRQ up to } 6 \text { months in the intervention } \\
\text { groups was } 3.46 \text { lower ( } 5.05 \text { to } 1.87 \text { lower) }\end{array}$ & - & (4 studies) & $\begin{array}{l}\oplus \oplus \odot{ }^{d} \\
\text { Low }\end{array}$ & $\begin{array}{l}\text { A lower score } \\
\text { indicates better } \\
\text { quality of life }\end{array}$ \\
\hline & $\begin{array}{l}\mathrm{FEV}_{1} \text { pre-dose - } \mathrm{FEV}_{1} 3-6 \\
\text { months mean difference }\end{array}$ & & $\begin{array}{l}\text { Mean } \mathrm{FEV}_{1} \text { pre-dose }-\mathrm{FEV}_{1} 3-6 \text { months mean } \\
\text { difference in the intervention groups was } 0.06 \\
(0.04 \text { to } 0.08)\end{array}$ & - & (4 studies) & $\begin{array}{l}\oplus \oplus \oplus \ominus \\
\text { Moderatee }\end{array}$ & \\
\hline & $\begin{array}{l}\mathrm{FEV}_{1} \text { pre-dose }-\mathrm{FEV}_{1} 1 \\
\text { year }\end{array}$ & & $\begin{array}{l}\text { Mean } \mathrm{FEV}_{1} \text { pre-dose }-\mathrm{FEV}_{1} 1 \text { year mean differ- } \\
\text { ence in the intervention groups was } 0.06 \text { ( } 0 \text { to } \\
0.12 \text { ) }\end{array}$ & - & (1 study) & $\begin{array}{l}\oplus \oplus \oplus \odot \\
\text { Moderatea,b }\end{array}$ & \\
\hline
\end{tabular}




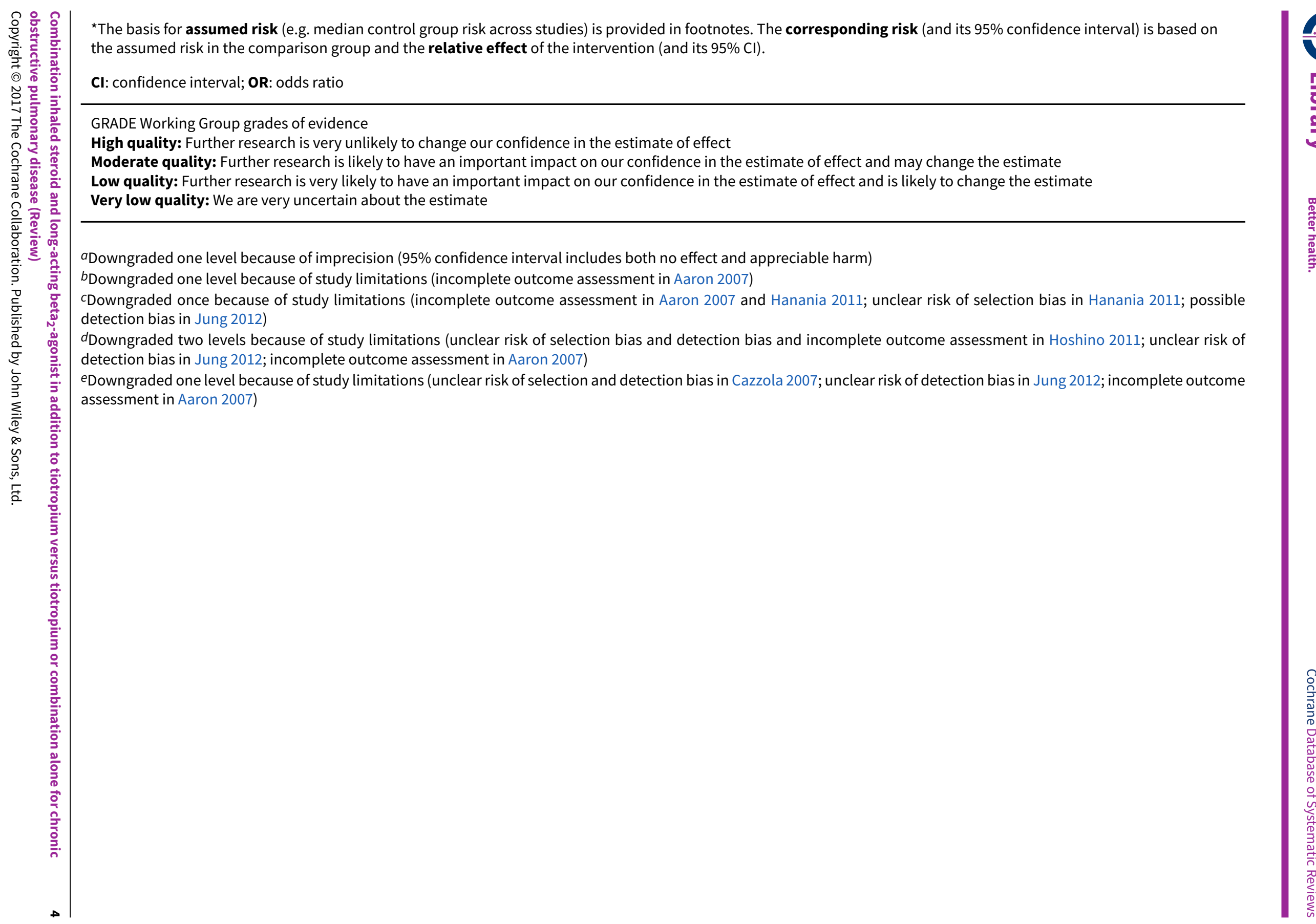




\section{B A C K G R O U N D}

\section{Description of the condition}

Chronic obstructive pulmonary disease (COPD) is a general term that refers to chronic bronchitis or emphysema, or both. COPD occurs when airflow to the lungs is restricted by narrowing of the airways. Symptoms include cough, breathlessness and reduced exercise capacity. The Global Initiative for Chronic Obstructive Lung Disease (GOLD 2015) guidelines describe COPD as a preventable and treatable condition that is not fully reversible. Worldwide, the main cause of COPD is tobacco smoking, but air pollution, burning of biomass and occupational exposure are also risk factors (GOLD 2015). The prevalence, morbidity and mortality of the disease vary across populations, and the disorder causes a substantial economic and social burden.

Various pharmacological treatments are commonly used in COPD management to relieve symptoms, improve exercise tolerance and quality of life, reduce mortality and prevent and treat exacerbations. Exacerbations of COPD impair patients' quality of life, and a large part of the economic burden of COPD is attributed to the cost of managing exacerbations, particularly those resulting in the use of acute care services or hospitalisations (Hutchinson 2010). Appropriate pharmacological management of the disease is therefore important to reduce and prevent exacerbations. Management of COPD tends to begin with one treatment, and additional therapies are introduced as necessary to control symptoms (GOLD 2015). Self-management, education, vaccination and rehabilitation can accompany these pharmacological interventions (Effing 2007; Lacasse 2006; Sehatzadeh 2012).

\section{Description of the intervention}

The first pharmacological step in treating patients with COPD consists of the use of short-acting bronchodilators for symptom control when needed. These include short-acting beta 2 -agonists (SABA) and the short-acting anticholinergic agent ipratropium. To manage persistent COPD symptoms, long-acting bronchodilators can be introduced (GOLD 2015). Regular treatment with long-acting bronchodilators is more efficient and convenient than treatment with regular short-acting bronchodilators (Beeh 2010). Long-acting bronchodilators include long-acting beta 2 -agonists (LABA) and the long-acting anticholinergic agent tiotropium. Tiotropium bromide has gained widespread acceptance as once daily maintenance therapy in COPD (Barr 2005; GOLD 2015). Tiotropium reduces COPD exacerbations and related hospitalisations compared with ipratropium (Barr 2005). Most LABA are taken twice daily. They improve lung function compared with ipratropium, but little difference is shown in improving COPD symptoms and exercise tolerance (Appleton 2006). For symptomatic patients with severe or very severe COPD (forced expiratory volume in one second $\left(\mathrm{FEV}_{1}\right)<50 \%$ predicted) and with repeated exacerbations, GOLD 2015 recommends the addition of inhaled corticosteroids (ICS) to bronchodilator treatment. Inhaled corticosteroids are licensed as combination inhalers with LABA. The most common combinations of ICS and LABA in combination inhalers are fluticasone and salmeterol; budesonide and formoterol; and mometasone and formoterol. Combination therapy reduces exacerbation rates and mortality compared with ICS alone (Nannini 2013). Also compared with LABA alone, combination therapy is more effective in reducing exacerbation rates, but with no significant difference in mortality
(Nannini 2007b). For patients who continue to have symptoms and are at high risk of experiencing exacerbations, triple therapy with LABA, long-acting muscarinic antagonists (LAMA, e.g. tiotropium) and ICS is recommended. Such patients are referred to as 'Group $D^{\prime}$ ' in the GOLD guidelines; this group typically includes patients classified as GOLD 3 and 4 , i.e. FEV $1<50 \%$ of predicted value (GOLD 2015). Benefits of combination inhalers should be viewed against the possible increased risk of pneumonia (Nannini 2007b; Nannini 2013). Potential risks and benefits of treatment with combination inhaler compared with tiotropium are uncertain (Welsh 2010), as are risks and benefits of treatment with combination inhaler in addition to tiotropium, which will be explored in this review.

\section{How the intervention might work}

\section{Tiotropium}

Tiotropium (TIO) is a long-acting anticholinergic agent that targets bronchospasm in COPD by relaxing the smooth muscle of the airways. Tiotropium is structurally related to ipratropium, a short-acting anticholinergic agent that binds to M1, M2 and M3 muscarinic receptors, which in turn open the bronchi (Barr 2005). Although tiotropium binds to the same receptors as ipratropium, it has different kinetic selectivity. Tiotropium dissociates slowly from $\mathrm{M} 1$ and $\mathrm{M} 3$ receptors, giving a bronchodilator effect lasting over 24 hours, but rapidly from $M 2$ receptors. It appears that $M 2$ receptors are feedback inhibitory receptors, and blocking them (as is the case for ipratropium) releases acetylcholine rather than reducing it as desired (Barr 2005). Benefits of tiotropium, in comparison with placebo, include reduced COPD exacerbations and exacerbationrelated hospitalisations, and improved health-related quality of life and symptom scores among patients with moderate and severe disease (Barr 2005). Anticholinergic side effects can occur with tiotropium and include dry mouth, constipation and tachycardia.

\section{Inhaled beta 2 -agonist plus inhaled corticosteroids}

Inhaled beta 2 -agonists activate beta 2 -receptors in the smooth muscle of the airways, releasing adenylate cyclase and increasing intracellular cyclic adenosine monophosphate (cAMP), which leads to a cascade of reactions resulting in bronchodilation. Beta $2_{2}$ agonists may act through other mechanisms such as respiratory muscle function or mucociliary clearance; patients have shown improvement in symptoms whilst showing no improvement in lung function tests. Beta 2 -agonists are particularly useful because they reverse bronchoconstriction regardless of its initial cause. Side effects include muscle tremors, nervousness and occasional insomnia, but, as with all inhaled medications, systemic side effects are minimised by a comparatively low dose administered directly to the lungs. Inhaled corticosteroids are anti-inflammatory drugs that have been associated with reduced risk of exacerbation in patients with COPD and with better quality of life outcomes when compared with placebo, with no effect on overall mortality or longterm FEV 1 (GOLD 2015; Yang 2012). Combination inhalers including ICS and LABA reduce exacerbation rates and all-cause mortality and improve lung function and quality of life compared with placebo (Nannini 2007a). These effects are thought to be greater for combination inhalers than for the component preparations (GOLD 2015). Use of inhaled corticosteroids, alone or in combination with beta 2 -agonists, potentially increases the risk of pneumonia (GOLD 2015; Yang 2012). 
The combination inhalers currently available are fluticasone/ salmeterol (FSC); budesonide/formoterol (BUD/F); and beclomethasone/formoterol (DPB/F).

\section{Combination therapy}

The nature of the interaction between the two systems is not yet fully understood, but combining beta ${ }_{2}$-adrenergic receptor agonists and muscarinic acetylcholine receptor antagonists is pharmacologically reasonable, given that airway tone is regulated by the parasympathetic and sympathetic nervous systems. The synergistic effect of these therapies can be explained in several ways. One explanation is that the addition of a beta ${ }_{2}$-adrenergic receptor agonist decreases release of acetylcholine (ACh) and amplifies bronchial smooth muscle relaxation; another is that the addition of a muscarinic acetylcholine receptor antagonist can reduce bronchoconstrictor effects of $\mathrm{ACh}$ and amplify bronchodilation through direct stimulation of the smooth muscle beta $_{2}$-adrenergic receptor (Cazzola 2010). An animal model showed activation of calcium-activated potassium ( $\mathrm{KCa}$ ) channels thought to hyperpolarise the cell membrane, causing reductions in the concentration of intracellular calcium $(\mathrm{Ca})$ and $\mathrm{ACh}$ release in prejunctional cholinergic nerves (Brichetto 2003).

\section{Why it is important to do this review}

The previous version of this review showed a significant effect of combination therapy tiotropium + LABA/ICS on $\mathrm{FEV}_{1}$ in participants with stable COPD, in comparison with tiotropium therapy alone. However, sparse evidence was found to support similar beneficial effects on other important outcomes, such as all-cause hospitalisations, exacerbations and mortality. New published trials have been conducted with the aim of comparing these therapies; therefore it is necessary to include their results as part of this review to obtain more precise estimations of treatment effects on outcomes for which combination therapy effects remain unclear.

\section{O B JECT IVES}

To assess relative effects of the following treatments on markers of exacerbations, symptoms, quality of life and lung function in patients with COPD.

- Tiotropium plus LABA/ICS versus tiotropium.

- Tiotropium plus LABA/ICS versus LABA/ICS.

\section{METHODS}

\section{Criteria for considering studies for this review}

\section{Types of studies}

For effectiveness and safety objectives, we included randomised controlled trials (RCTs) of parallel design conducted in patients with stable COPD who received the trial treatment for at least 12 weeks.

For economic objectives, we included economic evaluation studies such as cost-effectiveness analyses and cost-utility analyses addressing the same interventions in the population of interest for this review. We considered for inclusion the economic evaluation conducted alongside the RCT or economic evaluation modelling studies based on a comprehensive systematic review of the literature. We excluded partial economic evaluation studies reporting cost analysis or cost-outcome descriptions.

\section{Types of participants}

Populations with a diagnosis of COPD. We included only studies that used an external set of criteria to screen participants for this condition (e.g. ATS; BTS; GOLD 2015; TSANZ).

\section{Types of interventions}

Inhaled combination corticosteroid and long-acting beta $2^{-}$ agonist (such as fluticasone/salmeterol, budesonide/formoterol, beclomethasone/formoterol) and tiotropium bromide versus:

- inhaled tiotropium bromide alone; or

- inhaled corticosteroid and long-acting beta2-agonist combination.

\section{Types of outcome measures}

\section{Primary outcomes}

- Mortality (all-cause).

- Exercise tolerance.

- Hospital admissions: all-cause and due to exacerbations.

- Exacerbations: all-cause, requiring short burst oral corticosteroids or antibiotics as defined by agreed criteria.

- Health-related quality of life (measured with a validated scale for COPD, e.g. St George's Respiratory Questionnaire (SGRQ), Chronic Respiratory Disease Questionnaire (CRQ)).

- Serious adverse events non-fatal.

- Pneumonia.

\section{Secondary outcomes}

- Symptoms.

- Forced expiratory volume in one second $\left(\mathrm{FEV}_{1}\right)$.

- Adverse events.

- Side effects.

- Cost-effectiveness of interventions.

\section{Search methods for identification of studies}

\section{Electronic searches}

The previously published version of this review (Karner 2011) included searches up to July 2010. The search period for this update is July 2010 to April 2015.

For this update, we identified trials from the Cochrane Airways Group Specialised Register (CAGR), which is maintained by the Information Specialist for the Group. The Register contains trial reports identified through systematic searches of bibliographic databases including the Cochrane Central Register of Controlled Trials (CENTRAL), MEDLINE, EMBASE, the Cumulative Index to Nursing and Allied Health Literature (CINAHL), the Allied and Complementary Medicine Database (AMED) and PsycINFO, and by handsearching of respiratory journals and meeting abstracts (please see Appendix 1 for further details). We searched all records in the CAGR using the search strategy provided in Appendix 2.

We also conducted a search of ClinicalTrials.gov (www.ClinicalTrials.gov) and the World Health Organization (WHO) 
trials portal (www.who.int/ictrp/en/). We searched all databases from their inception to the present, with no restriction on the language of publication. We conducted the latest search in April 2015.

\section{Searching other resources}

We reviewed reference lists of all primary studies and review articles for additional references. We contacted authors of identified trials and asked them to identify other published or unpublished studies.

\section{Data collection and analysis}

\section{Selection of studies}

Two review authors (OMG and RJD) screened the titles and abstracts of citations retrieved through literature searches and obtained those deemed to be potentially relevant. We assigned each reference to a study identifier and assessed all references against the inclusion criteria of the protocol.

Two review authors (OMG and RJD) independently examined titles and abstracts for the selection of health economics studies to be included in the critical review of economic data. We removed records that did not report on cost-effectiveness or costutility analysis. Two review authors (MXR and RJD) independently examined full-text reports to determine which studies met the eligibility criteria of this review. We resolved disagreements by discussion between review authors. We included only full economic evaluations of high methodological and reporting quality.

\section{Data extraction and management}

We extracted the following characteristic information from each study.

- Design (design, total duration of study and run-in, number of study centres and locations, withdrawals, date of study).

- Participants (N, mean age, age range, gender, COPD severity, diagnostic criteria, baseline lung function, smoking history, inclusion criteria, exclusion criteria).

- Interventions (run-in, intervention treatment and inhaler type, control treatment and inhaler type).

- Outcomes (primary and secondary outcomes specified and collected, time points reported).

Two review authors (MXR and OMG) extracted data from the studies onto data collection forms. Review authors discussed discrepancies in the data and resolved them and transferred data from data collection forms into RevMan (RevMan 2014).

Data obtained by authors from the previous version of this review regarding all cause hospital admissions that were supplied by Aaron 2007 and by AstraZeneca (for Welte 2009) on request, were kept for this update without changes.

\section{Assessment of risk of bias in included studies}

We assessed all included studies for risk of bias according to the recommendations outlined in the Cochrane Handbook for Systematic Reviews of Interventions (Higgins 2011) for the following items.

\section{- Allocation sequence generation.}

- Concealment of allocation.

- Blinding of participants and investigators.

- Incomplete outcome data.

- Selective outcome reporting.

We noted other sources of bias and graded each potential source of bias as having high, low or unclear risk.

We assessed the methodological quality of economic evaluations by using the Drummond checklist (Drummond 1996), which addresses the following methodological and reporting aspects.

- Was a well-defined question posed?

- Was a comprehensive description of competing alternatives given?

- Does the paper provide evidence that the programme would be effective (i.e. would the programme do more harm than good)?

- Were all important and relevant resource uses (costs) for each alternative identified?

- Were all important and relevant health outcome consequences for each alternative identified?

- Were costs measured accurately in appropriate units before evaluation and valued credibly?

- Were health outcome consequences measured credibly?

- Were costs and health outcome consequences adjusted for the different times at which they occurred (i.e. was discounting applied)?

- Was an incremental analysis of the consequences and costs of alternatives performed?

- Was an adequate sensitivity analysis performed?

\section{Quality of the body of evidence for each outcome}

We assessed the quality of evidence for the main comparison at the outcome level using the Grading of Recommendations Assessment, Development and Evaluation (GRADE) approach (Guyatt 2011). This methodological approach considers RCTs as providing high-quality evidence that may be rated down by limitations in any of five areas: design (risk of bias), consistency across studies, directness of the evidence, precision of estimates and presence of publication bias (Guyatt 2011). The GRADE approach results in an assessment of the quality of a body of evidence in one of four grades: (1) high: We are very confident that the true effect lies close to that of the estimate of effect; (2) moderate: We are moderately confident in the effect estimate: The true effect is likely to be close to the estimate of effect but may be substantially different; (3) low: Our confidence in the effect estimate is limited: The true effect may be substantially different from the estimate of effect; (4) very low: We have very little confidence in the effect estimate: The true effect is likely to be substantially different from the estimate of effect (GRADE 2013).

Two review authors (OMG and MXR) independently assessed the quality of the body of evidence found for each of the outcomes identified as critical or important for clinical decision making: mortality, hospital admission (all causes), exacerbation at 12 months, improvement in $\mathrm{FEV}_{1}$, serious adverse events and quality of life. In the case that the study authors did not take measures to ensure concealment of allocation, randomised assignment, completion to follow-up or blinded outcome assessment, we downgraded the quality of evidence because of design limitations (GRADE 2013). We evaluated consistency by similarity of point

Combination inhaled steroid and long-acting beta 2 -agonist in addition to tiotropium versus tiotropium or combination alone for chronic 
estimates, extent of overlap of confidence intervals ( $\mathrm{Cls}$ ) and application of statistical criteria including testing for heterogeneity (12). We planned to downgrade the quality of evidence if we detected substantial unexplained heterogeneity across study results (i.e. some studies suggest important benefit and others no effect or harm without a clinical explanation) (GRADE 2013). We assessed precision according to the $95 \% \mathrm{Cl}$ around the pooled estimate (GRADE 2013). When studies were conducted in populations other than the target population, the GRADE framework suggests that the quality of evidence should be downgraded because of indirectness (GRADE 2013).

We entered data (i.e. pooled estimates of effects and corresponding $95 \% \mathrm{Cls}$ ) and explicit judgements that were made for each of the above aspects into the GRADEprofiler (GDT), the software used to create Summary of findings (SoF) tables. We explained in the SoF table footnotes all judgements involved in assessment of the aspects of the evidence described above.

\section{Measures of treatment effect}

We performed all statistical analyses using RevMan software (RevMan 2014). We analysed dichotomous data (such as mortality, hospital admission, number of participants with one or more exacerbations) using the Mantel-Haenszel odds ratio (OR) and risk difference (RD), unless events were rare, in which case we employed the Peto OR (as this does not require a continuity correction for zero cells). For statistically significant results of categorical variables, we reported the number needed to treat for an additional beneficial outcome (NNTB).

We analysed continuous outcome data (such as quality of life (score) and $\mathrm{FEV}_{1}$ ) using the mean difference (MD). We reported the $95 \% \mathrm{Cl}$ on all estimates as fixed-effect mean differences with $95 \%$ $\mathrm{CI}$. When treatment effects were reported as a mean difference with $95 \% \mathrm{Cl}$, we entered the MD and standard errors calculated from the $95 \% \mathrm{Cl}$ and analysed data using the generic inverse variance (GIV) tool.

\section{Unit of analysis issues}

We analysed dichotomous data by using participants as the unit of analysis (rather than events) to avoid counting the same participant more than once.

\section{Dealing with missing data}

We contacted investigators and study sponsors to verify key study characteristics and to obtain missing numerical outcome data.

\section{Assessment of heterogeneity}

We assessed the amount of statistical variation between study results by using the $1^{2}$ measurement.

\section{Assessment of reporting biases}

We minimised reporting bias from non-publication of studies or selective outcome reporting by using a broad search strategy, by contacting study authors directly and by checking references of included studies. We planned to assess reporting bias by visual inspection of funnel plots.

\section{Data synthesis}

We combined dichotomous data using the Mantel-Haenszel OR with $95 \% \mathrm{Cls}$ by using a fixed-effect model. We combined rate ratios and hazard ratios using GIV in a fixed-effect model and compared them with the random-effects model. We planned to calculate the NNTB outcome from the pooled OR and its $\mathrm{Cl}$, and to apply appropriate levels of baseline risk. We have presented the findings of our primary outcomes in Summary of findings for the main comparison, which we generated by using GradePro software.

We did not perform pooled calculations of economic data. Rather, we presented the characteristics and results of included economic studies in a descriptive way in the additional tables (Table 1; Table 2), including the final incremental cost-effectiveness ratios (ICERs) reported by study authors in Euros (EUR). We did not adjust the values of ICERs provided by study authors because most identified studies were conducted in similar settings and during a similar time period (2009 to 2010) using the same information resource, as all are based on the same clinical trial data.

\section{Subgroup analysis and investigation of heterogeneity}

We planned to perform subgroup analyses for effectiveness and safety data on the basis of types of combination therapy and differences in baseline risk (severity of disease at baseline), provided at least three studies per subgroup were included in a specific comparison. However, included studies did not provide data for these subgroup analyses. Included studies reported outcomes at different follow-up periods, and different followperiods may be associated with different treatment effects; therefore, we decided to include three subgroup analyses: at threemonth follow-up; at six-month follow-up; and at 12-month followup.

\section{Sensitivity analysis}

The sensitivity analysis takes into account biases that could significantly impact the outcomes of included studies. We planned to perform a sensitivity analysis to assess how results of the metaanalysis would be affected by excluding studies determined to be at a high risk of bias. Two studies (Hoshino 2011; Jung 2012) were open-label studies; therefore we performed a sensitivity analysis for outcomes of quality of life (QoL) and for all severe adverse events (non-fatal).

\section{RE S U L T S}

\section{Description of studies}

\section{Results of the search}

The initial search carried out in July 2010 yielded 101 references, from which only three studies (Aaron 2007; Cazzola 2007; Welte 2009) were included and one RCT was classified as awaiting assessment (Fang 2008). Details of the search results from the previous review are described in Appendix 3. We updated these searches in April 2015 and identified 250 new references from July 2010. Of these, 13 references were selected as potentially relevant and underwent full-text review. Three new studies (Hanania 2011; Hoshino 2011; Jung 2012) and three economic analyses (Mittmann 2011; Najafzadeh 2008; Nielsen 2013) met the criteria for inclusion, two RCTs were classified as ongoing studies (Betsuyaku 2013; Cohuet 2013) and one RCT was classified as awaiting assessment (Lee 2014) because only results from the abstract presented at a 
scientific meeting were available. We excluded four studies (see the Excluded studies section). We did not find published results of the Fang 2008 study for this review; therefore, it is still awaiting assessment.

In summary, for the clinical effectiveness objective we included a total of six studies (Aaron 2007; Cazzola 2007; Hanania
2011; Hoshino 2011; Jung 2012; Welte 2009), randomising 1902 participants to comparisons of interest for the review. We included three studies (Mittmann 2011; Najafzadeh 2008; Nielsen 2013) for the economic evaluation objective related to cost-effectiveness (Figure 1). 
Figure 1. Study flow diagram.

3 studies already included in previous version of this review

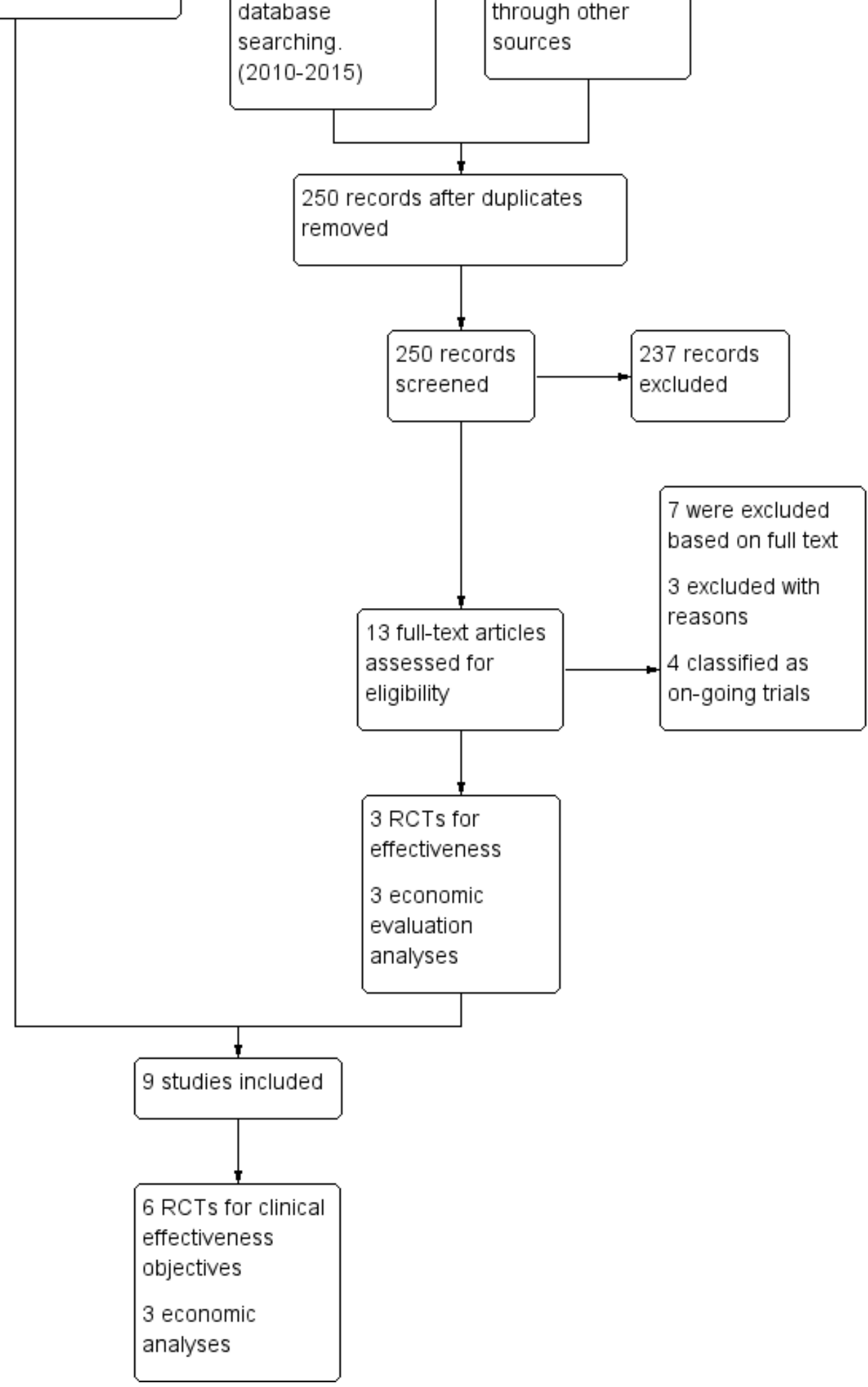

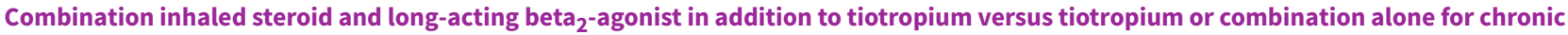




\section{Included studies}

\section{Randomised controlled trials (RCTs)}

We included a total of six RCTs in this review. All included studies (Aaron 2007; Cazzola 2007; Hanania 2011; Hoshino 2011; Jung 2012; Welte 2009) assessed the effectiveness of tiotropium plus LABA/ ICS in comparison with tiotropium, and just one study (Cazzola 2007) also compared the effectiveness of tiotropium plus LABA/ICS versus $L A B A / I C S$ (see the Characteristics of included studies table and Table 3). Not all of the participants enrolled in the included studies were eligible for triple therapy according to the current guidance (GOLD 2015).

Aaron 2007 is a randomised, double-blind, placebo-controlled study that was conducted in Canada with the aim of comparing the safety and effectiveness of tiotropium plus placebo versus tiotropium plus fluticasone plus salmeterol as one-year maintenance therapy in participants with moderate or severe COPD. This study included 449 participants (301 in a comparison of interest in this review) older than 35 years of age, with a forced expiratory volume in one second $\left(\mathrm{FEV}_{1}\right)$-to-forced vital capacity (FVC) ratio of less than 0.70 and a post-bronchodilator $\mathrm{FEV}_{1}$ of less than $65 \%$ of the predicted value. Participants had to have at least one exacerbation of COPD that required treatment with systemic steroids or antibiotics within the 12 months before randomisation. Participants were assigned to receive tiotropium plus placebo or tiotropium plus fluticasone-salmeterol. Measures of efficacy included the proportion of participants who experienced an exacerbation of COPD that required treatment with systemic steroids or antibiotics, lung function, disease-specific quality of life, number of hospitalisations for COPD exacerbations and all-cause hospitalisations. It is likely that most participants in this study would be eligible for triple therapy according to current guidance (GOLD 2015).

Cazzola 2007 is a randomised, double-blind, double-dummy, parallel-group study that was conducted in Italy to compare the efficacy and safety of three treatments for 12 weeks: (1) fluticasone/ salmeterol (FSC) 500/50 mg Diskus, one inhalation twice daily + placebo Handihaler, one inhalation once daily; (2) tiotropium 18 mg Handihaler, one inhalation once daily + placebo Diskus, one inhalation twice daily; (3) FSC 500/50 mg Diskus, one inhalation twice daily + tiotropium $18 \mathrm{mg}$ Handihaler, one inhalation once daily. This study included 90 participants 50 years of age or older with well-controlled severe or very severe COPD (FEV $1 \%$ predicted $\leq 50 \%$ ) who were current or former smokers (20 or more pack-years) and were randomised to receive FSC, tiotropium or their combination. Study authors provided no information on the exacerbation status of participants during the year before enrolment. The primary efficacy measure was the mean change from baseline in pre-dose $\mathrm{FEV}_{1}$ after three-months of treatment. Secondary efficacy measures included change from baseline in the validity assessment score (VAS) assessing dyspnoea and supplemental salbutamol. It is likely that most participants in this study would be eligible for triple therapy according to current guidance (GOLD 2015).

Hanania 2011 is a randomised, double-blind, parallel-group, multicentre study of 24 weeks, conducted at 33 centres in the USA to compare the efficacy and safety of FSC (250/50 mcg twice daily) when added to tiotropium ( $18 \mathrm{mcg}$ once daily) in participants with symptomatic moderate to severe COPD. The study included 342 participants who were 40 years of age or older with a cigarette smoking history $\geq 10$ pack-years and with a diagnosis of COPD and post-bronchodilator $\mathrm{FEV}_{1} \geq 40 \%$ to $\leq 80 \%$ of predicted normal and $\mathrm{FEV}_{1} / \mathrm{FVC}$ of 0.70 . In the year before enrolment, $43 \%$ of participants in the tiotropium plus FSC group had experienced at least one exacerbation, and $33 \%$ in the tiotropium alone group. Participants were randomised in a 1:1 double-blind fashion to open-label tiotropium $18 \mathrm{mcg}$ once daily plus FSC $250 / 50$ mcg twice daily or open-label tiotropium $18 \mathrm{mcg}$ once daily plus placebo twice daily. Measures of efficacy included evaluation of lung function (pre-dose $\mathrm{FEV}_{1}$, post-dose $\mathrm{FEV}_{1}$, pre-dose FVC and post-dose FVC), use of rescue medication, healthcare utilisation for COPD exacerbations, health status evaluated with domain scores on the Chronic Respiratory Disease Questionnaire-Self Administered Standardised (CRQ-SAS) and safety. It is likely that most participants in this study would not be recommended triple therapy according to current guidance (GOLD 2015).

Hoshino 2011 is a randomised, open-label, parallel-group study conducted in Japan with the aim of comparing the efficacy and tolerability of salmeterol/fluticasone propionate added to tiotropium for 12 weeks. This study included 30 participants with an $\mathrm{FEV}_{1} / \mathrm{FVC}$ ratio less than 0.70 , a smoking history $>10$ pack-years and no history of asthma or atopy. Eligible participants had mild to very severe COPD and were newly diagnosed or had not been treated previously with LAMA, LABA or ICS. Investigators provided no information on the exacerbation status of participants in the year before enrolment. They were randomised to receive inhaled tiotropium once daily or inhaled SFC twice daily, in combination with tiotropium once daily, for 12 weeks. Measures of efficacy included changes in airway dimensions on computed tomography (CT), pulmonary function testing and assessments of health-related quality of life using the SGRQ. It is unclear what proportion of participants in this study would be eligible for triple therapy according to current guidance (GOLD 2015).

Jung 2012 is a randomised, open-label, multi-centre two-arm parallel-group study conducted in 30 academic hospital-based pulmonary clinics in Korea with the aim of comparing the efficacy of tiotropium (18 mg once daily) plus FSC (250/50 mg twice daily) versus tiotropium monotherapy. This study included 479 participants diagnosed with moderate to very severe COPD, who had a post-bronchodilator $\mathrm{FEV}_{1} / \mathrm{FVC}$ ratio less than 0.70 and $\mathrm{FEV}_{1}$ less than $65 \%$ of predicted value; eligible participants were 40 to 80 years of age and had a smoking history of at least 10 pack-years. Investigators provided no information on the exacerbation status of participants in the year before enrolment. Participants were randomised to one of two treatment groups for 24-week treatment: tiotropium $18 \mathrm{mg}$ once daily; or tiotropium $18 \mathrm{mg}$ once daily plus FSC, 250/50 mg/puff, one puff twice daily. Measures of efficacy included evaluation of lung function (change in pre-bronchodilator $\mathrm{FEV}_{1}$ (L); changes in pre-bronchodilator inspiratory capacity (IC); FVC and percent predicted (\% pred) values for $\mathrm{FEV}_{1}$ ); mean changes in health-related quality of life; frequency of COPD exacerbations; exacerbations requiring hospitalisation, emergency room visits or outpatient clinic visits; and hospitalisation rates for all causes. It is unclear what proportion of participants in this study would be recommended triple therapy according to current guidance (GOLD 2015), but likely it would be less than half.

Combination inhaled steroid and long-acting beta ${ }_{2}$-agonist in addition to tiotropium versus tiotropium or combination alone for chronic 
Welte 2009 is a randomised, double-blind, parallel-group, multicentre study conducted to compare the efficacy and tolerability of budesonide/formoterol added to tiotropium for 12 weeks. This study included 660 participants with severe or very severe COPD, with a pre-bronchodilator $\mathrm{FEV}_{1}$ not exceeding $50 \%$ of predicted normal value and a history of at least one exacerbation requiring systemic steroids and/or antibiotics in the previous year. Participants were randomised to receive tiotropium $18 \mathrm{mg}$ once daily plus budesonide/formoterol $320 / 9 \mathrm{mg}$ one inhalation twice daily or placebo twice daily. Measures of efficacy included clinic assessment of lung function and health status (change in pre-dose $\mathrm{FEV}_{1}$, pre-dose and post-dose spirometry measurements and SGRQ for COPD), morning lung function assessments, COPD symptoms and morning activities, use of reliever medication, exacerbations and tolerability. It is likely that most of the participants in this study would be eligible for triple therapy according to current guidance (GOLD 2015).

\section{Economic evaluation analysis}

Of the three economic analyses included, two (Mittmann 2011; Nielsen 2013) reported on the economic evaluation conducted alongside the Welte 2009 clinical trial (the CLIMB trial) in six of the nine participant countries; Nielsen 2013 conducted the economic evaluation in four Nordic countries (Sweden, Denmark, Finland, Norway) and Mittmann 2011 in three countries (Canada, Australia, Sweden); both study authors reported on the incremental cost-effectiveness ratio for exacerbation avoided with tiotropium $+\mathrm{LABA} / \mathrm{ICS}$ relative to tiotropium from the healthcare system perspective. Najafzadeh 2008 conducted the economic evaluation from the Canadian healthcare system perspective alongside the Aaron 2007 study (OPTIMAL trial) and reported on the incremental cost-effectiveness ratio per exacerbation avoided and the incremental cost-effectiveness ratio per quality-adjusted lifeyear (QALY). Investigators calculated the utilities used for the cost-utility analysis from the results of SGRQ as applied to trial participants.

We have presented detailed characteristics of these economic evaluations in Table 1.

\section{Excluded studies}

The initial search carried out in July 2010 revealed eight studies that failed to meet eligibility criteria for the review (see the Characteristics of excluded studies table). Four of these compared tiotropium alone with combination therapy (Ando 2008; Bateman 2008; Golabi 2006; Hara 2007), and one study compared tiotropium with LABA alone (Petroianni 2008). The remaining three studies were shorter than three months in duration (Biscione 2009; Perng 2006), and one used a cross-over design (Singh 2008).

Searches updated to April 2015 identified seven studies that failed to meet eligibility criteria for the review (see the Characteristics of excluded studies table). Two of these evaluated tiotropium versus placebo (Tashkin 2008; Troosters 2008), and one study compared tiotropium alone versus the LABA/ICS combination (Sarac 2013). One study (Maltais 2013) was shorter than three months, and four were added to Studies awaiting classification and Ongoing studies.

\section{Risk of bias in included studies}

We have presented the assessment of risk of bias in the Characteristics of included studies table, and an overview of the findings in Figure 2. 
Figure 2. Risk of bias summary: review authors' judgements about each risk of bias item for each included study.

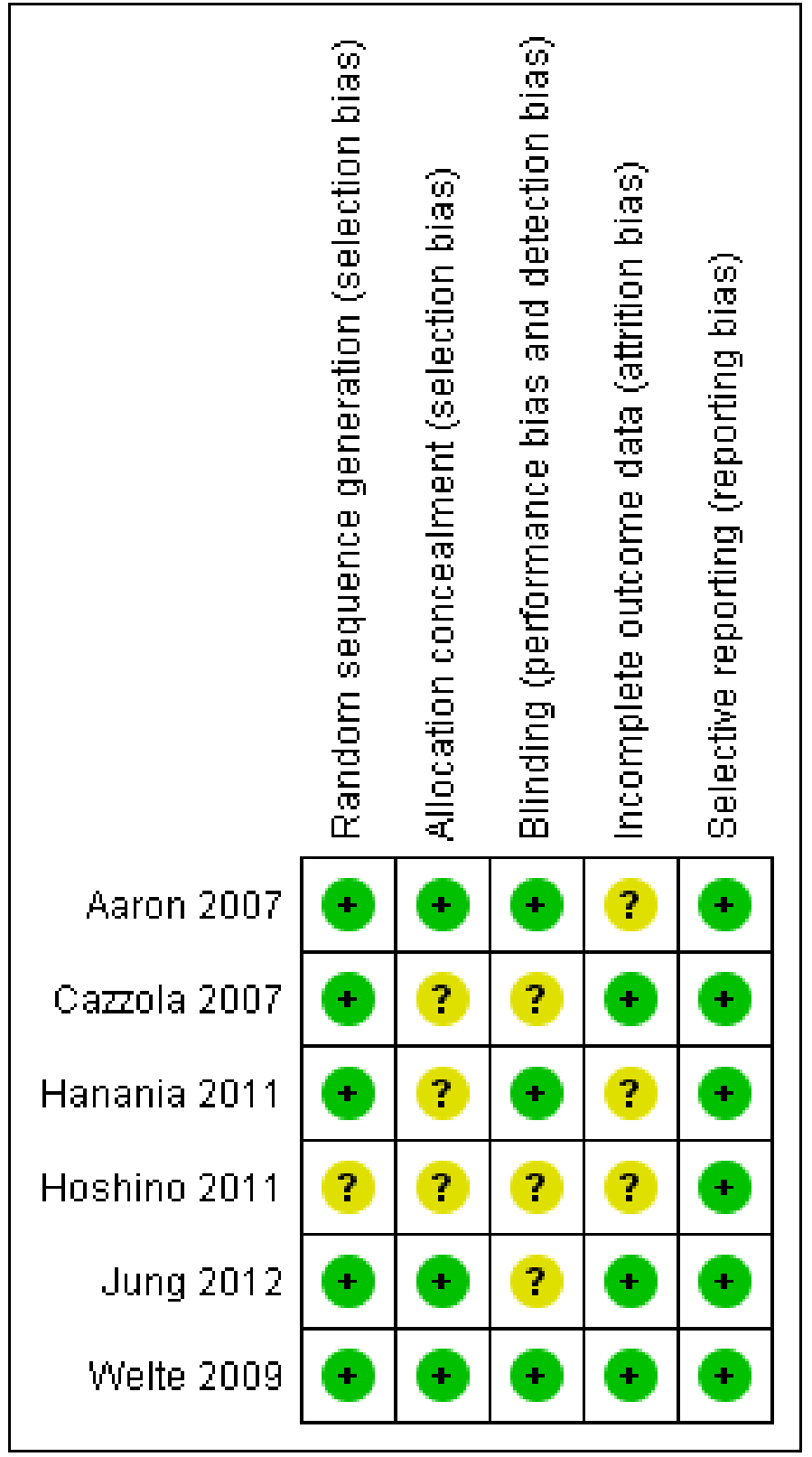

We have summarised results of the quality assessment of economic evaluation studies in Table 2. We assessed all included economic evaluations according to their full-text publications. In general, the economic evaluations included met the methodological and reporting aspects evaluated by the Drummond checklist, and their results can be considered valid (Drummond 1996). In the economic evaluations conducted by Mittmann 2011, Nielsen 2013 and Najafzadeh 2008, discounting was not applied to costs and consequences. However, this was considered to be methodologically correct because the time horizon used in these analyses was three months and one year, respectively, making discounting unnecessary.

\section{Allocation}

Aaron 2007, Welte 2009 and Jung 2012 reported adequate sequence generation and allocation concealment. Details for
Welte 2009 were supplied on request. For these three studies, randomisation was computer-generated through central allocation, and both research staff and participants were blinded to the treatment assignment until the end of the study. For Cazzola 2007, Hanania 2011 and Hoshino 2011, sequence generation and/ or allocation concealment is unclear because study authors did not report full details and did not respond to personal communication.

\section{Blinding}

Aaron 2007, Hanania 2011 and Welte 2009 performed a blinded outcome assessment. In the trial arms of Aaron 2007, inhalers containing placebo and fluticasone/salmeterol were identical in taste and appearance, and they were enclosed in identical tamper-proof blinding devices. Medication canisters within the blinding devices were stripped of identifying labelling. Clinical data for suspected exacerbations were reviewed by a blinded

Combination inhaled steroid and long-acting beta 2 -agonist in addition to tiotropium versus tiotropium or combination alone for chronic 13 obstructive pulmonary disease (Review)

Copyright (c) 2017 The Cochrane Collaboration. Published by John Wiley \& Sons, Ltd. 
committee to judge whether data met the study definition of COPD exacerbation. Blinding of participants was not broken for participants who prematurely discontinued treatment with study medications, and the statistician who performed the analysis was initially blinded to participant group assignments. In Hanania 2011, the DISKUS inhalers containing placebo and fluticasone-salmeterol were identical in taste and appearance. In Welte 2009, treatment assignment was concealed, as active and placebo inhalers were of identical appearance and both clinicians and participants were blinded to treatment until completion of the study. Hoshino 2011 was an open study; however, for evaluation of airway dimensions, a single observer, who was blind to all participant data, measured the outcome. Cazzola 2007 and Jung 2012 did not report details of the outcome assessment; therefore blinding is unclear for these studies.

\section{Incomplete outcome data}

Cazzola 2007, Jung 2012 and Welte 2009 reported comparable attrition rates $(<14 \%)$ for both intervention and control groups; reasons for attrition were provided in all cases, making the risk of bias low. In Aaron 2007, withdrawal rates were different between intervention groups ( 74 participants (47\%) withdrew from the tiotropium + placebo group, and 37 participants (26\%) from the tiotropium + LABA/ICS group); however, mortality data were obtained for all participants, apart from six (2/145 on tiotropium + LABA/ICS and 4/156 on tiotropium + placebo) who withdrew and declined to be involved further in the study; therefore, we rated risk of bias as unclear. Hanania 2011 had high withdrawal rates in both groups ( $21 \%$ in fluticasone/salmeterol (FSC) + tiotropium group and $25 \%$ in tiotropium + placebo group); reasons for attrition were provided and were similar among groups; therefore, we rated this study as having an unclear risk of bias. In Hoshino 2011, a total of 36 participants were enrolled in the study, but only 30 were included in the analysis (16 participants on FSC + tiotropium and 14 on tiotropium + placebo); therefore the withdrawal rate was $20 \%$ because of loss to follow-up, making risk of attrition bias unclear.

\section{Selective reporting}

All six studies adequately reported outcome data for primary and secondary outcomes that were pre-specified in the study record.

\section{Effects of interventions}

See: Summary of findings for the main comparison Tiotropium + LABA/ICS combination compared with tiotropium for chronic obstructive pulmonary disease
Because of the small number of eligible studies for the two comparisons (tiotropium + LABA/ICS vs tiotropium alone and vs LABA/ICS alone), no subgroup analysis by disease severity or by type of combination therapy was possible.

\section{Comparison 1. Tiotropium plus LABA/ICS versus tiotropium}

We identified six RCTs addressing the comparison of tiotropium + LABA/ICS versus tiotropium + placebo (Aaron 2007; Cazzola 2007; Hanania 2011; Hoshino 2011; Jung 2012; Welte 2009).

\section{Primary outcomes}

\section{All-cause mortality}

Two studies (Aaron 2007; Welte 2009) reported mortality at three months and 12 months of follow-up, respectively. Both studies recruited participants who, on average, were likely to have fulfilled current GOLD criteria for triple therapy (GOLD 2015). These two studies did not find a significant effect on mortality with the use of tiotropium + LABA/ICS compared with tiotropium + placebo. Meta-analysis of these studies showed a non-statistically significant trend towards reduced risk of mortality with the use of tiotropium + LABA/ICS (two studies; 961 participants; OR 1.80, 95\% Cl 0.55 to $\left.5.91 ;\left.\right|^{2}=0 \%\right)$. The quality of evidence for this outcome is moderate because of imprecision in estimates of effect (Summary of findings for the main comparison).

\section{Hospital admission (all causes)}

The same two studies (Aaron 2007; Welte 2009) reported on all causes of hospital admission at three months and 12 months of follow-up, respectively. Welte 2009 did not find a significant difference in hospital admissions at three months of follow-up. Aaron 2007 found a statistically significant reduction in hospital admission at 12 months of follow-up with the use of tiotropium + LABA/ICS. Meta-analysis of these studies (Figure 3) showed a non statistically significant trend towards to decreased risk of hospital admission associated with the use of tiotropium + LABA/ICS (two studies; 961 participants; OR $0.84,95 \% \mathrm{Cl} 0.53$ to 1.33 ; $12=0 \%$ ); the quality of evidence for this outcome is low because of the risk of bias in included studies and imprecision of the estimate (Summary of findings for the main comparison). 
Figure 3. Forest plot of comparison: 1 Tiotropium + LABA/ICS combination versus tiotropium + placebo, outcome: 1.2 Hospital admission (all causes).

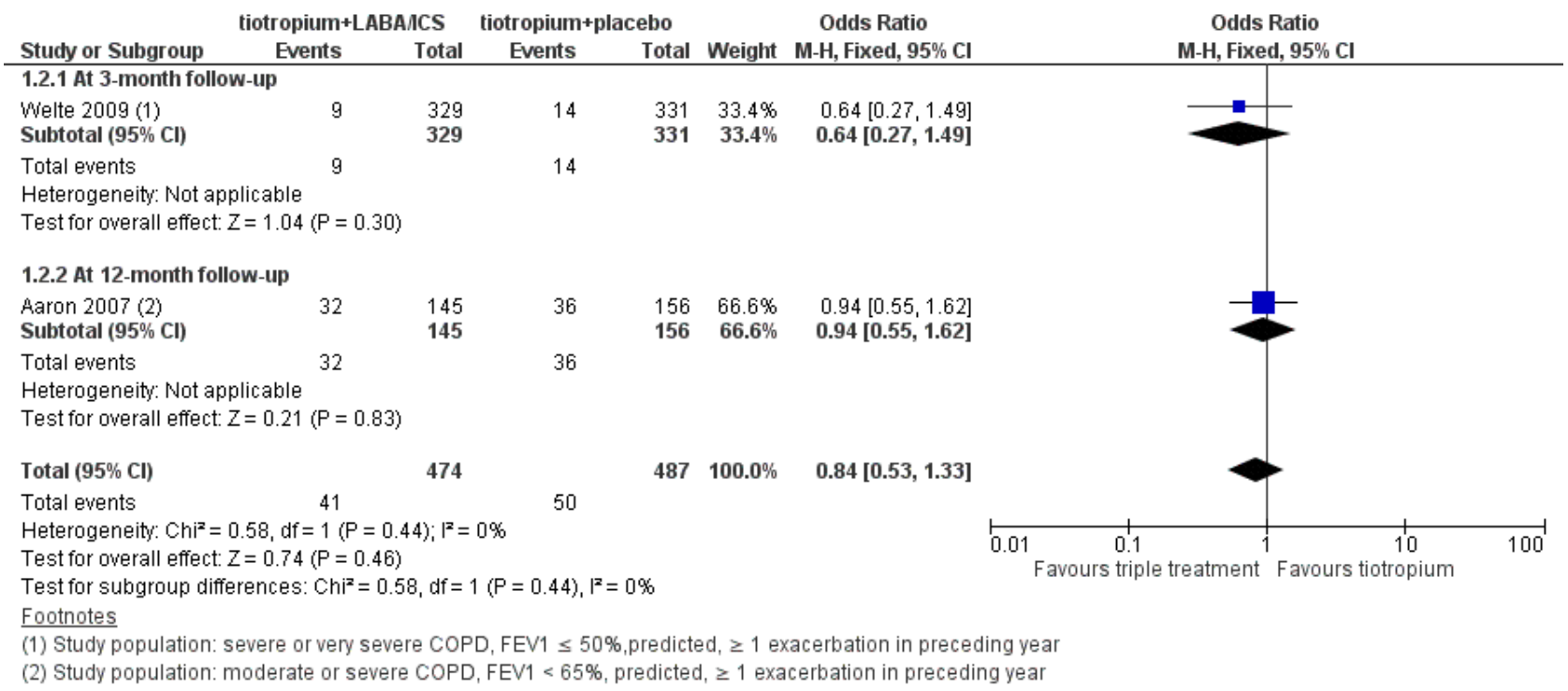

\section{Exacerbations}

Three studies (Aaron 2007; Jung 2012; Welte 2009) reported on exacerbations at three, six and 12 months of followup, respectively. Welte 2009 found a significant difference in exacerbations at three months of follow-up with the use of combined therapy tiotropium + LABA/ICS (one study; 660 participants; OR $0.36,95 \% \mathrm{Cl} 0.22$ to 0.60 ). Jung 2012 did not find a significant difference in exacerbations at six months of followup (one study; 479 participants; OR $0.83,95 \% \mathrm{Cl} 0.52$ to 1.34 ). Aaron 2007 did not find a statistically significant reduction in exacerbations at 12 months of follow-up with the use of combined therapy tiotropium + LABA/ICS (one study; 301 participants; OR $0.89,95 \% \mathrm{Cl} 0.56$ to 1.41 ). We did not pool study results because statistical heterogeneity across studies was considerable. Of note, Jung 2012 may have recruited a population of participants with less severe COPD, not all of whom would be recommended triple therapy according to current guidelines. The quality of evidence for this outcome is low because of the risk of bias and imprecision in estimates of effect (Summary of findings for the main comparison).

\section{Quality of life}

Four studies (Aaron 2007; Hoshino 2011; Jung 2012; Welte 2009) reported on quality of life using the SGRQ (Meguro 2007) at six months. The meta-analysis of these studies showed a statistically significant difference in quality of life (SGRQ total score) in favour of combined therapy of tiotropium + LABA/ICS compared with tiotropium + placebo (Figure 4) (four studies; 1446 participants; MD $-3.46,95 \% \mathrm{Cl}-5.05$ to $\left.-1.87 ; \mathrm{I}^{2}=16 \%\right)$. Only one study reported on the percentage of participants who were responders to treatment. Welte 2009 reported the percentage of participants with improvement in SGRQ score greater than four units, which was significantly higher in the tiotropium + LABA/ICS group (49.5\%) than in the tiotropium + placebo group $(40.0 \%)(P$ value $=0.016)$. The percentage of participants who showed deterioration in SGRQ score greater than four units was similar in the two groups (tiotropium + LABA/ICS 27.6\%, tiotropium + placebo 29.7\%). 
Figure 4. Forest plot of comparison: 1 Tiotropium + LABA/ICS combination versus tiotropium + placebo, outcome: 1.4 Quality of life up to 6 months (SGRQ).

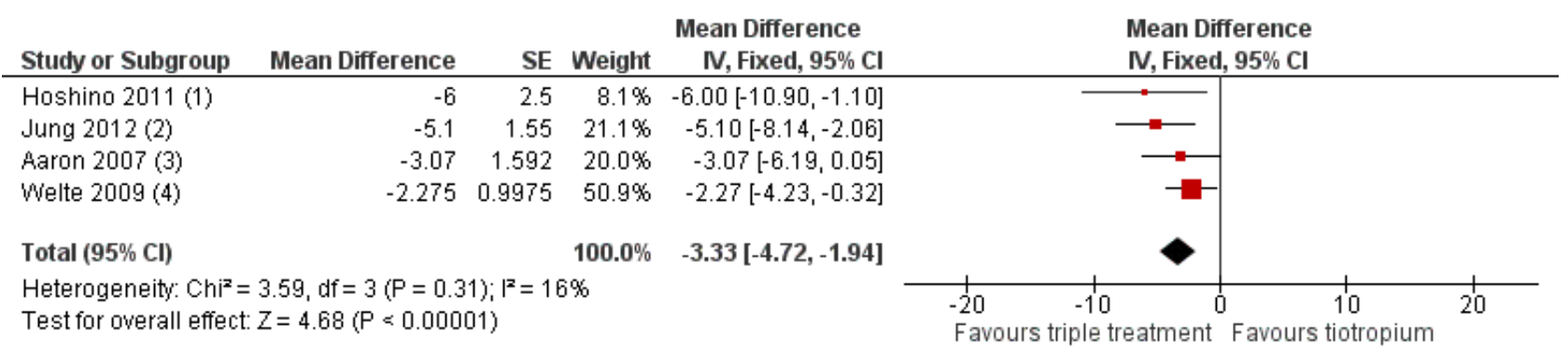

\section{$\underline{\text { Footnotes }}$}

(1) Study population: mild to very severe COPD, mean FEV1 64.6 and $57.1 \%$ predicted, exacerbation status unknown

(2) Study population: moderate to very severe COPD ( $>50 \%$ moderate), FEV1 $<65 \%$ predicted, exacerbation status unknown

(3) Study population: moderate or severe COPD, FEV1 $<65 \%$ predicted, $\geq 1$ exacerbation in preceding year

(4) Study population: severe or very severe COPD, FEV1 $\leq 50 \%$ predicted, $\geq 1$ exacerbation in preceding year

The sensitivity analysis excluding two open-label studies, which also included participants with less severe COPD (Hoshino 2011; Jung 2012), revealed no changes in the direction of treatment effect (two studies; 961 participants; MD $-2.5,95 \% \mathrm{Cl}-4.16$ to $-0.84 ; \mathrm{I}^{2}=$ $0 \%)$.

The quality of evidence for this outcome is low because of very serious risk of bias in the trial design (Summary of findings for the main comparison).

\section{Exercise tolerance}

None of the included studies reported exercise tolerance as an outcome.

\section{Serious adverse events non-fatal (all reported)}

Four studies (Aaron 2007; Hanania 2011; Jung 2012; Welte 2009) reported on serious adverse events (non-fatal). Aaron 2007 reported no differences in serious adverse events between intervention groups; a total of 19 serious adverse events not related to COPD (respiratory failure, cancer and myocardial infarction or acute arrhythmia) were reported in both intervention groups, and one case of pneumonia in the combined therapy group. Jung 2012 reported no differences in serious adverse event rates between trial arms; the event most commonly reported in the combined therapy group was productive cough, whereas dyspnoea was the most common event in the tiotropium group. Two cases of pneumonia were reported in each intervention group. Hanania 2011 reported no statistically significant differences in serious adverse event rates between therapy groups; two cases of pneumonia were reported in the combined therapy group, and nobody in the tiotropium presented with pneumonia. In Welte 2009, six cases of pneumonia were reported in each trial arm as serious adverse events, representing $<1 \%$ of the total adverse events reported by the trial.

Meta-analysis for all non-fatal serious adverse events reported in these studies showed no statistically significant differences (four studies; 1758 participants; OR $0.86,95 \% \mathrm{Cl} 0.57$ to $1.30 ; \mathrm{I}^{2}=$ $9 \%)$ (Figure 5). The sensitivity analysis excluding the open-label study (Jung 2012) revealed no differences in the treatment effect estimation (three studies; 1303 participants; OR 0.67, 95\% Cl 0.4 to $1.13 ; 1^{2}=0 \%$ ). Exclusion of both Hanania 2011 and Jung 2012 from the meta-analysis on the basis of the less severe population recruited widened the $\mathrm{Cls}$ but had little impact on size and direction of the effect.

Figure 5. Forest plot of comparison: 1 Tiotropium + LABA/ICS combination versus tiotropium + placebo, outcome: 1.7 Serious adverse events all reported (non-fatal).

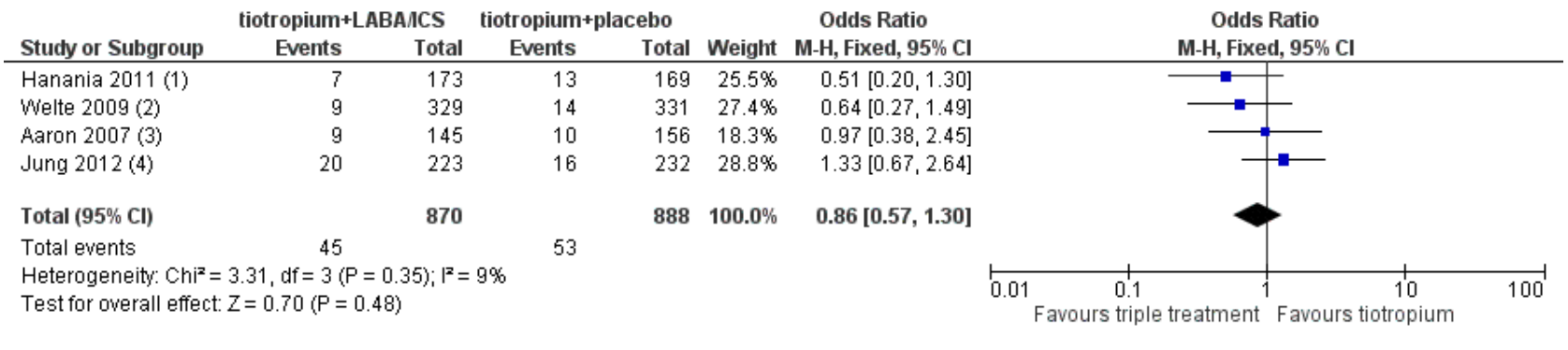

\section{Footnotes}

(1) Study population: moderate or severe COPD (severe $37 \%$ and $28 \%$ ), FEV1 $\geq 40$ to $\leq 80 \%$ predicted, $\geq 1$ exacerbation in preceding year in $43 \%$ and $33 \%$

(2) Study population: severe or very severe COPD, FEV1 $\leq 50 \%$ predicted, $\geq 1$ exacerbation in preceding year

(3) Study population: moderate or severe COPD, FEV1 $<65 \%$ predicted, $\geq 1$ exacerbation in preceding year

(4) Study population: moderate to very severe $\mathrm{COPD}$ ( $>50 \%$ moderate), $\mathrm{FEV} 1<65 \%$ predicted, exacerbation status unknown 
The quality of evidence for this outcome is low because of risk of bias and imprecision in estimates of effect (Summary of findings for the main comparison).

Independent meta-analysis for pneumonia including four studies (Aaron 2007; Hanania 2011; Jung 2012; Welte 2009) revealed no statistically significant differences in effects on pneumonia between treatments (four studies; 1758 participants; Peto OR 1.62, $95 \% \mathrm{Cl} 0.54$ to $\left.4.82 ; 1^{2}=0 \%\right)$.

\section{Secondary outcomes}

\section{Symptoms}

Welte 2009 was the only included study that reported changes in COPD symptom scores for breathlessness (MD - $0.142,95 \% \mathrm{Cl}-0.214$ to -0.069 ), night awakening (MD $-0.157,95 \% \mathrm{Cl}-0.222$ to -0.092 ), chest tightness (MD $-0.142,95 \% \mathrm{Cl}-0.212$ to -0.072 ) and cough (MD $-0.161,95 \% \mathrm{Cl}-0.238$ to -0.084 ) among 660 participants. Scores for all symptoms favoured the tiotropium + LABA/ICS group compared with the tiotropium + placebo group.

\section{Forced expiratory volume in one second $\left(\mathrm{FEV}_{1}\right)$}

Six studies (Aaron 2007; Cazzola 2007; Hanania 2011; Hoshino 2011; Jung 2012; Welte 2009) reported mean change in $\mathrm{FEV}_{1}$ at three to six months. These studies found statistically significant changes in $\mathrm{FEV}_{1}$ with the use of tiotropium + LABA/ICS compared with tiotropium + placebo (four studies; 1678 participants; MD 0.06, 95\% $\mathrm{Cl} 0.04$ to $0.08 ; 1^{2}=0 \%$; Figure 6 ); however, these changes are not clinically significant. The quality of evidence for this outcome is moderate as a result of the risk of bias.

\section{Figure 6. Forest plot of comparison: 1 Tiotropium + LABA/ICS combination versus tiotropium + placebo, outcome: 1.4 $\mathrm{FEV}_{1}$ pre-dose.}

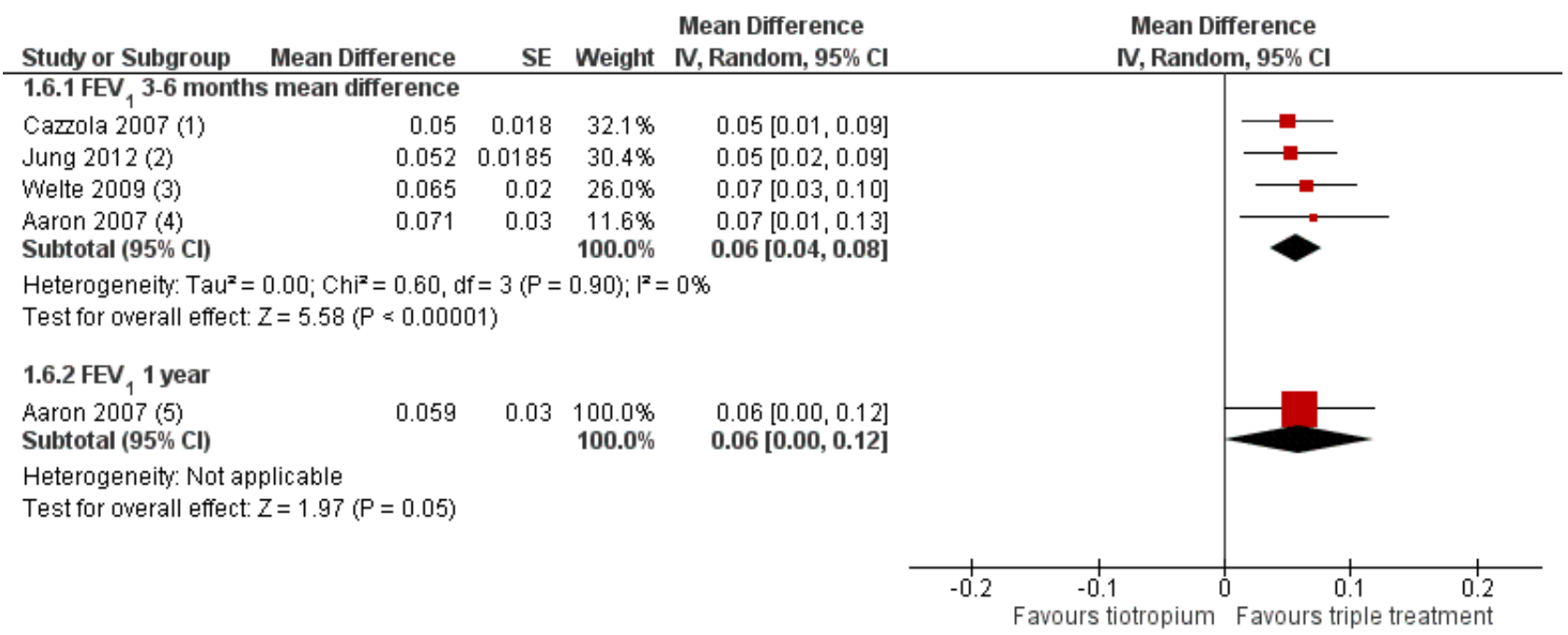

\section{Footnotes}

(1) Study population: severe to very severe COPD, FEV1 $\leq 50 \%$ predicted, exacerbation status unknown

(2) Study population: moderate to very severe COPD ( $>50 \%$ moderate), FEV1 $<65 \%$ predicted, exacerbation status unknown

(3) Study population: severe or very severe COPD, FEV1 $\leq 50 \%$ predicted, $\geq 1$ exacerbation in preceding year

(4) Study population: moderate or severe COPD, FEV1 $<65 \%$ predicted, $\geq 1$ exacerbation in preceding year

(5) Study population: moderate or severe COPD, FEV1 $<65 \%$ predicted, $\geq 1$ exacerbation in preceding year

Hoshino 2011 was excluded from the analysis because all data were not available. Hanania 2011 was not included in the pooled estimates of effect because this study generated significant heterogeneity $(12>90 \%)$. We considered the statistical heterogeneity to result from differences in baseline risk, as participants in Hanania 2011 had on average a greater degree of dyspnoea (modified Medical Research Council scale $(\mathrm{MRCm})>2$ ), which may have resulted in a greater response to pharmacological management.

Exclusion of Jung 2012 due to concerns about the relevance of the recruited population to current guidelines on triple therapy had a minimal impact on size and direction of the effect estimate (GOLD 2015).

\section{Adverse events (not serious)}

Four studies (Aaron 2007; Cazzola 2007; Hanania 2011; Welte 2009) reported adverse events. These studies did not find statistically significant differences with the use of tiotropium + LABA/ICS compared to tiotropium + placebo. Meta-analysis of these studies did not show a statistically significant difference (four studies; 1363 participants OR $1.16,95 \% \mathrm{Cl} 0.92$ to $1.47, \mathrm{I}^{2}=0 \%$ ). Removing Hanania 2011, a study in which the participants may not, on average, have fulfilled current GOLD criteria for receiving triple therapy, had little impact on the outcome (GOLD 2015).

\section{Cost-effectiveness of interventions}

In the economic evaluation conducted by Mittmann 2011; Nielsen 2013 Tiotropium + LABA/ICS was the dominant strategy (less costly and more effective) in three of the countries where it was assessed, 
in comparison with Tiotropium (Canada, Australia and Norway) (Table 1). In all other countries including Sweden, Finland, Denmark and Norway the ICER per exacerbation avoided was under the established willingness to pay threshold (between 600 to 1000 EUR); therefore the Tiotropium + LABA/ICS therapy resulted in a cost-effective alternative. Sensitivity analyses in both studies indicated that the variables with the largest effect on the ICER were hospitalisation costs, the incidence of exacerbations and hospital admission-related costs.

In the study conducted by Najafzadeh 2008 Tiotropium + LABA/ ICS showed significantly better quality of life and less hospital admissions than Tiotropium alone, but this improvement in health outcomes was associated with increased costs. The Tiotropium therapy showed the highest probability of being cost-effective when the "willingness to pay" is CAN $\$ 6.000^{\circ}$; when QALY was used as the effectiveness outcome, treatment with Tiotropium had the highest probability of being the best option compared to Tiotropium + LABA/ICS.

\section{Comparison 2. Tiotropium plus LABA/ICS versus $L A B A / I C S$}

Cazzola 2007 was the only eligible study identified that compared tiotropium + LABA/ICS versus LABA/ICS + placebo (60 participants) and recruited those with severe or very severe COPD at baseline, most of whom were likely to have met current GOLD criteria for triple therapy (GOLD 2015). This study reported results for the following outcomes of interest for this review.

\section{Primary outcome}

\section{Mortality (all-cause)}

Cazzola 2007 reported zero serious adverse events; therefore, we assumed that no deaths occurred during the study.

\section{Secondary outcomes}

\section{Forced expiratory volume in one second $\left(F^{2} V_{1}\right)$}

Tiotropium in combination with LABA/ICS improves $\mathrm{FEV}_{1}$ significantly compared with LABA/ICS + placebo (MD 0.05, 95\% CI 0.00 to 0.09 ), but $\mathrm{MD}$ and $\mathrm{Cl}$ were below the minimally clinically important difference of 100 to $140 \mathrm{~mL}$.

\section{Serious adverse events (non-fatal)}

No serious adverse events were reported in either intervention group.

\section{Adverse events}

More adverse events were reported in the tiotropium + LABA/ICS group (15/30) than in the tiotropium + placebo group (8/30), but the $\mathrm{Cl}$ was wide because of the small numbers of participants (OR 2.75, $95 \% \mathrm{Cl} 0.93$ to 8.10$)$.

\section{Withdrawal}

Fewer withdrawals were reported in the tiotropium + LABA/ICS group $(1 / 30)$ than in the tiotropium + placebo group $(4 / 30)$, but the number of events was small and was not statistically significant (OR $0.22,95 \% \mathrm{Cl} 0.02$ to 2.14 ).

\section{DISCUSSION}

\section{Summary of main results}

This systematic review set out to investigate the long-term ( $\geq$ three months) effects of tiotropium in combination with long-acting beta-agonists/inhaled corticosteroids (LABA/ICS) compared with either LABA/ICS alone or tiotropium alone for the treatment of chronic obstructive pulmonary disease (COPD). We identified six randomised controlled trials (RCTs). All six studies looked at the effects of combination therapy (tiotropium + LABA/ICS) compared with tiotropium alone, whereas only one of these studies (Cazzola 2007) compared triple therapy versus LABA/ICS alone. Additionally, we included three cost-effectiveness analyses based on data from two of these studies (Aaron 2007; Welte 2009) for evaluation of economic outcomes.

\section{Tiotropium + LABA/ICS versus tiotropium}

Since the first version of this systematic review was published, three clinical trials comparing tiotropium + LABA/ICS versus tiotropium alone have been published (Hanania 2011; Hoshino 2011; Jung 2012). These three trials reported on quality of life; exacerbations, $\mathrm{FEV}_{1}$ and non serious adverse events but do not report on hospital admission and mortality; therefore the evidence for the last two outcomes remain the same that failed to show a statistically significant difference in mortality and hospital admission between tiotropium + LABA/ICS versus tiotropium alone (moderate and low quality of evidence). Participants recruited to the two studies included in the analyses of hospitalisations and mortality (Aaron 2007; Welte 2009) are likely to have been candidates for tiotropium + LABA/ICS therapy according to current guidance GOLD 2015 (i.e. forced expiratory volume in one second $\left(\mathrm{FEV}_{1}\right)<50 \%$ predicted and frequent exacerbations ), suggesting that these findings are clinically applicable.

Even though investigators found statistically significant differences between treatment arms for other important outcomes such as $\mathrm{FEV}_{1}$ and quality of life, these results must be interpreted with caution, as the differences found may not be clinically significant. According to Jones 2005, the minimal clinically important difference (MCID) for $\mathrm{FEV}_{1}$ may vary but is accepted to be within the range of 100 to $140 \mathrm{~mL}$ (American Thoracic Society/European Respiratory Society Task Force). In this review, the difference in treatment effect on $\mathrm{FEV}_{1}$ was $60 \mathrm{~mL}$; this difference did not reach the MCID needed to have a beneficial impact on participants' quality of life (Jones 2005). Similarly, the MCID in quality of life scores evaluated with St. George's Respiratory Questionnaire (SGRQ) has been proposed to be four units of improvement; the meta-analysis for this outcome showed a difference smaller than a four-unit change that could be reached just as part of a Hawthorne effect. Westwood et al described that in participants with COPD, a Hawthorne effect influences SGRQ scores in COPD trials; typically, this results in improvement of two to three points on the SGRQ with placebo (Westwood 2011). Welte 2009 reported a percentage of participants with improvement in SGRQ score greater than four units, which was significantly higher in the tiotropium + LABA/ICS group (49.5\%) than in the tiotropium + placebo group $(40.0 \%)$ ( $P$ value $=0.016$ ). The percentage of participants with a decrease in SGRQ score greater than four units was similar in the two groups (tiotropium + LABA/ICS $27.6 \%$, tiotropium + placebo $29.7 \%$ ). 
Of note, Hoshino 2011 and Jung 2012 contributed data to the quality of life analysis, and Jung 2012 to the FEV 1 analysis, but on average, participants included in these studies may not have been candidates for tiotropium + LABA/ICS therapy according to current guidelines (GOLD 2015). However, removing these studies from the analyses had little impact on the size or direction of the effect estimate.

We did not pool data on exacerbations reported in these studies, as we considered that several sources of variation among the studies resulted in important heterogeneity $\left(1^{2}>80 \%\right)$ that could not be removed by subgroup analyses based on length of followup (three, six and 12 months) (Aaron 2007; Jung 2012; Welte 2009) nor by the definition of exacerbation used (Aaron 2007 defined exacerbation as worsening of COPD leading to treatment with systemic steroids and/or antibiotics; Jung 2012 cited the definition of Rodriguez-Roisin: sustained worsening of the patient's condition from the stable state and beyond normal day-to-day variations that is acute in onset and necessitates a regular change in medication in a patient with underlying COPD; and Welte 2009 defined an exacerbation as worsening of COPD leading to treatment with systemic steroids and/or hospitalisation/emergency room visits). All these individual studies failed to show significant differences in exacerbations between the two treatment arms at six and 12 months of follow-up. The study by Welte 2009 showed a significant reduction in the risk of exacerbation at three-month follow-up associated with triple therapy in comparison with tiotropium alone. However, this finding may be considered clinically irrelevant because the follow-up period needed to define the real effect that any COPD treatment could have on exacerbation is 52 months (Cazzola 2008; Miravitlles 2004).

The effect of tiotropium + LABA/ICS combination treatment on mortality remains uncertain because of the small number of events. The difference in serious adverse event rates between intervention groups was not statistically significant. For pneumonia, the number of cases in each study was small compared with the number of withdrawals and the number of participants lost to follow-up. Withdrawals did not seem to be linked to adverse events but rather to the efficacy of treatment. Even though use of inhaled corticosteroids has been associated with pneumonia, our findings suggest no safety concerns related to use of the tiotropium + LABA/ ICS combination in the treatment of patients with COPD when compared with tiotropium alone.

Economic evaluation results show a high probability that tiotropium + LABA/ICS combination treatment could be a costeffective alternative in various settings, as it was associated with fewer hospital admissions and better quality of life, which may drive most of the long-term costs associated with this condition. The two economic evaluations conducted in Canada (Mittmann 2011; Najafzadeh 2008) differ in the final conclusions presented regarding cost-effectiveness of combined therapy (tiotropium + LABA/ICS); these differences may be explained by differences in willingness to pay thresholds used in the sensitivity analyses, making comparison of the conclusions of these two studies impossible.

\section{LABA/ICS + tiotropium versus LABA/ICS + placebo}

The one pilot study (Cazzola 2007; no publications after 2007) that looked at the effect of LABA/ICS + tiotropium versus LABA/ ICS + placebo showed significantly greater improvement in $\mathrm{FEV}_{1}$ with tiotropium + LABA/ICS compared with LABA/ICS; however, the mean difference in $\mathrm{FEV}_{1}$ was not clinically significant. All other outcomes of interest were not studied, revealed no events or did not achieve a statistically significant difference.

\section{Overall completeness and applicability of evidence}

For the comparison of benefits and risks of treatment with tiotropium + LABA/ICS versus LABA/ICS, we identified just one small eligible study (Cazzola 2007), which did not look at, or report on, any of the primary outcomes specified in this review, except for mortality. Therefore, this review found little applicable evidence for this comparison.

Current international guidance suggests that triple therapy with long-acting muscarinic agonists (LAMA), LABA and ICS should be reserved for patients who continue to have symptoms despite receiving dual therapy with either $\angle A B A / I C S$ or $L A B A+\angle A M A$, have an $\mathrm{FEV}_{1}<50 \%$ predicted and are at a high risk of experiencing exacerbations (i.e. $\geq$ two exacerbations in the preceding year) (GOLD 2015). Lack of detailed reporting of baseline characteristics has somewhat limited our ability to assess to what extent the studies included in this review recruited participants who would meet these criteria. This could potentially limit the generalisability of our findings to a clinical setting. Table 3 summarises the available information, and, when relevant, we performed a sensitivity analysis that excluded the study or studies in which investigators raised concerns about the relevance of the recruited population. This did not have a substantial impact on any of the effect estimates. We have also included in the individual analyses footnotes that detail the baseline characteristics of participants included in the analysis.

\section{Quality of the evidence}

Methods used for randomisation and outcome assessment in some of the included studies were not clearly described and in some cases explanations were missing, thus presenting a source of potential bias.

The quality of the evidence, according to the GRADE (Grades of Recommendation, Assessment, Development and Evaluation Working Group) framework, was moderate for mortality but low for hospital admissions and other important outcomes such as exacerbations, adverse events and quality of life (GRADE 2013).

\section{Potential biases in the review process}

The issue of large and/or uneven numbers of withdrawals, as mentioned above (Quality of the evidence), will, even if addressed, have a high likelihood of introducing selection bias, as no consensus has been reached on how best to handle participants for whom no data are available. The high drop-off rates observed in these types of studies may have been a consequence of the longterm follow-up required to measure effectiveness outcomes.

We analysed available data as specified in the protocol. However, we expanded the review question from the protocol to include the comparison of tiotropium + LABA/ICS versus $L A B A / I C S$ + placebo. We also highlighted the percentage of participants with a clinically significant change in health-related quality of life as reported by study authors, although this was not specified in Measures of treatment effect. 


\section{Agreements and disagreements with other studies or reviews}

Liu 2014 and Rodrigo 2012 published reviews that evaluated the long-term efficacy and adverse effects of tiotropium + LABA/ ICS treatment compared with tiotropium. Both reviews revealed benefits for lung function, quality of life and exacerbation risk. Our review validates these findings. However, with respect to this last outcome, we believe it is not advisable to combine the results, given that length of follow-up differed among the studies, that the only study that showed length of follow-up to 52 weeks is Aaron 2007 and that results should be presented independently, as has been done in the present review. The present review also describes a beneficial impact on hospitalisation risk, another clinically relevant outcome that was not previously considered. Additionally, the current review presents results reflecting the GRADE method, which allows the reader to consider the quality of the evidence for each outcome - a critical piece of information on which to base clinical decisions.

A systematic review looking at LABA/ICS combination treatment compared with placebo has shown that combination treatment significantly reduces mortality and exacerbation rates and improves lung function (Nannini 2013). LABA/ICS also increases the risk of pneumonia compared with placebo. A systematic review comparing tiotropium versus placebo showed that tiotropium treatment was associated with a significant improvement in participants' quality of life and reduced the risk of exacerbations, with a number needed to treat for an additional beneficial outcome (NNTB) of 16 to prevent one exacerbation. Tiotropium also reduced exacerbations leading to hospitalisation when compared with placebo (Karner 2014).

\section{AUTHORS' CONCLUSIONS}

\section{Implications for practice}

This review update includes three additional studies and provides new low quality evidence supporting the finding that tiotropium + LABA/ICS-based therapy improves the disease-specific quality of life but is insufficient to support the benefit of tiotropium
+ LABA/ICS-based therapy for mortality, hospital admission or exacerbations (moderate and low quality evidence). Compared with use of tiotropium alone, tiotropium + LABA/ICS-based therapy does not seem to increase undesirable effects nor serious non-fatal adverse events.

\section{Implications for research}

Randomised controlled trials with complete follow-up of 12 months are required to reduce uncertainty about the impact that tiotropium in combination with LABA/ICS might have on mortality and exacerbations when used as treatment for patients with COPD.

\section{ACK N O WLEDGEMENTS}

The review authors thanks Liz Stovold, Information Specialist from the Cochrane Airways Group, for running the new searches used to update this review. We also thank Rebecca Normansell, Deputy Coordinating Editor, for her invaluable help.

John White was the Editor for this review and commented critically on the review.

Professors Olga Milena García Morales, María Ximena Rojas-Reyes and Rodolfo J. Dennis thank Melissa Giraldo Duque, Research Assistant at the Clinical Epidemiology and Biostatistics Department of the Pontificia Universidad Javeriana, who contributed to the risk of bias assessment of included studies and assisted review authors in extracting data from new studies.

The Faculty of Medicine of the Pontificia Universidad Javeriana, Bogotá, Colombia, supported the time dedicated by authors Olga Milena García Morales, María Ximena Rojas-Reyes and Rodolfo J. Dennis to update this review as part of a collaboration agreement with the Iberoamerican Cochrane Center.

This project was supported by the National Institute for Health Research (NIHR), via Cochrane Infrastructure funding to the Cochrane Airways Group. The views and opinions expressed therein are those of the review authors and do not necessarily reflect those of the Systematic Reviews Programme, NIHR, the National Health Service (NHS) or the Department of Health. 


\section{R E F E R E N C E S}

\section{References to studies included in this review}

\section{Aaron 2007 \{published data only\}}

Aaron SD, Vandemheen K, Ferguson D, FitzGerald M, Maltais F, Boureau J, et al. The Canadian optimal therapy of COPD trial: design, organization and patient recruitment. Canadian Respiratory Journal 2004;11(8):581-5.

* Aaron SD, Vandemheen KL, Fergusson D, Maltais F, Bourbeau J, Goldstein R, et al. Tiotropium in combination with placebo, salmeterol, or fluticasone-salmeterol for treatment of chronic obstructive pulmonary disease: a randomized trial. Annals of Internal Medicine 2007;146(8):545-55.

Kaplan A. Effects of tiotropium combined with either salmeterol or salmeterol/fluticasone in moderate to severe COPD. Primary Care Respiratory Journal 2007;16(4):258-60.

Najafzadeh M, Marra CA, Sadatsafavi M, Aaron SD, Sullivan SD, Vandemheen $\mathrm{KL}$, et al. Cost effectiveness of therapy with combinations of long acting bronchodilators and inhaled steroids for treatment of COPD. Thorax 2008;63(11):962-7.

Roisman G. Tiotropium in combination with placebo, salmeterol, or fluticasone-salmeterol for treatment of chronic obstructive pulmonary disease. A randomized trial. Revue de Pneumologie Clinique 2007;63(6):390-1.

\section{Cazzola 2007 \{published data only\}}

* Cazzola M, Ando F, Santus P, Ruggeri P, Di Marco F, Sanduzzi A, et al. A pilot study to assess the effects of combining fluticasone propionate/salmeterol and tiotropium on the airflow obstruction of patients with severe-to-very severe COPD. Pulmonary Pharmacology and Therapeutics 2007;20(5):556-61.

D'Amato M, Ando F, Santus P, Ruggeri P, Di Marco F, Cazzola M. Clinical effects of adding fluticasone propionate/salmeterol (FSC) and tiotropium (TIO) in severe-to-very severe COPD [Abstract]. European Respiratory Journal 2005;26(Suppl 49):218.

\section{Hanania 2011 \{published data only\}}

Hanania NA, Crater GD, Morris AN, Emmett AH, O'Dell DM, Niewoehner DE. Benefits of adding fluticasone propionate/ salmeterol to tiotropium in moderate to severe COPD. Respiratory Medicine 2012;106(1):91-101. [PUBMED: PMID: 22040533.]

\section{Hoshino 2011 \{published data only\}}

Hoshino M, Ohtawa J. Effects of adding salmeterol/fluticasone propionate to tiotropium on airway dimensions in patients with chronic obstructive pulmonary disease. Respirology 2011;16(1):95-101. [DOI: 10.1111/j.1440-1843.2010.01869.x]

\section{Jung 2012 \{published data only\}}

Jung KS, Park HY, Park SY, Kim SK, Kim YK, Shim JJ, et al. Comparison of tiotropium plus fluticasone propionate/ salmeterol with tiotropium in COPD: a randomized controlled study. Respiratory Medicine 2012;106(3):382-9. [MEDLINE: doi: 10.1016]
Welte 2009 \{published data only\}

Mittmann N, Hernandez P. Cost effectiveness of budesonide/ formoterol added to tiotropium bromide versus placebo added to tiotropium bromide in patients with chronic obstructive pulmonary disease: Australian, Canadian and Swedish Healthcare Perspectives. Pharmacoeconomics 2011;29(5):403-14. [PUBMED: 21504240]

Nielsen R, Kankaanranta H, Bjermer L. Cost effectiveness of adding budesonide/formoterol to tiotropium in COPD in four Nordic countries. Respiratory Medicine 2013;107(11):1709-21. [DOI: http://dx.doi.org/10.1016/j.rmed.2013.06.007]

Welte T, Hartman L, Polanowski T, Hernandez P. Budesonide/ formoterol added to tiotropium is well tolerated and reduces risk of severe exacerbations in COPD patients [Abstract]. American Thoracic Society International Conference; 2009 May 15-20 San Diego. 2009:A6188 [Poster \#215].

Welte T, Miravitlles M, Hernandez P, Eriksson G, Peterson S, Polanowski T, et al. Addition of budesonide/formoterol to tiotropium reduces the number of exacerbation days compared with tiotropium alone. Chest 2009;136(4):26S-f.

Welte T, Miravitlles M, Hernandez P, Eriksson G, Peterson S, Polanowski T, et al. Budesonide/formoterol added to tiotropium provides rapid improvements in lung function and ability to undertake morning activities. Chest 2009;136(4):24S-g.

* Welte T, Miravitlles M, Hernandez P, Eriksson G, Peterson S, Polanowski T, et al. Efficacy and tolerability of budesonide/ formoterol added to tiotropium in patients with chronic obstructive pulmonary disease. American Journal of Respiratory and Critical Care Medicine 2009;180(8):741-50.

Welte T, Miravitlles M, Hernandez P, Hartman L, Polanowski T, Kessler R. Budesonide/formoterol added to tiotropium improves lung function, health status, symptoms \& morning activities in COPD patients [Abstract]. European Respiratory Society Annual Congress; Sep 12-16; Vienna. 2009:[P2005].

Welte T, Miravitlles M, Hernandez P, Peterson S, Polanowski T, Kessler R. Budesonide/formoterol added to tiotropium improves exacerbations and exacerbation-related antibiotic use in patients with COPD [Abstract]. European Respiratory Society Annual Congress; September 12-16; Vienna. 2009:[P2012].

Welte T, Miravitlles M, Peterson S, Polanowski T, Kessler R. Budesonide/formoterol added to tiotropium improves the management of COPD patients [Abstract]. American Thoracic Society International Conference; 2009 May 15-20; San Diego. 2009:A6192 [Poster \#216].

\section{References to studies excluded from this review}

Ando 2008 \{published data only\}

Ando F, Ruggeri P, Girbino G, Cazzola M. Tiotropium and salmeterol/fluticasone combination do not cause oxygen desaturation in COPD. Respiratory Medicine 2008;102(6):815-8. 
Bateman 2008 \{published data only\}

Bateman E, Van-Dyk M, Chang A. A pilot study comparing tiotropium to salmeterol plus fluticasone in moderate COPD [Abstract]. European Respiratory Journal 2005;26(Suppl 49):Abstract No. 851.

* Bateman ED, Van Dyk M, Sagriotis A. Comparable spirometric efficacy of tiotropium compared with salmeterol plus fluticasone in patients with COPD: a pilot study. Pulmonary Pharmacology and Therapeutics 2008; Vol. 21, issue 1:20-5.

Biscione 2009 \{published data only\}

Biscione G, Crigna G, Auciello L, Pasqua F, Cazzola M. Addition of tiotropium $(T)$ to a regular treatment with long-acting beta-agonist + inhaled corticosteroid (LABA + ICS) in patients with severe to very-severe COPD under in-patient pulmonary rehabilitation program (PRP) [Abstract]. European Respiratory Society Annual Congress; 2009 Sep 12-16; Vienna. 2009:[P526]

\section{Golabi 2006 \{published data only\}}

Golabi P, Topaloglu N, Karakurt S, Celikel T. Effects of tiotropium and salmeterol/fluticasone combination on lung hyperinflation dyspnea and exercise tolerance in COPD [Abstract]. European Respiratory Journal 2006; Vol. 28, issue Suppl 50:33s [E304].

\section{Hara 2007 \{published data only\}}

Hara K, Kurashima K, Tokunaga D, Ueno M, Aoyagi K, Isobe Z, et al. Single blind comparison of tiotropium and salmeterol plus fluticasone propionate of treatment in patients with chronic obstructive pulmonary disease (COPD) [Abstract]. American Thoracic Society International Conference; 2007 May 18-23; San Francisco. 2007:Poster \#A1.

\section{Maltais 2013 \{published data only\}}

Maltais F, Mahler D. Effect of fluticasone propionate/salmeterol plus tiotropium versus tiotropium on walking endurance in COPD. European Respiratory Journal 2013;42:539-41. [DOI: 10.1183/09031936.00074113]

\section{Perng 2006 \{published data only\}}

Perng DW, Wu CC, Su KC, Lee YC, Perng RP, Tao CW. Additive benefits of tiotropium in COPD patients treated with longacting beta 2 agonists and corticosteroids. Respirology 2006;11(5):598-602.

\section{Petroianni 2008 \{published data only\}}

Petroianni A, Ceccarelli D, Conti V, Graziani E, Terzano C. Evening administration of tiotropium during combination therapy reduces night symptoms in COPD patients [Abstract]. European Respiratory Society 18th Annual Congress; 2008 Oct 3-7; Berlin 2008:[E4282]

\section{Sarac 2013 \{published data only\}}

Sarac P. Comparison of the efficacy and safety of longacting anticholinergic and a combination of inhaled steroids and long-acting beta-2 agonist in moderate chronic obstructive pulmonary disease. European Respiratory Journal 2013;42(Suppl 57):P4143.
Singh 2008 \{published data only\}

* Singh D, Brooks J, Hagan G, Cahn A, O'Connor BJ. Superiority of "triple" therapy with salmeterol/fluticasone propionate and tiotropium bromide versus individual components in moderate to severe COPD. Thorax 2008;63(7):592-8.

Singh D, Hagan G, Cahn A, Leonard TB, Riley JH, O'Connor BJ. Individual and combined responses to salmeterol/fluticasone propionate combination (SFC) and tiotropium (Tio) shown in a COPD clinical trial [Abstract]. American Thoracic Society International Conference; 2008 May 16-21; Toronto. 2008:A648[\#F10].

Tashkin 2008 \{published data only\}

Tashkin D. Impact of tiotropium on the course of moderate-tovery severe chronic obstructive pulmonary disease: the UPLIFT ${ }^{\oplus}$ trial. Expert Review of Respiratory Medicine 2010;4(3):279-89.

Troosters 2008 \{published data only\}

Troosters T, Celli B, Kesten S. Effectiveness of combination therapy with tiotropium in COPD. A secondary analysis of the UPLIFT trial. Primary Care Respiratory Journal 2010;19(2):A13.

\section{References to studies awaiting assessment}

Fang 2008 \{published data only\}

Fang L, Liang X, Zhang F, Liu L, Fu W, Zhao Z, et al. Combination of inhaled salmeterol/fluticasone and tiotropium in the treatment of chronic obstructive pulmonary disease: a randomised controlled trial. Zhonghua Jiehe He Huxi Zazhi [Chinese Journal of Tuberculosis and Respiratory Diseases] 2008;31(11):811-4

Lee 2014 \{published and unpublished data\}

\section{References to ongoing studies \\ Betsuyaku 2013 \{published data only\}}

Betsuyaku T, Kato M. A study to assess COPD symptom-based management and to optimise treatment strategy in Japan (COSMOS-J) based on GOLD 2011. International Journal of Chronic Obstructive Pulmonary Disease 2013;8:453-9. [DOI: 10.2147/COPD.S48298]

\section{Cohuet 2013 \{published data only\}}

Cohuet Geraldine. A study to compare the effect of inhaled treatments: the combination of 3 components (beclometasone/ formoterol/glycopyrrolate) to a known single treatment (tiotropium) or the double combination of tiotropium (Spiriva) and beclometasone plus formoterol in patients with chronic obstructive pulmonary disease treated for one year.. The European Union Clinical Trials Register 2013-10-11. [EudraCT Number:2013-000063-91] 


\section{Additional references}

\section{Appleton 2006}

Appleton S, Jones T, Poole P, Pilotto L, Adams R, Lasserson TJ, et al. Ipratropium bromide versus long-acting beta- 2 agonists for stable chronic obstructive pulmonary disease. Cochrane Database of Systematic Reviews 2006, Issue 3. [DOI: 10.1002/14651858.CD006101]

\section{Barr 2005}

Barr RG, Bourbeau J, Camargo CA. Tiotropium for stable chronic obstructive pulmonary disease. Cochrane Database of Systematic Reviews 2005, Issue 2. [DOI: 10.1002/14651858.CD002876.pub2]

\section{Beeh 2010}

Beeh KM, Beier J. The short, the long and the "ultra-long": why duration of bronchodilator action matters in chronic obstructive pulmonary disease. Advances in Therapy 2010;27(3):150-9.

\section{Brichetto 2003}

Brichetto L, Song P, Crimi E. Modulation of cholinergic responsiveness through the [beta]-adrenoceptor signal transmission pathway in bovine trachealis. Journal of Applied Physiology 2003;95(2):735-41.

\section{Cazzola 2008}

Cazzola M, MacNee W, Martinez FJ, Rabe KF, Franciosi LG, Barnes PJ, et al. American Thoracic Society; European Respiratory Society Task Force on outcomes of COPD. Outcomes for COPD pharmacological trials: from lung function to biomarkers. European Respiratory Journal 2008;31(2):416-69. [DOI: 10.1183/09031936.00099306]

\section{Cazzola 2010}

Cazzola M, Molimard M. The scientific rationale for combining long-acting b2-agonists and muscarinic antagonists in COPD. Pulmonary Pharmacology \& Therapeutics 2010;23(4):257-67. [DOI: 10.1016/j.pupt.2010.03.003]

\section{Drummond 1996}

Drummond MF, Jefferson TO. Guidelines for authors and peer reviewers of economic submissions to the BMJ.BMJ 1996;313:275-83. [DOI: 10.1136/bmj.313.7052.275]

\section{Effing 2007}

Effing T, Monninkhof EEM, van der Valk PP, Zielhuis GGA, Walters EH, van der Palen JJ, et al. Self-management education for patients with chronic obstructive pulmonary disease. Cochrane Database of Systematic Reviews 2007, Issue 4. [DOI: 10.1002/14651858.CD002990.pub2]

\section{GOLD 2015}

From the Global Strategy for the Diagnosis, Management and Prevention of COPD, Global Initiative for Chronic Obstructive Lung Disease (GOLD). http://www.goldcopd.org/ (accessed 11 June 2015).

\section{GRADE 2013}

Schünemann H, Brożek J, Guyatt G, Oxman A. Handbook for grading the quality of evidence and the strength of recommendations using the GRADE approach. http:// www.guidelinedevelopment.org/handbook/\#h.buaodtl66dyx (accessed 11 June 2015).

\section{Guyatt 2011}

Guyatt G, Oxman AD, Akl EA, Kunz R, Vist G, Brozek J, et al. GRADE guidelines: 1 . Introduction-GRADE evidence profiles and summary of findings tables. Journal of Clinical Epidemiology 2011;64(4):383-94.

\section{Higgins 2011}

Higgins JPT, Green S (editors). Cochrane Handbook for Systematic Reviews of Interventions Version 5.1.0 [updated March 2011]. The Cochrane Collaboration, 2011. www.cochranehandbook.org (accessed 11 June 2015).

\section{Hutchinson 2010}

Hutchinson A, Brand C, Irving L, Roberts C, Thompson P, Campbell D. Acute care costs of patients admitted for management of chronic obstructive pulmonary disease exacerbations: contribution of disease severity, infection and chronic heart failure. Internal Medical Journal 2010;40(5):364-71. [1445-5994: (Electronic)]

\section{Jones 2005}

Jones PW. St. George's Respiratory Questionnaire: MCID. COPD 2005;2:75-9.

\section{Karner 2014}

Karner C, Chong J, Poole P. Tiotropium versus placebo for chronic obstructive pulmonary disease. Cochrane Database of Systematic Reviews 2014, Issue 7. [DOI: 10.1002/14651858.CD009285.pub3]

\section{Lacasse 2006}

Lacasse Y, Goldstein R, Lasserson TJ, Martin S. Pulmonary rehabilitation for chronic obstructive pulmonary disease. Cochrane Database of Systematic Reviews 2006, Issue 4. [DOI: 10.1002/14651858.CD003793.pub2]

\section{Liu 2014}

Liu Y, Shi H, Sun X. Benefits of adding fluticasone propionate/ salmeterol to tiotropium in COPD: a meta-analysis. European Journal of Internal Medicine 2014;25(5):491-5. [DOI: 10.1016/ j.ejim.2014.04.007]

\section{Meguro 2007}

Meguro M, Barley EA, Spencer S, Jones PW. Development and validation of an improved, COPD-specific version of the St. George Respiratory Questionnaire. Chest 2007; Vol. 132, issue 2:456-63.

\section{Miravitlles 2004}

Miravitlles M, Ferrer M, Pont A, Zalacain R, Alvarez-Sala JL, Masa F. Effect of exacerbations on quality of life in patients with chronic obstructive pulmonary disease: a 2 year follow up study. Thorax 2004;59(5):387-95. 


\section{Mittmann 2011}

Mittmann N, Hernandez P. Cost effectiveness of budesonide/ formoterol added to tiotropium bromide versus placebo added to tiotropium bromide in patients with chronic obstructive pulmonary disease: Australian, Canadian and Swedish Healthcare Perspectives. Pharmacoeconomics 2011;29(5):403-14. [PUBMED: 21504240]

\section{Najafzadeh 2008}

Najafzadeh M, Marra CA, Sadatsafavi M, Aaron SD, Sullivan SD, Vandemheen $\mathrm{KL}$, et al. Cost effectiveness of therapy with combinations of long acting bronchodilators and inhaled steroids for treatment of COPD. Thorax 2008;63(11):962-7.

\section{Nannini 2007a}

Nannini L, Cates CJ, Lasserson TJ, Poole P. Combined corticosteroid and long-acting beta-agonist in one inhaler versus placebo for chronic obstructive pulmonary disease. Cochrane Database of Systematic Reviews 2007, Issue 4. [DOI: 10.1002/14651858.CD003794.pub2]

\section{Nannini 2007b}

Nannini LJ, Cates CJ, Lasserson TJ, Poole P. Combined corticosteroid and long-acting beta-agonist in one inhaler versus long-acting beta-agonists for chronic obstructive pulmonary disease. Cochrane Database of Systematic Reviews 2007, Issue 4. [DOI: 10.1002/14651858.CD003794.pub2]

\section{Nannini 2013}

Nannini LJ, Poole P, Milan SJ, Holmes R, Normansell R. Combined corticosteroid and long-acting beta $_{2}$-agonist in one inhaler versus placebo for chronic obstructive pulmonary disease. Cochrane Database of Systematic Reviews 2013, Issue 11. [DOI: 10.1002/14651858.CD003794.pub4]

\section{Nielsen 2013}

Nielsen R, Kankaanranta H, Bjermer L. Cost effectiveness of adding budesonide/formoterol to tiotropium in COPD in four Nordic countries. Respiratory Medicine 2013;107(11):1709-21. [DOI: http://dx.doi.org/10.1016/j.rmed.2013.06.007]

\section{RevMan 2014 [Computer program]}

Copenhagen, The Nordic Cochrane Centre: The Cochrane Collaboration. Review Manager (RevMan). Version 5.3.5. Copenhagen, The Nordic Cochrane Centre: The Cochrane Collaboration, 2014

\section{CHARACTERISTICS OF STUDIES}

Characteristics of included studies [ordered by study ID]

\section{Rodrigo 2012}

Rodrigo GJ, Plaza V, Castro-Rodríguez JA. Comparison of three combined pharmacological approaches with tiotropium monotherapy in stable moderate to severe COPD: a systematic review. Pulmonary Pharmacology \& Therapeutics 2012;25(1):40-7. [DOI: 10.1016/j.pupt.2011.10.006]

\section{Sehatzadeh 2012}

Sehatzadeh S. Influenza and pneumococcal vaccinations for patients with chronic obstructive pulmonary disease (COPD): an evidence-based analysis. Ontario Health Technology Assessment Series 2012;12(3):1-64. [PUBMED: 3384373]

\section{Welsh 2010}

Welsh EJ, Cates CJ, Poole P. Combination inhaled steroid and long-acting beta2-agonist versus tiotropium for chronic obstructive pulmonary disease. Cochrane Database of Systematic Reviews 2010, Issue 5. [DOI: 10.1002/14651858.CD007891.pub2]

\section{Westwood 2011}

Westwood M, Bourbeau J, Jones PW, Cerulli A, CapkunNiggli G, Worthy G. Relationship between FEV1 change and patient-reported outcomes in randomised trials of inhaled bronchodilators for stable COPD: a systematic review. Respiratory Research 2011;12:40.

\section{Yang 2012}

Yang IA, Clarke MS, Sim EHA, Fong KM. Inhaled corticosteroids for stable chronic obstructive pulmonary disease. Cochrane Database of Systematic Reviews 2012, Issue 7. [DOI: 10.1002/14651858.CD002991.pub3]

\section{References to other published versions of this review}

\section{Karner 2011}

Karner C, Cates CJ. Combination inhaled steroid and longacting beta ${ }_{2}$-agonist in addition to tiotropium versus tiotropium or combination alone for chronic obstructive pulmonary disease. Cochrane Database of Systematic Reviews 2011, Issue 3. [DOI: 10.1002/14651858.CD008532.pub2]

* Indicates the major publication for the study

\section{Aaron 2007}

Methods

Design: a randomised, double-blind, placebo-controlled, parallel-group trial from October 2003 to January 2006. The trial included 27 Canadian medical centres; 20 centres were academic hospital-based pulmonary clinics, 5 were community-based pulmonary clinics and 2 were community-based primary care clinics 
Baseline characteristics: mean age 68 years. COPD severity moderate to severe with mean $\mathrm{FEV}_{1}$ predicted of $39 \% .44 \%$ women

Inclusion criteria: at least 1 exacerbation of COPD that required treatment with systemic steroids or antibiotics within the 12 months before randomisation; age older than 35 years; history of 10 or more pack-years of cigarette smoking; documented chronic airflow obstruction, with an $\mathrm{FEV}_{1} / \mathrm{FVC}$ ratio < 0.70 and a post-bronchodilator $\mathrm{FEV}_{1}<65 \%$ of predicted value

Exclusion criteria: history of physician-diagnosed asthma before 40 years of age; history of physician-diagnosed chronic congestive heart failure with known persistent severe left ventricular dysfunction; those receiving oral prednisone; those with a known hypersensitivity or intolerance to tiotropium, salmeterol or fluticasone-salmeterol; history of severe glaucoma or severe urinary tract obstruction, previous lung transplantation or lung volume reduction surgery or diffuse bilateral bronchiectasis; those who were pregnant or breastfeeding

Interventions

- Tiotropium + salmeterol + fluticasone: tiotropium (Spiriva, Handihaler (Boehringer Ingelheim Pharma, Ingelheim, Germany)), 18 mcg once daily, plus fluticasone-salmeterol (Advair (GlaxoSmithKline, Research Triangle Park, North Carolina, USA)), 250/25 mcg/puff, 2 puffs twice daily

- Tiotropium + salmeterol: tiotropium, 18 mcg once daily, plus salmeterol (Serevent (GlaxoSmithKline)), $25 \mathrm{mcg} /$ puff, 2 puffs twice daily

- Tiotropium + placebo: tiotropium, 18 mcg once daily, plus placebo inhaler, 2 puffs twice daily

Outcomes Primary: proportion of participants with $\geq 1$ exacerbation of COPD

Secondary: mean number of COPD exacerbations per patient-year; total number of exacerbations that resulted in urgent visits to a healthcare provider or emergency department; number of hospitalisations for COPD; total number of hospitalisations for all causes; changes in health-related quality of life, dyspnoea or lung function

Notes

Co-medication: All study participants were provided with inhaled albuterol and were instructed to use it when necessary to relieve symptoms. Any treatment with ICS, LABA and anticholinergics that the patient may have been using before entry was discontinued on entry into the study. Therapy with other respiratory medications, such as oxygen, antileukotrienes and methylxanthines, was continued in all patient groups

Funding source: The Canadian Institutes of Health Research and The Ontario Thoracic Society provided peer-reviewed funding for this study

\section{Risk of bias}

\begin{tabular}{lll}
\hline Bias & Authors' judgement & Support for judgement \\
\hline $\begin{array}{l}\text { Random sequence genera- } \\
\text { tion (selection bias) }\end{array}$ & Low risk & $\begin{array}{l}\text { Randomisation was done through central allocation of a randomisation sched- } \\
\text { ule that was prepared from a computer-generated random listing of the } 3 \\
\text { treatment allocations in variable blocks of } 9 \text { or } 12 \text { and stratified by site }\end{array}$ \\
\hline $\begin{array}{l}\text { Allocation concealment } \\
\text { (selection bias) }\end{array}$ & Low risk & $\begin{array}{l}\text { Neither research staff nor participants were aware of the treatment assign- } \\
\text { ment before or after randomisation }\end{array}$ \\
\hline $\begin{array}{l}\text { Blinding (performance } \\
\text { bias and detection bias) }\end{array}$ & Low risk & $\begin{array}{l}\text { Metered-dose inhalers containing placebo, salmeterol and fluticasone-salme- } \\
\text { terol were identical in taste and appearance and were enclosed in identical } \\
\text { tamper-proof blinding devices. Medication canisters within the blinding de- } \\
\text { vices were stripped of all identifying labelling }\end{array}$ \\
\hline $\begin{array}{l}\text { Incomplete outcome data } \\
\text { (attrition bias) }\end{array}$ & Unclear risk & $\begin{array}{l}\text { The number of people who stopped drug therapy was high, with large varia- } \\
\text { till outcomes between groups (74 (47\%) tiotropium + placebo and } 37 \text { (26\%) tiotropium } \\
+ \text { LABA/ICS comb). However, the number of people who did not complete the } \\
\text { trial was smaller, although large variations between groups were evident (30 }\end{array}$
\end{tabular}


(19\%) tiotropium + placebo and 15 (10\%) tiotropium + LABA/ICS comb). The issue of incomplete data was addressed by sensitivity analyses of the data comprising alternative assumptions for participants who prematurely withdrew from treatment

Selective reporting (re- Low risk Results for all listed primary and secondary outcomes were reported

\section{Cazzola 2007}

\begin{tabular}{|c|c|}
\hline Methods & Design: a randomised, double-blind, double-dummy, parallel-group trial over 12-weeks \\
\hline \multirow[t]{5}{*}{ Participants } & Population: 90 participants with well-controlled COPD \\
\hline & Baseline characteristics: mean age 66 years. Severe to very severe COPD with mean $\mathrm{FEV}_{1}$ predicted of \\
\hline & $38 \% .11 \%$ women \\
\hline & $\begin{array}{l}\text { Inclusion criteria: baseline } \mathrm{FEV}_{1}<50 \% \text { predicted and post-bronchodilator } \mathrm{FEV}_{1} / \mathrm{FVC}<70 \% \text { following } \\
\text { salbutamol } 400 \mathrm{mcg} \text { according to the GOLD criteria of severity }\end{array}$ \\
\hline & $\begin{array}{l}\text { Exclusion criteria: current evidence of asthma as primary diagnosis; unstable respiratory disease re- } \\
\text { quiring oral/parenteral corticosteroids within } 4 \text { weeks before the beginning of the study; upper or low- } \\
\text { er respiratory tract infection within } 4 \text { weeks of the screening visit; unstable angina or unstable arrhyth- } \\
\text { mias; concurrent use of medications that affected COPD; evidence of alcohol abuse }\end{array}$ \\
\hline \multirow[t]{3}{*}{ Interventions } & $\begin{array}{l}\text { - LABA/ICS comb + placebo: FSC 500/50 mcg Diskus, } 1 \text { inhalation twice daily + placebo Handihaler } 1 \text { in- } \\
\text { halation once daily }\end{array}$ \\
\hline & $\begin{array}{l}\text { - Tiotropium + placebo: tiotropium } 18 \text { mcg Handihaler, } 1 \text { inhalation once daily + placebo Diskus, } 1 \text { in- } \\
\text { halation twice daily }\end{array}$ \\
\hline & $\begin{array}{l}\text { - Tiotropium + LABA/ICS comb: FSC 500/50 mcg Diskus, } 1 \text { inhalation twice daily + tiotropium } 18 \text { mcg } \\
\text { Handihaler, } 1 \text { inhalation once daily }\end{array}$ \\
\hline Outcomes & $\begin{array}{l}\text { Mean change from baseline in pre-dose } \mathrm{FEV}_{1} \text { after } 3 \text {-month treatment, change from baseline in VAS } \\
\text { score assessing dyspnoea and in supplemental salbutamol }\end{array}$ \\
\hline Notes & $\begin{array}{l}\text { Run-in: Participants entered a } 2 \text {-week run-in period during which their regular treatment for COPD (all } \\
\text { were receiving regular treatment with a LABA and an ICS, many ( } 81 \text { out of } 90) \text { with theophylline also) } \\
\text { was stopped, with the exception of stable regimens of theophylline (no change in dose for } 1 \text { month be- } \\
\text { fore screening), and they received salbutamol for relief of breakthrough symptoms. Use of all other in- } \\
\text { haled or oral bronchodilators, systemic corticosteroids, ipratropium bromide, oxitropium bromide or } \\
\text { leukotriene modifiers was prohibited }\end{array}$ \\
\hline
\end{tabular}

\section{Risk of bias}

\begin{tabular}{lll}
\hline Bias & Authors' judgement & Support for judgement \\
\hline $\begin{array}{l}\text { Random sequence genera- } \\
\text { tion (selection bias) }\end{array}$ & Low risk & $\begin{array}{l}\text { Participants were randomised to receive FSC, tiotropium or their combination } \\
\text { by a computer-generated list. Randomisation was performed in blocks of } 9\end{array}$ \\
\hline $\begin{array}{l}\text { Allocation concealment } \\
\text { (selection bias) }\end{array}$ & Unclear risk & No details \\
\hline $\begin{array}{l}\text { Blinding (performance } \\
\text { bias and detection bias) } \\
\text { All outcomes }\end{array}$ & Unclear risk & No details \\
\hline
\end{tabular}


Cazzola 2007 (Continued)

Incomplete outcome data Low risk $\quad$ Dropout rate 10\%
(attrition bias)

All outcomes

Selective reporting (re- Low risk Results for all listed outcomes were reported
porting bias)

\section{Hanania 2011}

$\begin{array}{ll}\text { Methods } & \text { Design: a randomised, double-blind, parallel-group, multi-centre study over 24-weeks. The trial includ- } \\ \text { ed } 33 \text { centres in the USA }\end{array}$
ed 33 centres in the USA

\section{Participants}

Population: 342 adults with a clinical history of moderate to severe COPD as defined by ATS and ERS guidelines

Baseline characteristics: mean age 61 years. Moderate to severe COPD with mean $\mathrm{FEV}_{1}$ predicted of $56 \%$

Inclusion criteria: age $\geq 40$ years; diagnosis of COPD according to ATS-ERS criteria; history of 10 or more pack-years of cigarette smoking; post-albuterol $\mathrm{FEV}_{1}>40$ to $<80 \%$ of predicted normal and postalbuterol $\mathrm{FEV}_{1} / \mathrm{FVC}$ ratio $<0.70$ according to NHANES III reference values

Exclusion criteria: clinical diagnosis of respiratory disorder other than COPD; long-term oxygen; BMI $>40 \mathrm{~kg} / \mathrm{m}^{2}$; clinically significant and uncontrolled medical disorder; lung resection surgery within the past year; inability to give informed consent

\begin{tabular}{ll}
\hline Interventions & - Tiotropium 18 mcg once daily via HandiHaler + fluticasone/salmeterol 250/50 mcg via DISKUS (FSC; \\
Advair, Seretide, GlaxoSmithKline, Research Triangle Park, North Carolina, USA) twice daily \\
• Tiotropium $18 \mathrm{mcg}$ once daily + placebo DISKUS twice daily \\
\hline Outcomes \\
Primary: AM pre-dose FEV 1 \\
Secondary: 2 hours post-dose FEV ${ }_{1}$; AM pre-dose FVC; 2 hours post-dose FVC; AM pre-dose IC; domain \\
scores on the CRQ-SAS; rescue albuterol use and healthcare utilisation for COPD exacerbations \\
Co-medication: All study participants were provided with inhaled albuterol and were instructed to use \\
it when necessary to relieve symptoms. Use of concurrent inhaled long-acting bronchodilators (be- \\
ta2-agonist and anticholinergic), ipratropium/albuterol combination products, oral beta2-agonists, ICS \\
and OCS and theophylline preparations was not allowed during the treatment period \\
Funding source: Hanania has received research grant support and honoraria for serving as a consul- \\
tant and on the speaker bureau of GlaxoSmithKline; Niewoehner has received advisory or consulting \\
fees from Boehringer Ingelheim, AstraZeneca, GlaxoSmithKline, Forest Research, Novartis, Merck, Ny- \\
comed, Sanofi Aventis, Sepracor and Bayer Schering
\end{tabular}

\section{Risk of bias}

\begin{tabular}{lll}
\hline Bias & Authors' judgement & Support for judgement \\
\hline $\begin{array}{l}\text { Random sequence genera- } \\
\text { tion (selection bias) }\end{array}$ & Low risk & $\begin{array}{l}\text { After 4-week treatment with open-label tiotropium 18 mcg once daily, partici- } \\
\text { pants were randomised in a double-blind fashion to either the addition of FSC } \\
250 / 50 \text { DISKUS twice daily or matching placebo }\end{array}$ \\
\hline $\begin{array}{l}\text { Allocation concealment } \\
\text { (selection bias) }\end{array}$ & Unclear risk & No details \\
\hline
\end{tabular}


Hanania 2011 (Continued)

Blinding (performance Low risk The DISKUS inhalers containing placebo and fluticasone-salmeterol were idenbias and detection bias) tical in taste and appearance

All outcomes

$\begin{array}{lll}\text { Incomplete outcome data } & \text { Unclear risk } & \text { Drop-out rate 23\%. FSC + tiotropium 137/173 (79\%) and tiotropium + placebo } \\ \text { (attrition bias) } & 127 / 169(75 \%) \\ \text { All outcomes } & \end{array}$

All outcomes

\begin{tabular}{|c|c|}
\hline Methods & Design: a randomised, open-label, parallel-group study over 12 weeks \\
\hline \multirow[t]{5}{*}{ Participants } & Population: 30 adults with COPD with post-bronchodilator $\mathrm{FEV}_{1} / \mathrm{FVC}<0.7$ \\
\hline & $\begin{array}{l}\text { Baseline characteristics: mean age } 73 \text { years; the proportions of participants at each disease stage, } \\
\text { according to the GOLD criteria, were as follows: stage I, } 10 \% \text {; stage II, } 33.3 \% \text {; stage III, } 36.6 \% \text {; stage IV, } \\
20 \% \text {. Proportions of men and women were } 14 / 0 \text { (Tiotropium) and } 14 / 2 \text { (SFC + tiotropium) }\end{array}$ \\
\hline & $\begin{array}{l}\text { Inclusion criteria: participants with COPD confirmed on the basis of spirometry (post-bronchodila- } \\
\left.\text { tor } \mathrm{FEV}_{1} / \mathrm{FVC}<0.7\right) \text {, smoking history of }>10 \text { pack-years and no history of asthma or atopy as defined by }\end{array}$ \\
\hline & $\begin{array}{l}\text { a positive skin prick test to one or more common allergens. Participants were newly diagnosed with } \\
\text { COPD or had not previously used tiotropium, OCS or ICS or LABA }\end{array}$ \\
\hline & $\begin{array}{l}\text { Exclusion criteria: use of supplemental oxygen and respiratory infection or COPD exacerbation in the } \\
12 \text { weeks before commencement of the study }\end{array}$ \\
\hline \multirow[t]{2}{*}{ Interventions } & - Tiotropium 18 mcg (Boehringer Ingelheim Pharma, Ingelheim, Germany) once daily \\
\hline & $\begin{array}{l}\text { - SFC 50/250 mcg (GlaxoSmithKline, London, UK) twice daily, in combination with Tio, } 18 \text { mcg once dai- } \\
\text { ly }\end{array}$ \\
\hline
\end{tabular}

Outcomes

Primary: analysis of airway dimensions

Secondary: mean change in FVC, FEV 1 , IC, FCR, RV/TLC and DLCO/VA after 3-months of treatment; change on the SGRQ

Participants entered a 2-week washout period before the start of the study, during which all current
COPD medications were discontinued. Use of additional bronchodilators was not permitted through-
out the study period, except for SABA as required

\section{Risk of bias}

\begin{tabular}{lll}
\hline Bias & Authors' judgement & Support for judgement \\
\hline $\begin{array}{l}\text { Random sequence genera- } \\
\text { tion (selection bias) }\end{array}$ & Unclear risk & $\begin{array}{l}\text { Randomisation was done in a 1:1 ratio. No details about the method were pro- } \\
\text { vided }\end{array}$ \\
\hline $\begin{array}{l}\text { Allocation concealment } \\
\text { (selection bias) }\end{array}$ & Unclear risk & No details \\
\hline $\begin{array}{l}\text { Blinding (performance } \\
\text { bias and detection bias) } \\
\text { All outcomes }\end{array}$ & Unclear risk & Open, but assessor(s) were blinded \\
\hline
\end{tabular}


Hoshino 2011 (Continued)

Incomplete outcome data Unclear risk Drop-out rate 20\%. A total of 36 participants were enrolled in the study, but 6 (attrition bias) participants were withdrawn because of lack of follow-up

All outcomes

Selective reporting (re- Low risk porting bias)

Results for all listed primary and secondary outcomes were reported

Jung 2012

Methods

Design: a randomised, open-label, multi-centre, 2-arm, parallel study from April 2009 to March 2010.

The trial was conducted at 30 academic hospital-based pulmonary clinics in Korea

\section{Participants Population: 479 participants with COPD}

Baseline characteristics: mean age 67 years. Moderate to very severe COPD with mean FEV predicted $_{1}$ of $50.8 \% .98 \%$ men

Inclusion criteria: participants diagnosed with COPD who had a post-bronchodilator $\mathrm{FEV}_{1} / \mathrm{FVC}$ ratio < 0.70 and $\mathrm{FEV}_{1}<65 \%$ of predicted value in the past 1 year or at screening. Eligible participants were 40 to 80 years of age and had a smoking history of 10 or more pack-years

Exclusion criteria: a history of physician-diagnosed asthma or a chronic respiratory disorder other than COPD that was clinically significant; any uncontrollable or serious disease that might affect participation in the study; use of systemic corticosteroids or immunosuppressants within 4 weeks before study entry; any malignant disease; a history of severe glaucoma, urinary tract obstruction or previous lung volume reduction surgery; women who were pregnant or lactating; known hypersensitivity or intolerance to tiotropium or FSC

$\begin{array}{ll}\text { Interventions } & \text { Tiotropium (Spiriva HandiHaler (Boehringer Ingelheim Pharma, Ingelheim, Germany)), } 18 \text { mcg once } \\ \text { daily } & \\ & \text { Tiotropium } 18 \text { mcg once daily + FSC (Seretide Diskus (GlaxoSmithKline, Brentford, UK)), 250/50 mcg/ } \\ \text { puff, } 1 \text { puff twice daily }\end{array}$

Outcomes

Primary: change in pre-bronchodilator $\mathrm{FEV}_{1}(\mathrm{~L})$ from baseline to week 24

Secondary: mean changes in pre-bronchodilator $\mathrm{FEV}_{1}(\mathrm{~L})$ from baseline to weeks 4,8 and 16; mean changes in pre-bronchodilator inspiratory capacity (IC); FVC and percent predicted (\% pred) values for $\mathrm{FEV}_{1}$; mean changes in $\mathrm{HRQ}$ oL; frequency of COPD exacerbations; exacerbations requiring hospitalisations, emergency room visits or outpatient clinic visits; hospitalisation rates for all causes

Notes

Co-medication: All participants were provided with a salbutamol inhalation aerosol and were instructed to use it when necessary to relieve symptoms. Before the run-in period, participants stopped their usage of ICA and long-acting bronchodilators, but therapy with other regular medications such as oxygen, mucolytics and methylxanthines was allowed throughout the study for all participants

This study was supported by a grant from the Korea Healthcare Technology R\&D Project, Ministry for Health and Welfare, Republic of Korea (A102065), and from GlaxoSmithKline Korea

\section{Risk of bias}

\begin{tabular}{lll}
\hline Bias & Authors' judgement & Support for judgement \\
\hline $\begin{array}{l}\text { Random sequence genera- } \\
\text { tion (selection bias) }\end{array}$ & Low risk & $\begin{array}{l}\text { Randomisation was done in a 1:1 ratio through a computerised random-num- } \\
\text { ber generator }\end{array}$ \\
\hline
\end{tabular}


Jung 2012 (Continued)

\begin{tabular}{ll}
$\begin{array}{l}\text { Allocation concealment } \\
\text { (selection bias) }\end{array} \quad$ Low risk & $\begin{array}{l}\text { Neither research staff nor participants were aware of treatment assignment } \\
\text { until randomised }\end{array}$ \\
\hline
\end{tabular}
(selection bias)

Unclear risk

No details

Blinding (performance

bias and detection bias)

All outcomes

$\begin{array}{ll}\begin{array}{l}\text { Incomplete outcome data } \\ \text { (attrition bias) }\end{array} & \text { Low risk } \\ \text { tiotropium + LABA/ICS comb group }\end{array}$

All outcomes

tiotropium + LABA/ICS comb group

Selective reporting (re- Low risk

Results were reported for all listed primary and secondary outcomes

porting bias)

Welte 2009

Methods

Design: a randomised, double-blind, parallel-group, multi-centre trial from May 2007 to June 2008. The trial included 102 centres in 9 countries: Australia (10 centres), Canada (16), France (12), Germany (12), Hungary (13), Poland (10), Slovakia (13), Spain (6) and Sweden (10)

Participants

Population: 660 participants with COPD eligible for LABA/ICS combination therapy, with pre-bronchodilator $\mathrm{FEV}_{1}$ not exceeding $50 \%$ of predicted normal value and a history of exacerbations requiring systemic steroids and/or antibiotics

Baseline characteristics: mean age 62 years. Moderate, severe or very severe COPD with mean FEV 1 predicted of $38 \% .25 \%$ women

Inclusion criteria: participants with COPD eligible for LABA/ICS combination therapy $\geq 40$ years of age, with a clinical diagnosis of COPD and symptoms for $\geq 2$ years; $\geq 1$ COPD exacerbation in the previous 12 months requiring systemic steroids and/or antibiotics; current or previous smokers with a smoking history of $\geq 10$ pack-years; forced expiratory volume in 1 second $\left(\mathrm{FEV}_{1}\right) \leq 50 \%$ of predicted normal value and

$\mathrm{FEV}_{1} / \mathrm{FVC}<70 \%$ pre-dose

Exclusion criteria: worsening of COPD during run-in or within 4-weeks before visit 2 requiring hospitalisation; a course of OCS and/or ICS and/or antibiotics; use of ICS within 2 weeks before visit 2; use of oral/parenteral glucocorticosteroids within 4 weeks before visit 2; a history of asthma or any significant disease/disorder that, in the opinion of the investigator, may put the patient at risk or might influence results

Interventions

- Tiotropium + LABA/ICS comb: tiotropium (Handihaler) $18 \mathrm{mcg}$ once daily + budesonide/formoterol (Symbicort Turbuhaler; AstraZeneca, Lund, Sweden) 320/9 mcg 1 inhalation twice daily

- Tiotropium + placebo: tiotropium 18 mcg once daily + placebo (identical Turbuhaler) twice daily

Outcomes

Primary: change in pre-dose $\mathrm{FEV}_{1}$ from randomisation (week 0 ) to full treatment period (mean $\mathrm{FEV}_{1}$ at 1,6 and 12 weeks of treatment)

Secondary: pre-dose and post-dose spirometry measurements (pre-dose FVC and inspiratory capacity and post-treatment $\mathrm{FEV}_{1}(5$ and $60 \mathrm{~min}), \mathrm{FVC}(5$ and $60 \mathrm{~min}$ ) and inspiratory capacity $(60 \mathrm{~min})$ ) and SGRQ

Notes

Run-in: Before entering the study, participants stopped their LABA and ICS medications (4 weeks and 2 weeks before run-in, respectively). During the 2-week run-in period, all participants used tiotropium (Spiriva HandiHaler, Boehringer Ingelheim Pharma, Ingelheim, Germany) 18 mcg once daily. Terbu- 
Welte 2009 (Continued)

taline $0.5 \mathrm{mg}$ /inhalation (Bricanyl Turbuhaler, AstraZeneca, Lund, Sweden) was used as needed for symptom relief during the run-in period

Co-medication: Terbutaline $0.5 \mathrm{mg} /$ inhalation (Bricanyl Turbuhaler, AstraZeneca, Lund, Sweden) was used as needed for symptom relief during the treatment period in both treatment arms

\begin{tabular}{|c|c|c|}
\hline \multicolumn{3}{|l|}{ Risk of bias } \\
\hline Bias & Authors' judgement & Support for judgement \\
\hline $\begin{array}{l}\text { Random sequence genera- } \\
\text { tion (selection bias) }\end{array}$ & Low risk & $\begin{array}{l}\text { Randomisation codes were sequentially assigned to participants from a com- } \\
\text { puter-generated list at AstraZeneca R\&D, Lund, Sweden, as they became eligi- } \\
\text { ble }\end{array}$ \\
\hline $\begin{array}{l}\text { Allocation concealment } \\
\text { (selection bias) }\end{array}$ & Low risk & $\begin{array}{l}\text { Investigators were provided with a blinded randomisation code for each par- } \\
\text { ticipant. Both clinicians and participants were blinded to treatment until com- } \\
\text { pletion of the study }\end{array}$ \\
\hline $\begin{array}{l}\text { Blinding (performance } \\
\text { bias and detection bias) } \\
\text { All outcomes }\end{array}$ & Low risk & $\begin{array}{l}\text { Treatment assignment was concealed, as active and placebo Turbuhalers } \\
\text { were of identical appearance }\end{array}$ \\
\hline $\begin{array}{l}\text { Incomplete outcome data } \\
\text { (attrition bias) } \\
\text { All outcomes }\end{array}$ & Low risk & $\begin{array}{l}\text { Drop-out rates were } 9 \% \text { in the tiotropium + placebo group and } 8 \% \text { in the } \\
\text { tiotropium + LABA/ICS comb group }\end{array}$ \\
\hline $\begin{array}{l}\text { Selective reporting (re- } \\
\text { porting bias) }\end{array}$ & Low risk & All collected data were reported \\
\hline
\end{tabular}

ATS: American Thoracic Society

BMI: body mass index

CRQ-SAS: Chronic Respiratory Disease Questionnaire-Self-Administered Standardized

COPD: chronic obstructive pulmonary disease

DLCO/VA: diffusing capacity of the lungs for carbon monoxide/alveolar volume

ERS: European Respiratory Society

FCR: functional residual capacity

$\mathrm{FEV}_{1}$ : forced expiratory volume in one second

FSC: fluticasone/salmeterol

FVC: forced vital capacity

GOLD: Global Initiative for Chronic Obstructive Lung Disease

HRQoL: health-related quality of life

IC: inspiratory capacity

ICS: inhaled corticosteroids

LABA: long-acting beta 2 -agonists

NHANES: National Health and Nutrition Examination Survey

OCS: oral corticosteroids

RV/TCL: residual volume/total lung capacity

SABA: short-acting beta $_{2}$-agonists

SGRQ: St. George's Respiratory Questionnaire

Tio: tiotropium

VAS: visual analogue scale

Characteristics of excluded studies [ordered by study ID]

\begin{tabular}{ll}
\hline Study & Reason for exclusion \\
\hline Ando 2008 & Evaluated the effects of tiotropium alone vs LABA/ICS combination \\
\hline \hline
\end{tabular}

Combination inhaled steroid and long-acting beta ${ }_{2}$-agonist in addition to tiotropium versus tiotropium or combination alone for chronic 31 obstructive pulmonary disease (Review)

Copyright $\odot 2017$ The Cochrane Collaboration. Published by John Wiley \& Sons, Ltd. 


\begin{tabular}{ll}
\hline Study & Reason for exclusion \\
\hline Bateman 2008 & Evaluated the effects of tiotropium alone vs LABA/ICS combination \\
\hline Biscione 2009 & Treatment period: 4 weeks \\
\hline Golabi 2006 & Evaluated the effects of tiotropium alone vs LABA/ICS combination \\
\hline Hara 2007 & Evaluated the effects of tiotropium alone vs LABA/ICS combination \\
\hline Maltais 2013 & Time of follow up was less than 8 weeks; treatment period for triple therapy was just 4 weeks \\
\hline Perng 2006 & Treatment period: 4 weeks \\
\hline Petroianni 2008 & Evaluated effects of tiotropium alone vs formoterol alone \\
\hline Sarac 2013 & Assessed for effects of tiotropium alone vs LABA/ICS combination \\
\hline Singh 2008 & 14 days of treatment and of cross-over design \\
\hline Tashkin 2008 & Evaluated tiotropium vs placebo; co-treatment allowed \\
\hline Troosters 2008 & Evaluated tiotropium vs placebo; co-treatment allowed \\
\hline
\end{tabular}

ICS: inhaled corticosteroids

LABA: long-acting beta-agonists

\section{Characteristics of studies awaiting assessment [ordered by study ID]}

Fang 2008

\begin{tabular}{ll}
\hline Methods & Design: randomised, parallel-group, 12 months of treatment \\
\hline Participants & 126 participants (M/F: 92/34) with COPD \\
\hline Interventions & Salmeterol/fluticasone (50/250 mcg) twice daily and tiotropium $18 \mathrm{mcg}$ once daily ( $\mathrm{n}=33, \mathrm{M} / \mathrm{F}:$ \\
& Salmeterol/fluticasone $(50 / 250 \mathrm{mcg})$ twice daily $(\mathrm{n}=32, \mathrm{M} / \mathrm{F}: 24 / 8)$ \\
& Tiotropium $18 \mathrm{mcg}$ once daily $(\mathrm{n}=32, \mathrm{M} / \mathrm{F}: 23 / 9)$ \\
& $\begin{array}{l}\text { Blank control group }(\mathrm{n}=29, \mathrm{M} / \mathrm{F}: 22 / 7): \text { Participants in this group did not receive inhaled anticholin- } \\
\text { ergic drugs, LABA or glucocorticoid therapy }\end{array}$
\end{tabular}

Outcomes

Symptoms, health status, use of rescue medication, frequency of exacerbations, FEV 1

Notes

Lee 2014

Methods Design: multi-centre, randomised, parallel-group, open-label study

Participants

578 participants with COPD. Mean age: 67 years, $96 \%$ male 
Lee 2014 (Continued)

Interventions
Following a 14-day run-in period during which participants received tiotropium 18 mcg once daily, participants were randomised to BUD/FORM 160/4.5 mcg 2 inhalations twice daily + tiotropium 18 mcg once daily (BUD/FORM+T), or tiotropium alone (18 mcg once daily), for 12 weeks

Outcomes $\quad$ Primary endpoint: ratio of treatment period mean to baseline in pre-dose FEV 1

Secondary outcomes: post-dose $\mathrm{FEV}_{1}$, pre-dose FVC, post-dose IC, pre-dose PEF, use of reliever medication, change in COPD symptoms, COPD exacerbations

Notes

BUD: budesonide

COPD: chronic obstructive pulmonary disease

$\mathrm{FEV}_{1}$ : forced expiratory volume in one second

FORM: formoterol

FVC: forced vital capacity

IC: inspiratory capacity

LABA: long-acting beta-agonists

PEF: peak expiratory flow

$\mathrm{T}$ : tiotropium

Characteristics of ongoing studies [ordered by study ID]

Betsuyaku 2013

Trial name or title Evaluating the Control of COPD Symptoms in Patients Treated With Tiotropium Bromide $18 \mathrm{mcg}$ Once Daily Alone, ADOAIR 50/250 mcg Twice Daily Alone or ADOAIR 50/250 mcg Plus Tiotropium Bromide $18 \mathrm{mcg}$

Methods Design: multi-centre, randomised, parallel- group study; 24 weeks of treatment

Participants

Participants will be 40-80 years of age with an established clinical history of COPD as defined by the GOLD guidelines, with a current or former smoking history of $>10$ pack-years, post-bronchodilator $\mathrm{FEV}_{1}>30 \%$ to $<80 \%$ of predicted normal value, post-bronchodilator $\mathrm{FEV}_{1} / \mathrm{FVC}$ ratio $<$ $70 \%$ and grade $\geq 1$ on the MRCm scale

Interventions

- Salmeterol/fluticasone propionate (SFC) 50/250 mcg twice daily delivered via the Diskus

- Tiotropium bromide $18 \mathrm{mcg}$ delivered once daily via the Handihaler inhalation device

- Salmeterol/fluticasone propionate (SFC) 50/250 mcg twice daily delivered via the Diskus + tiotropium bromide $18 \mathrm{mcg}$ delivered once daily via the Handihaler inhalation device

Outcomes

Primary: proportion of participants able to remain on the randomised therapy

\section{Secondary:}

- Proportion of participants who switched to triple therapy

- Proportion of participants controlled by triple therapy

- Proportion of participants controlled by randomised therapy + triple therapy

- Time to switch to triple therapy

- Time to first exacerbation

-Proportion of exacerbations confirmed by EXACT

- Proportion of exacerbations detected by EXACT not diagnosed 
Betsuyaku 2013 (Continued)

$$
\text { - CAT score change }
$$

- Change in $\mathrm{FEV}_{1}$

\begin{tabular}{ll}
\hline Starting date & February 2013 \\
\hline Contact information & GSKClinicalSupportHD@gsk.com \\
\hline Notes & ClinicalTrials.gov register NCT01762800 \\
\hline
\end{tabular}

\section{Cohuet 2013}

Trial name or title

A Study to Compare the Effect of Inhaled Treatments: The Combination of 3 Components (Beclometasone/Formoterol/Glycopyrrolate) to a Known Single Treatment (Tiotropium) or the Double Combination of Tiotropium (Spiriva) and Beclometasone plus Formoterol in Participants With COPD Treated for One Year

Methods Design: randomised, double-blind, double-dummy, parallel-group study; 52-weeks of treatment

Participants

Participants $>40$ years of age with a diagnosis of COPD (according to GOLD guidelines, updated February 2013) $\geq 12$ months before the screening visit. Current smokers or ex-smokers who quit smoking $\geq 6$ months before screening visit, with a smoking history of $\geq 10$ pack-years (pack-years $=$ (number of cigarettes per day $\times$ number of years) $/ 20$ )

Post-bronchodilator $\mathrm{FEV}_{1}<50 \%$ of predicted normal value and post-bronchodilator $\mathrm{FEV}_{1} / \mathrm{FVC}$ ratio $<0.7$ within $30 \mathrm{~min}$ after 4 puffs $(4 \times 100 \mathrm{mcg})$ of salbutamol pMDI

Interventions $\quad$ Beclometasone dipropionate + formoterol fumarate + glycopyrrolate bromide administered via
pMDI
$\cdot$ Tiotropium bromide
$\begin{aligned} & \cdot \text { Beclometasone dipropionate + formoterol fumarate administered via pMDI and tiotropium bro- } \\ & \text { mide }\end{aligned}$

\begin{tabular}{ll}
\hline Outcomes & Primary: moderate and severe COPD exacerbation rate \\
& Secondary: \\
& Change from baseline in pre-dose morning FEV 1 \\
& COPD exacerbation (moderate or severe, rate and time to first) \\
& $\begin{array}{l}\text { FEV } 1 \text { response (change from baseline in pre-dose morning FEV } 1 \geq 100 \mathrm{~mL}) \\
\text { SGRQ score (change from baseline in total/domain scores) } \\
\text { Use of rescue medication } \\
\text { PK analysis }\end{array}$ \\
\hline Starting date & November 2013 \\
\hline Contact information & g.cohuet@chiesi.com \\
\hline Notes & EudraCT number: 2013-000063-91 \\
\hline
\end{tabular}

COPD: chronic obstructive pulmonary disease

EXACT: Emboshield and Xact Post Approval Carotid Stent Trial

$\mathrm{FEV}_{1}$ : forced expiratory volume in one second

FVC: forced vital capacity

Combination inhaled steroid and long-acting beta 2 -agonist in addition to tiotropium versus tiotropium or combination alone for chronic

Copyright (C 2017 The Cochrane Collaboration. Published by John Wiley \& Sons, Ltd. 
GOLD: Global Initiative for Chronic Obstructive Lung Disease

mMRC: modified Medical Research Council

pMDI: pressurised metered-dose inhaler

SFC: salmeterol/fluticaso ne

SGRQ: St. George's Respiratory Questionnaire

\section{DATA AND ANALYSES}

\section{Comparison 1. Tiotropium + LABA/ICS combination versus tiotropium + placebo}

\begin{tabular}{|c|c|c|c|c|}
\hline Outcome or subgroup title & No. of studies & $\begin{array}{l}\text { No. of partici- } \\
\text { pants }\end{array}$ & Statistical method & Effect size \\
\hline 1 Mortality (all-cause) & 2 & 961 & Odds Ratio (M-H, Fixed, 95\% Cl) & $1.80[0.55,5.91]$ \\
\hline 1.1 At 3-month follow-up & 1 & 660 & Odds Ratio (M-H, Fixed, 95\% Cl) & $3.03[0.12,74.59]$ \\
\hline 1.2 At 12-month follow-up & 1 & 301 & Odds Ratio (M-H, Fixed, 95\% Cl) & $1.64[0.45,5.93]$ \\
\hline $\begin{array}{l}2 \text { Hospital admission (all caus- } \\
\text { es) }\end{array}$ & 2 & 961 & Odds Ratio (M-H, Fixed, 95\% Cl) & $0.84[0.53,1.33]$ \\
\hline 2.1 At 3-month follow-up & 1 & 660 & Odds Ratio (M-H, Fixed, 95\% Cl) & $0.64[0.27,1.49]$ \\
\hline 2.2 At 12-month follow-up & 1 & 301 & Odds Ratio (M-H, Fixed, 95\% Cl) & $0.94[0.55,1.62]$ \\
\hline 3 Exacerbation & 3 & & Odds Ratio (M-H, Fixed, 95\% Cl) & Totals not selected \\
\hline 3.1 At 3-month follow-up & 1 & & Odds Ratio (M-H, Fixed, 95\% Cl) & $0.0[0.0,0.0]$ \\
\hline 3.2 At 6-month follow-up & 1 & & Odds Ratio (M-H, Fixed, 95\% Cl) & $0.0[0.0,0.0]$ \\
\hline 3.3 At 12-month follow-up & 1 & & Odds Ratio (M-H, Fixed, 95\% Cl) & $0.0[0.0,0.0]$ \\
\hline $\begin{array}{l}4 \text { Quality of life up to } 6 \text { months } \\
\text { (SGRQ) }\end{array}$ & 4 & & Mean Difference (Fixed, 95\% CI) & $-3.33[-4.72,-1.94]$ \\
\hline $\begin{array}{l}5 \text { Sensitivity analysis - QoL up } \\
\text { to } 6 \text { months (SGRQ) }\end{array}$ & 2 & & $\begin{array}{l}\text { Mean Difference (Random, 95\% } \\
\mathrm{Cl} \text { ) }\end{array}$ & $-2.50[-4.16,-0.84]$ \\
\hline $6 \mathrm{FEV}_{1}$ pre-dose & 4 & & $\begin{array}{l}\text { Mean Difference (Random, 95\% } \\
\mathrm{Cl} \text { ) }\end{array}$ & Subtotals only \\
\hline $\begin{array}{l}6.1 \mathrm{FEV}_{1} 3-6 \text { months mean dif- } \\
\text { ference }\end{array}$ & 4 & & $\begin{array}{l}\text { Mean Difference (Random, 95\% } \\
\mathrm{Cl} \text { ) }\end{array}$ & $0.06[0.04,0.08]$ \\
\hline $6.2 \mathrm{FEV}_{1} 1$ year & 1 & & $\begin{array}{l}\text { Mean Difference (Random, 95\% } \\
\mathrm{Cl} \text { ) }\end{array}$ & $0.06[0.00,0.12]$ \\
\hline $\begin{array}{l}7 \text { Serious adverse events all re- } \\
\text { ported (non-fatal) }\end{array}$ & 4 & 1758 & Odds Ratio (M-H, Fixed, 95\% Cl) & $0.86[0.57,1.30]$ \\
\hline 8 Pneumonia & 4 & 1758 & $\begin{array}{l}\text { Peto Odds Ratio (Peto, Fixed, 95\% } \\
\mathrm{Cl} \text { ) }\end{array}$ & $1.62[0.54,4.82]$ \\
\hline
\end{tabular}




\begin{tabular}{lllll}
\hline Outcome or subgroup title & No. of studies & $\begin{array}{l}\text { No. of partici- } \\
\text { pants }\end{array}$ & Statistical method & Effect size \\
\hline $\begin{array}{l}\text { 9 Sensitivity analysis - SAE all } \\
\text { reported (non-fatal) }\end{array}$ & 3 & 1303 & Odds Ratio (M-H, Fixed, 95\% Cl) & $0.67[0.40,1.13]$ \\
\hline 10 Adverse event & 4 & 1363 & Odds Ratio (M-H, Fixed, 95\% Cl) & $1.16[0.92,1.47]$ \\
\hline
\end{tabular}

\section{Analysis 1.1. Comparison 1 Tiotropium + LABA/ICS combination versus tiotropium + placebo, Outcome 1 Mortality (all-cause).}

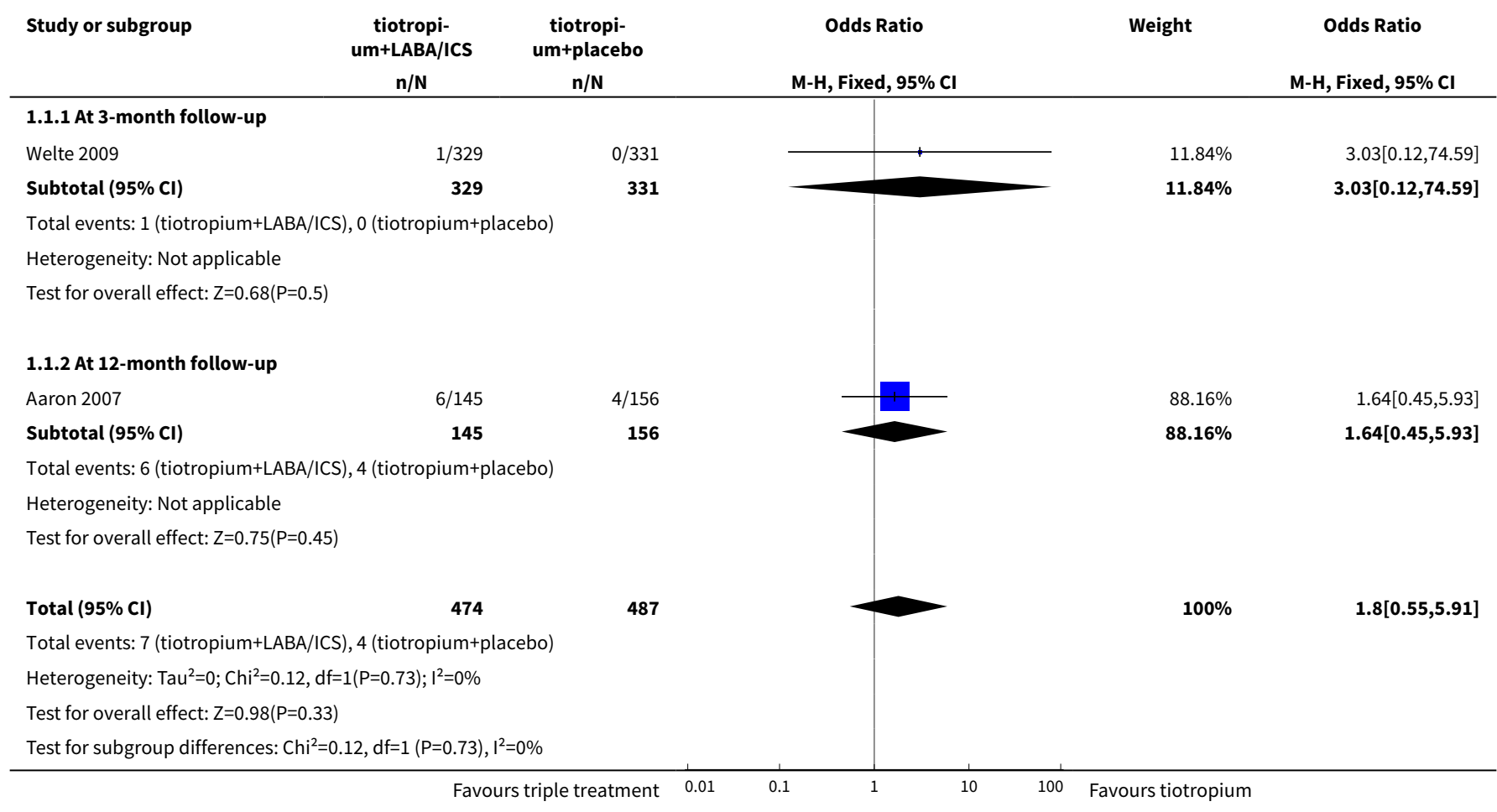

\section{Analysis 1.2. Comparison 1 Tiotropium + LABA/ICS combination versus tiotropium + placebo, Outcome 2 Hospital admission (all causes).}

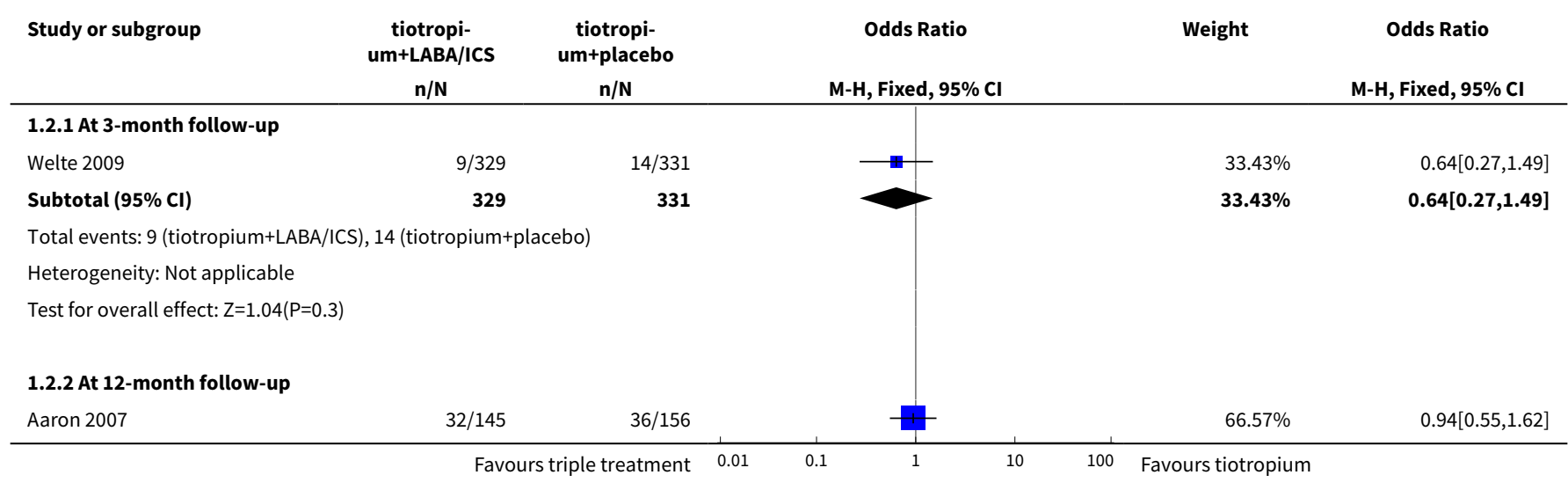

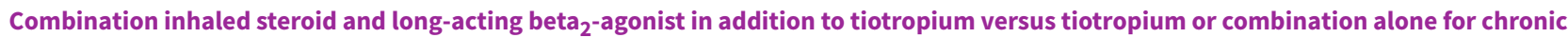
36 obstructive pulmonary disease (Review)

Copyright (C 2017 The Cochrane Collaboration. Published by John Wiley \& Sons, Ltd. 


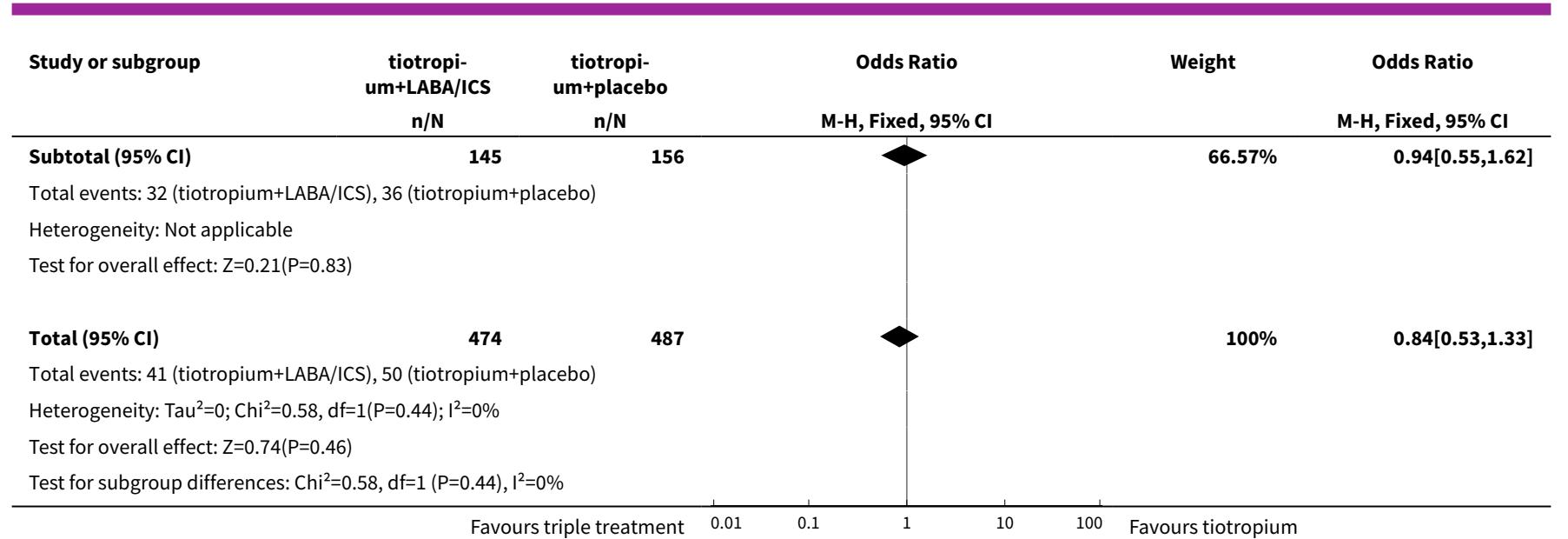

\section{Analysis 1.3. Comparison 1 Tiotropium + LABA/ICS combination versus tiotropium + placebo, Outcome 3 Exacerbation.}

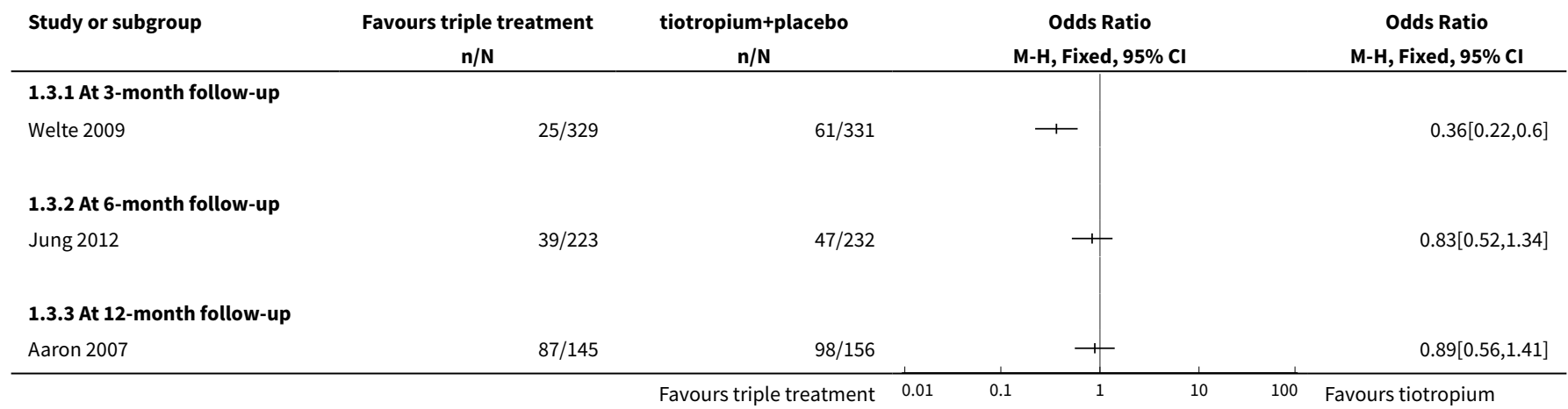

Analysis 1.4. Comparison 1 Tiotropium + LABA/ICS combination versus tiotropium + placebo, Outcome 4 Quality of life up to 6 months (SGRQ).

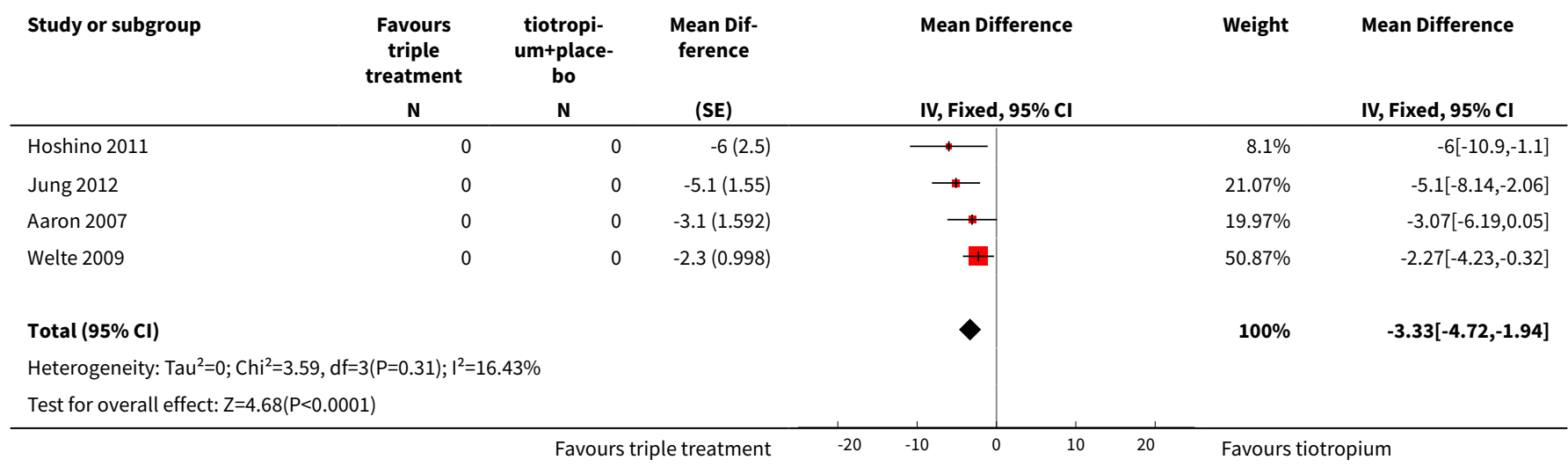


Analysis 1.5. Comparison 1 Tiotropium + LABA/ICS combination versus tiotropium + placebo, Outcome 5 Sensitivity analysis - QoL up to 6 months (SGRQ).

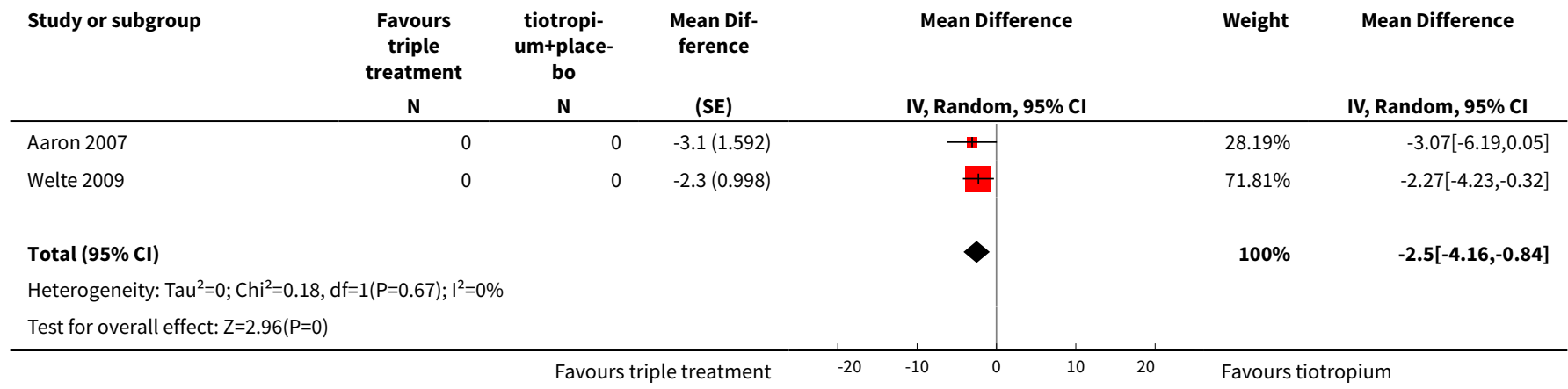

\section{Analysis 1.6. Comparison 1 Tiotropium + LABA/ICS combination} versus tiotropium + placebo, Outcome $6 \mathrm{FEV}_{1}$ pre-dose.

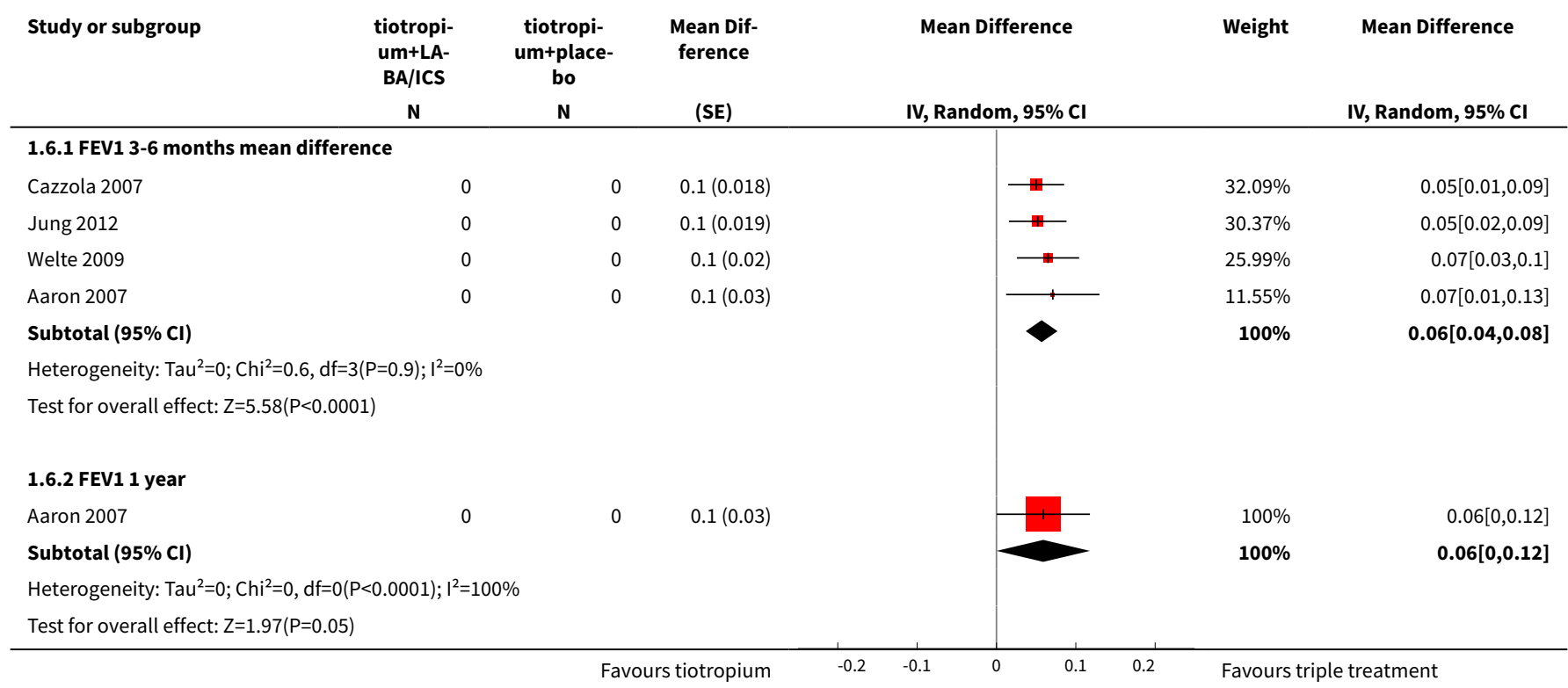

Analysis 1.7. Comparison 1 Tiotropium + LABA/ICS combination versus tiotropium + placebo, Outcome 7 Serious adverse events all reported (non-fatal).

\begin{tabular}{|c|c|c|c|c|c|}
\hline Study or subgroup & $\begin{array}{c}\text { tiotropi- } \\
\text { um+LABA/ICS } \\
n / N\end{array}$ & $\begin{array}{c}\text { tiotropi- } \\
\text { um+placebo } \\
n / N\end{array}$ & $\begin{array}{c}\text { Odds Ratio } \\
\text { M-H, Fixed, } 95 \% \mathrm{Cl}\end{array}$ & Weight & $\begin{array}{c}\text { Odds Ratio } \\
\text { M-H, Fixed, 95\% Cl }\end{array}$ \\
\hline Hanania 2011 & $7 / 173$ & $13 / 169$ & $\longrightarrow$ & $25.49 \%$ & $0.51[0.2,1.3]$ \\
\hline Welte 2009 & $9 / 329$ & $14 / 331$ & $\longrightarrow$ & $27.42 \%$ & $0.64[0.27,1.49]$ \\
\hline Aaron 2007 & $9 / 145$ & $10 / 156$ & - & $18.25 \%$ & $0.97[0.38,2.45]$ \\
\hline Jung 2012 & $20 / 223$ & $16 / 232$ & $\rightarrow-$ & $28.84 \%$ & $1.33[0.67,2.64]$ \\
\hline Total $(95 \% \mathrm{Cl})$ & 870 & 888 & & $100 \%$ & $0.86[0.57,1.3]$ \\
\hline
\end{tabular}




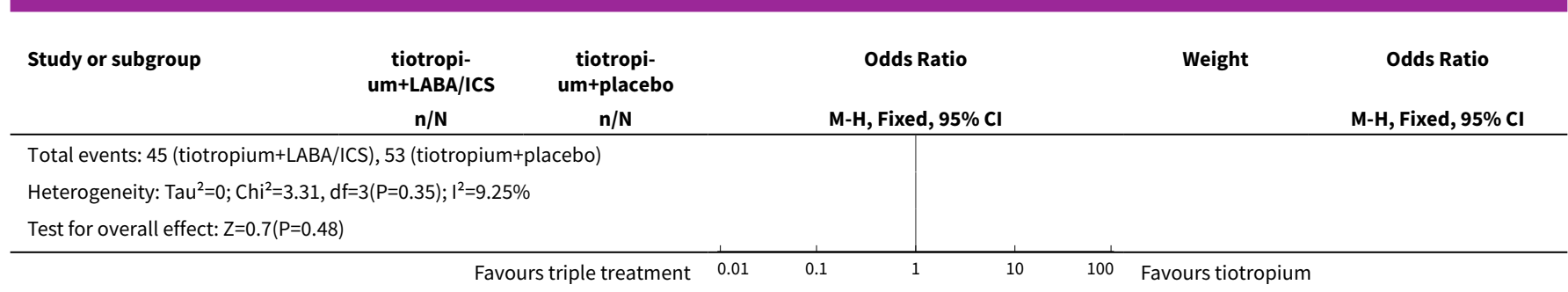

Analysis 1.8. Comparison 1 Tiotropium + LABA/ICS combination versus tiotropium + placebo, Outcome 8 Pneumonia.

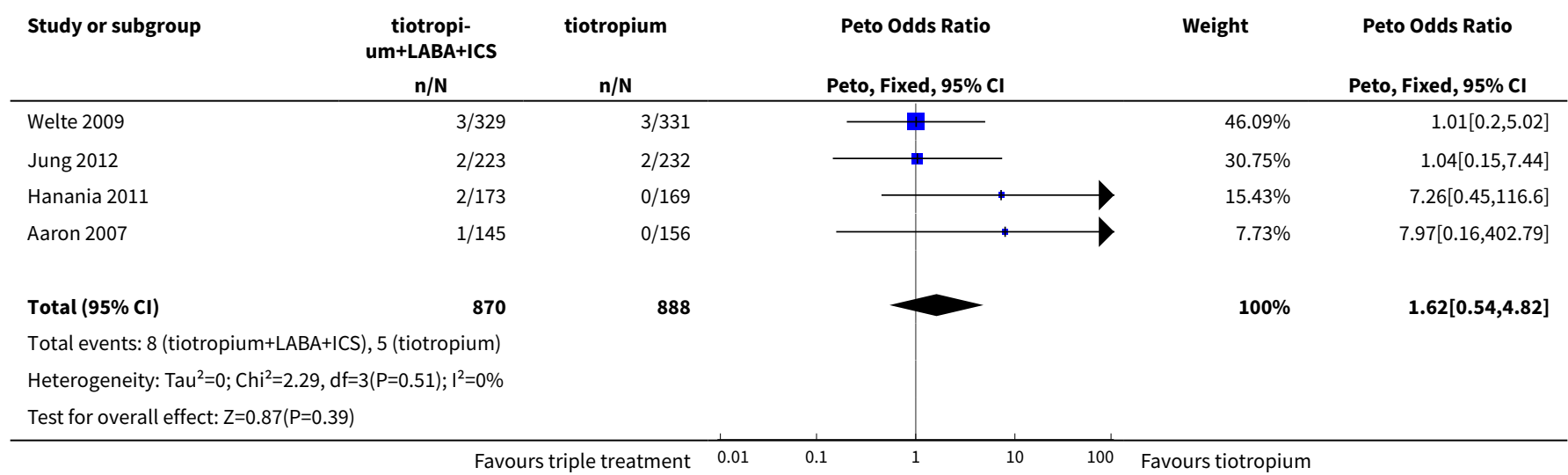

Analysis 1.9. Comparison 1 Tiotropium + LABA/ICS combination versus tiotropium + placebo, Outcome 9 Sensitivity analysis - SAE all reported (non-fatal).

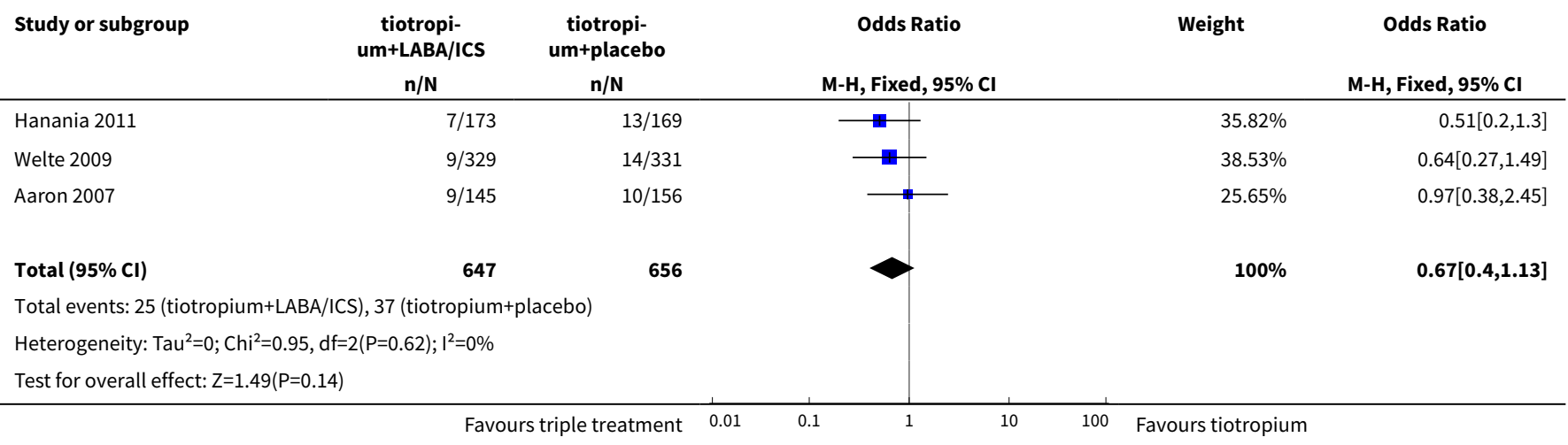




\section{Analysis 1.10. Comparison 1 Tiotropium + LABA/ICS combination} versus tiotropium + placebo, Outcome 10 Adverse event.

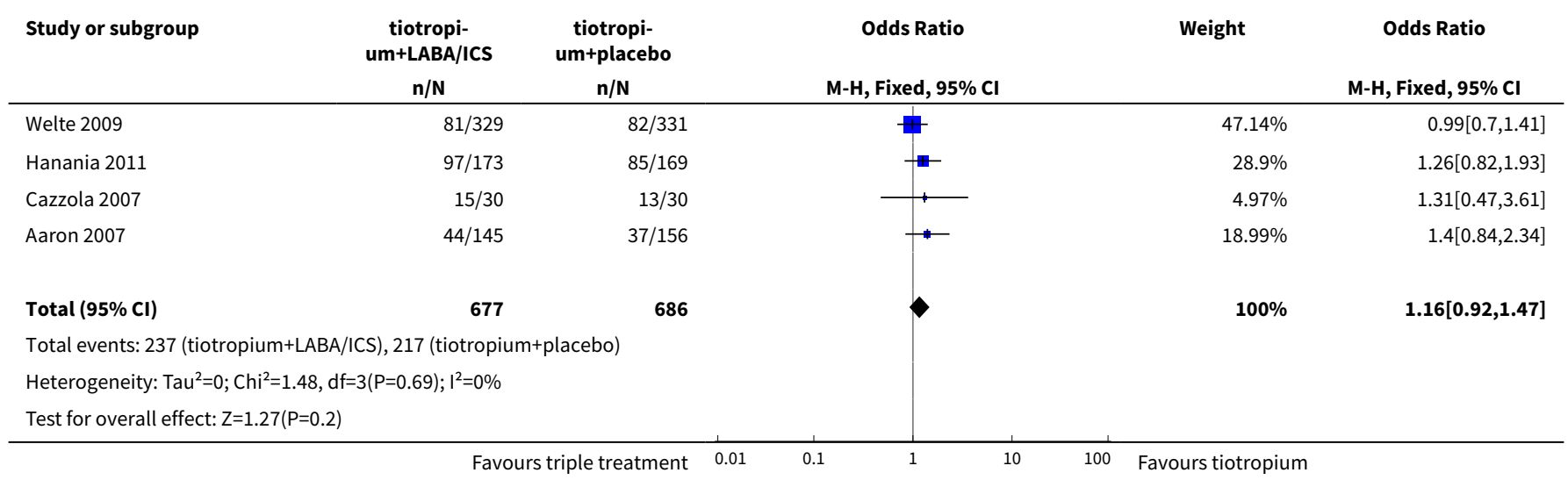

\section{Comparison 2. Tiotropium + LABA/ICS combination vs LABA/ICS combination + placebo}

\begin{tabular}{lllll}
\hline $\begin{array}{l}\text { Outcome or sub- } \\
\text { group title }\end{array}$ & No. of studies & $\begin{array}{l}\text { No. of partici- } \\
\text { pants }\end{array}$ & Statistical method & Effect size \\
\hline $1 \mathrm{FEV}_{1}$ GIV & 1 & Mean Difference (Fixed, 95\% Cl) & Totals not selected \\
\hline 2 Adverse event & 1 & Odds Ratio (M-H, Fixed, 95\% Cl) & Totals not selected \\
\hline 3 FEV 1 & 1 & Mean Difference (IV, Fixed, $95 \% \mathrm{Cl})$ & Totals not selected \\
\hline
\end{tabular}

Analysis 2.1. Comparison 2 Tiotropium + LABA/ICS combination vs LABA/ICS combination + placebo, Outcome 1 FEV $_{1}$ GIV.

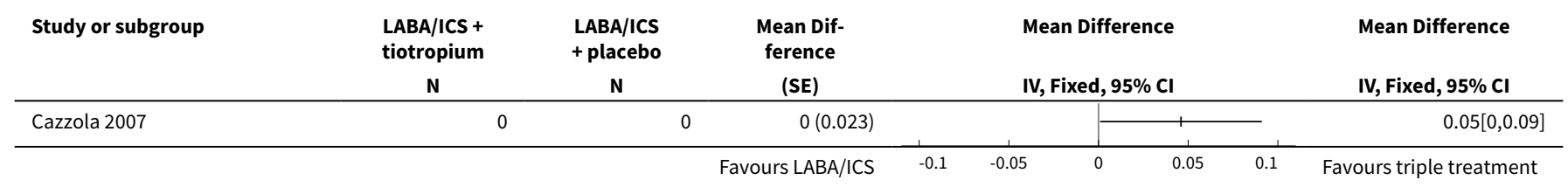

Analysis 2.2. Comparison 2 Tiotropium + LABA/ICS combination vs LABA/ICS combination + placebo, Outcome 2 Adverse event.

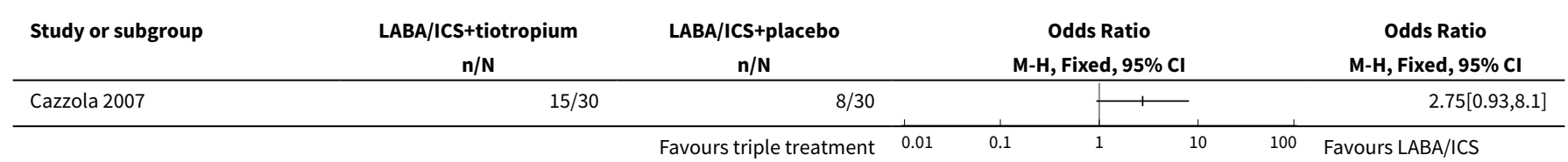




\section{Analysis 2.3. Comparison 2 Tiotropium + LABA/ICS combination} vs LABA/ICS combination + placebo, Outcome $3 \mathrm{FEV}_{\mathbf{1}}$.

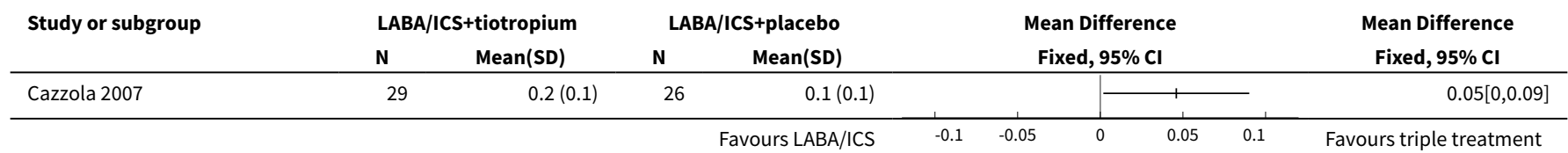




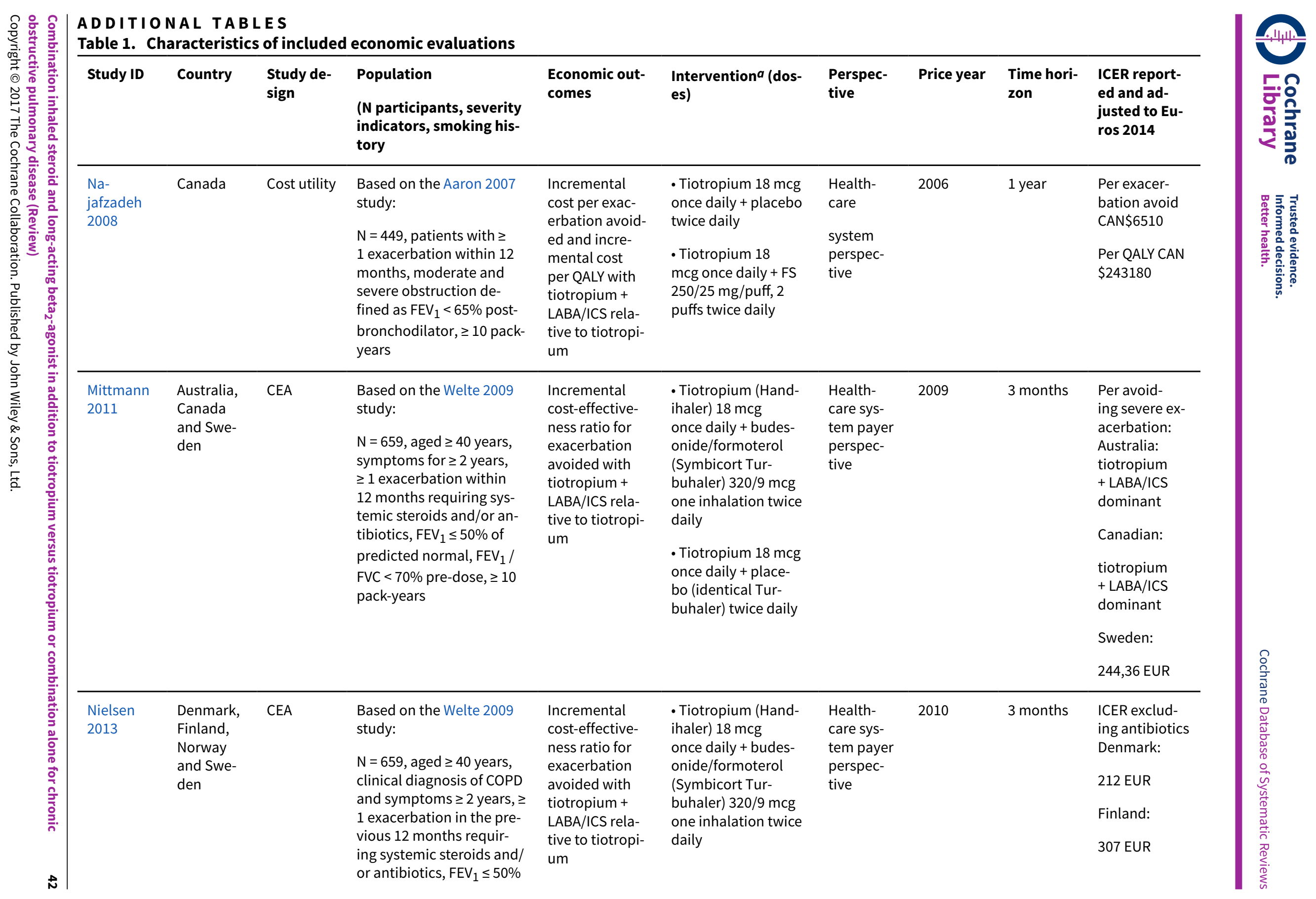




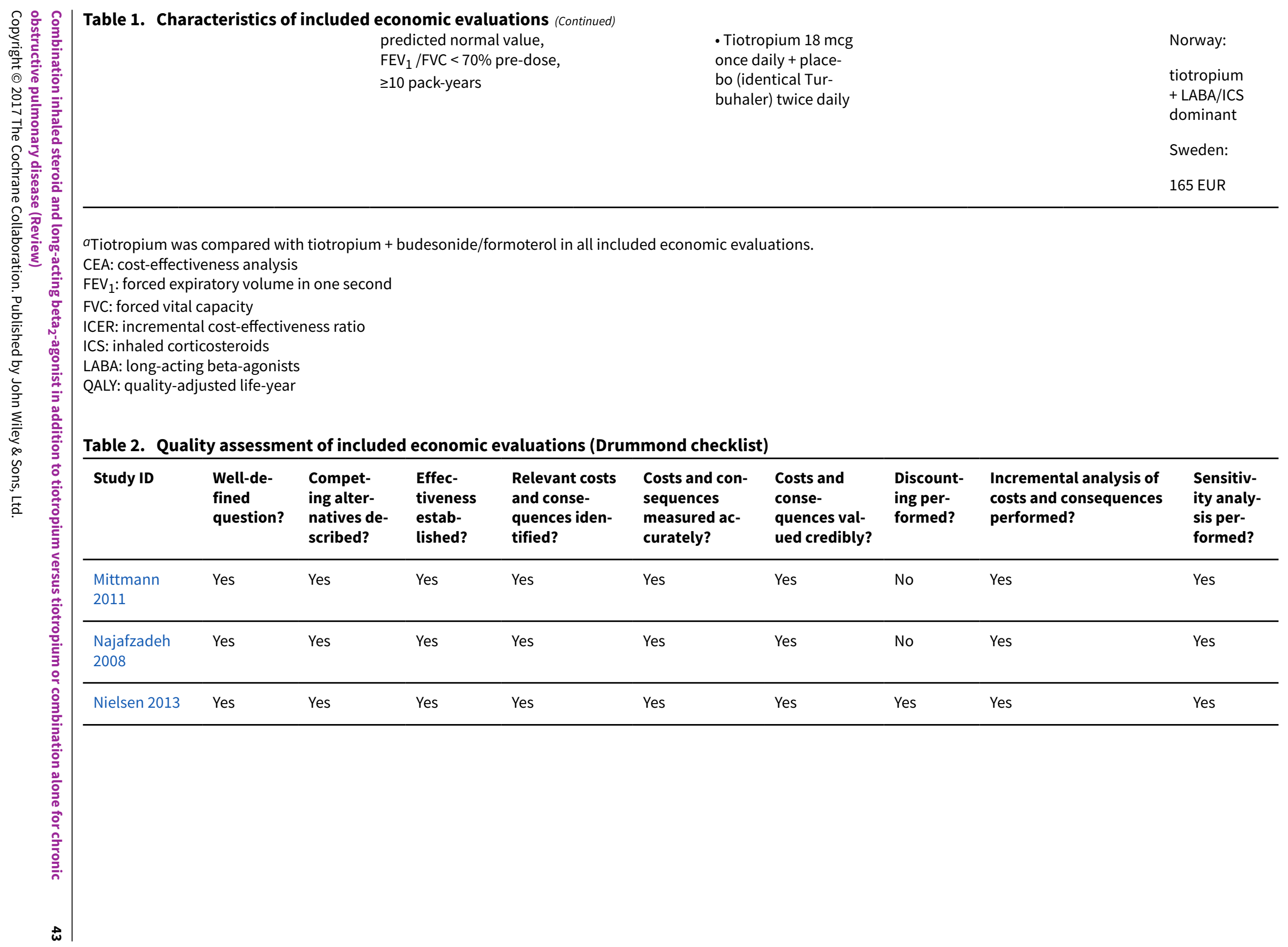


Table 3. Characteristics of included studies: baseline COPD severity and exacerbation status

\begin{tabular}{|c|c|c|c|}
\hline Study ID & Baseline COPD severity & Baseline $\mathrm{FEV}_{\mathbf{1}} \%$ predicted & $\begin{array}{l}\text { Exacerbation status preceding en- } \\
\text { rolment }\end{array}$ \\
\hline Aaron 2007 & Moderate or severe & $\begin{array}{l}\text { Inclusion criteria }<65 \% \text { predicted } \\
\text { Mean } \mathrm{FEV}_{1} \% \text { predicted tiotropium + LA- } \\
\mathrm{BA} / \mathrm{ICS} \text { group } 42.2 \% \text { and in tiotropium } \\
\text { group } 42.1 \%\end{array}$ & $\begin{array}{l}\text { Required to have had } \geq 1 \text { exacerba- } \\
\text { tion in previous year }\end{array}$ \\
\hline Cazzola 2007 & Severe and very severe & $\begin{array}{l}\text { Inclusion criteria } \leq 50 \% \text { predicted } \\
\text { Mean } \mathrm{FEV}_{1} \% \text { predicted LABA } / \mathrm{ICS} \text { group } \\
=36.9 \% \text {, tiotropium group }=38.5 \% \text {, } \\
\text { tiotropium + LABA } / \mathrm{ICS} \text { group }=39 \%\end{array}$ & $\begin{array}{l}\text { No information on exacerbation sta- } \\
\text { tus before enrolment }\end{array}$ \\
\hline Hanania 2011 & $\begin{array}{l}\text { Moderate: } \text { tiotropium } \\
+ \text { LABA } / I C S=63 \% \text { and } \\
\text { tiotropium }=72 \% \\
\text { Severe: tiotropium }+ \\
\text { LABA } / I C S=37 \% \text { and } \\
\text { tiotropium }=28 \%\end{array}$ & $\begin{array}{l}\text { Inclusion criteria } \geq 40 \text { to } \leq 80 \% \text { predicted } \\
\text { Mean } \mathrm{FEV}_{1} \% \text { predicted tiotropium }+ \text { LA- } \\
\mathrm{BA} / \mathrm{ICS} \text { group }=56 \% \text { and tiotropium group } \\
=57.4 \%\end{array}$ & $\begin{array}{l}\text { Exacerbations in past } 12 \text { months re- } \\
\text { quiring antibiotics/corticosteroid: } \\
\text { tiotropium + LABA/ICS: } 1 \text { exacerba- } \\
\text { tion }=37 \%, \geq 2 \text { exacerbations }=6 \% \\
\text { Tiotropium: } 1 \text { exacerbation }=27 \%, \geq \\
2 \text { exacerbations }=6 \%\end{array}$ \\
\hline Hoshino 2011 & $\begin{array}{l}\text { Mild to very severe } \\
\text { Overall: } \text { mild }=10 \% \text {, } \\
\text { moderate }=33 \%, \text { severe } \\
=36.6 \% \text {, very severe }= \\
20 \% .\end{array}$ & $\begin{array}{l}\text { Mean } \mathrm{FEV}_{1} \% \text { predicted tiotropium }+ \text { LA- } \\
\mathrm{BA} / \mathrm{ICS} \text { group }=64.6 \% \text { and tiotropium } \\
\text { group }=57.1 \%\end{array}$ & $\begin{array}{l}\text { Participants were excluded if they } \\
\text { had experienced an exacerbation in } \\
\text { the previous } 12 \text { weeks before com- } \\
\text { mencement of the study. No other } \\
\text { information on exacerbation status }\end{array}$ \\
\hline Jung 2012 & $\begin{array}{l}\text { Moderate: tiotropium + } \\
\text { LABA } / I C S=56.6 \% \text { and } \\
\text { tiotropium }=60.3 \% \\
\text { Severe: } \text { tiotropium + } \\
\text { LABA } / \text { ICS }=40.8 \% \text { and } \\
\text { tiotropium }=35.5 \% \\
\text { Very severe: } \text { tiotropium } \\
+ \text { LABA } / I C S=2.7 \% \text { and } \\
\text { tiotropium }=3.5 \%\end{array}$ & $\begin{array}{l}\text { Inclusion criteria }<65 \% \text { predicted } \\
\text { Mean } \mathrm{FEV}_{1} \% \text { predicted tiotropium + LA- } \\
\mathrm{BA} / \mathrm{ICS} \text { group }=47.4 \% \text { and tiotropium } \\
\text { group }=47.5 \%\end{array}$ & $\begin{array}{l}\text { No information on exacerbation be- } \\
\text { fore enrolment }\end{array}$ \\
\hline Welte 2009 & Severe and very severe & $\begin{array}{l}\text { Inclusion criteria } \leq 50 \% \text { predicted } \\
\text { Mean } \mathrm{FEV}_{1} \% \text { predicted tiotropium + LA- } \\
\mathrm{BA} / \mathrm{ICS} \text { group }=38.1 \% \text { and tiotropium } \\
\text { group }=37.7 \%\end{array}$ & $\begin{array}{l}\text { Required to have had } \geq 1 \text { exacerba- } \\
\text { tion in previous year } \\
\text { Mean exacerbations last year: } 1.4 \text { for } \\
\text { both groups, range } 1-7\end{array}$ \\
\hline
\end{tabular}

COPD: chronic obstructive pulmonary disease

$\mathrm{FEV}_{1}$ : forced expiratory volume in one second

LABA: long-acting beta-agonists

ICS: inhaled corticosteroids 


\section{APPENDICES}

\section{Appendix 1. Sources and search methods for the Cochrane Airways Group Specialised Register (CAGR) \\ Electronic searches: core databases}

\begin{tabular}{ll}
\hline Database & Frequency of search \\
\hline CENTRAL (The Cochrane Library) & Monthly \\
\hline MEDLINE (Ovid) & Weekly \\
\hline EMBASE (Ovid) & Weekly \\
\hline PSyCINFO (Ovid) & Monthly \\
\hline CINAHL (EBSCO) & Monthly \\
\hline AMED (EBSCO) & Monthly \\
\hline
\end{tabular}

\section{Handsearches: core respiratory conference abstracts}

\begin{tabular}{ll}
\hline Conference & Years searched \\
\hline American Academy of Allergy, Asthma and Immunology (AAAAI) & 2001 onwards \\
\hline American Thoracic Society (ATS) & 2001 onwards \\
\hline Asia Pacific Society of Respirology (APSR) & 2004 onwards \\
\hline British Thoracic Society Winter Meeting (BTS) & 2000 onwards \\
\hline Chest Meeting & 2003 onwards \\
\hline European Respiratory Society (ERS) & $1992,1994,2000$ onwards \\
\hline International Primary Care Respiratory Group Congress (IPCRG) & 2002 onwards \\
\hline Thoracic Society of Australia and New Zealand (TSANZ) & 1999 onwards \\
\hline
\end{tabular}

\section{MEDLINE search strategy used to identify trials for the CAGR COPD search}

1. Lung Diseases, Obstructive/

2. exp Pulmonary Disease, Chronic Obstructive/

3. emphysema\$.mp.

4. (chronic\$ adj3 bronchiti\$).mp.

5. (obstruct\$ adj3 (pulmonary or lung\$ or airway\$ or airflow\$ or bronch\$ or respirat\$)).mp. 
6. COPD.mp.

7. COAD.mp.

8. COBD.mp.

9. AECB.mp.

10. or $/ 1-9$

\section{Filter to identify RCTs}

1. exp "clinical trial [publication type]"/

2. (randomized or randomised).ab,ti.

3. placebo.ab,ti.

4. dt.fs.

5. randomly.ab,ti.

6. trial.ab,ti.

7. groups.ab,ti.

8. or/1-7

9. Animals/

10. Humans/

11.9 not (9 and 10$)$

12. 8 not 11

The MEDLINE strategy and RCT filter are adapted to identify trials in other electronic databases.

Appendix 2. Search strategy to identify relevant trials from the CAGR

\#1 MeSH DESCRIPTOR Pulmonary Disease, Chronic Obstructive Explode All

\#2 MeSH DESCRIPTOR Bronchitis, Chronic

\#3 (obstruct ${ }^{\star}$ ) near3 (pulmonary or lung* or airway* or airflow* ${ }^{\star}$ or bronch or respirat $^{\star}$ )

\#4 COPD:MISC1

\#5 (COPD OR COAD OR COBD):TI,AB,KW

\#6 \#1 OR \#2 OR \#3 OR \#4 OR \#5

\#7 tiotropium*

\#8 Spiriva

\#9 glycopyrronium*

\#10 glicopirronio*

\#11 Seebri

\#12 \#7 or \#8 or \#9 or \#10 or \#11

\#13 budesonide

\#14 fluticasone

\#15 beclomethasone

Combination inhaled steroid and long-acting beta $_{2}$-agonist in addition to tiotropium versus tiotropium or combination alone for chronic

Copyright $\odot 2017$ The Cochrane Collaboration. Published by John Wiley \& Sons, Ltd. 
\#16 mometasone

\#17 ciclesonide

\#18 steroid* $^{*}$ or corticosteroid*

$\# 19 \# 13$ or \#14 or \#15 or \#16 or \#17 or \#18

\#20 *formoterol

\#21 salmeterol

\#22 indacaterol

\#23 olodaterol

\#24 beta* NEAR agonist* $^{*}$

\#25 \#20 or \#21 or \#22 or \#23 or \#24

\#26 \#19 and \#25

\#27 symbicort

\#28 viani

\#29 seretide

\#30 advair

\#31 foster

\#32 fostair

\#33 inuvair

\#34 fostex

\#35 kantos

\#36 combination*

\#37 \#27 or \#28 or \#29 or \#30 or \#31 or \#32 or \#33 or \#34 or \#35 or \#36

\#38 \#6 and \#12 and (\#26 or \#37)

[In search line \#4, MISC1 denotes the field in the record where the reference has been coded for condition, in this Case, COPD]

\section{Appendix 3. Results of the search 2010}

The initial search identified 101 references. Of these, we identified 24 as potentially relevant, and we obtained full-text versions for further assessment. Fourteen of these were eligible for inclusion and belonged to three studies (Aaron 2007; Cazzola 2007; Welte 2009) (see Characteristics of included studies table). Peer review identified one further potentially eligible study; this is noted in the Characteristics of studies awaiting classification table (Fang 2008).

\section{FEE D B A C K}

\section{Errors in data entry introduced by update, 8 April 2017}

\section{Summary}

In this 2016 review, I was surprised to read the authors' conclusions read "we found new moderate-quality evidence that combined tiotropium + LABA/ICS therapy compared with tiotropium plus placebo decreases hospital admission." The forest plot (Figure 3) shows that two RCTs (Welte 2009 and Aaron 2007) contribute to this analysis: hospital admission (all cause): OR 0.61 [95\% $\mathrm{Cl} 0.40,0.92]$. These are the same two RCTs used in the 2011 version of the same review which did not find a reduction in hospital admission (all cause): OR $0.84[95 \% \mathrm{Cl} 0.53,1.33]$. The discrepancy seems to originate from the data input for Aaron 2007 in the 2016 review. The 2016 review reports: 41 events for triple therapy compared to 62 events for tiotropium. The 2011 review reports: 32 events for triple therapy compared to 36 events tiotropium. The 2011 review reports that the data for Aaron 2007 were supplied by the authors, that is, the numbers of people with 
one or more hospitalization (all cause) was not reported in the Annals of Internal Medicine publication of the trial. Therefore the numbers contributing to the analysis in the 2016 review are total numbers of events, not numbers of people with one or more events.The 2016 review reads "We analysed dichotomous data by using participants as the unit of analysis (rather than events) to avoid counting the same participant more than once". The use of events for this outcome would not be consistent with that analysis plan. I do hope the discrepancies can be clearly addressed.

\section{Reply}

We thank Dr O'Sullivan for their feedback and interest in our review.

The data used in our 2016 review update for the analysis of the "Hospital admissions" outcome was that reported by Aaron 2007 in the Annals of Internal Medicine paper. As correctly pointed out, the data used in the 2011 review were unpublished data supplied directly by Aaron to the prior review authors. We have since obtained this data and have corrected the meta-analysis for "hospital admissions" and the corresponding sections ("Effects of interventions", SoF table and conclusions) in accordance with these new findings.

\section{Contributors}

Cait O'Sullivan (PharmD)Island Health, British Columbia, Canada

I certify that I have no affiliations with or involvement in any organisation or entity with a direct financial interest in the subject matter of my criticisms.

\section{WHAT'S NEW}

\begin{tabular}{lll}
\hline Date & Event & Description \\
\hline 24 May 2017 & Amended & $\begin{array}{l}\text { Feedback and reply added. Data in analys es 1.2 (hospital ad- } \\
\text { misssion) reverted to that shown in the original review. Clarifica- } \\
\text { tions made in the text. }\end{array}$ \\
\hline 24 May 2017 & Feedback has been incorporated & New feedback received \\
\hline
\end{tabular}

\section{H I S T O R Y}

Protocol first published: Issue 6, 2010

Review first published: Issue 3, 2011

\begin{tabular}{|c|c|c|}
\hline Date & Event & Description \\
\hline 10 April 2015 & $\begin{array}{l}\text { New citation required and conclusions } \\
\text { have changed }\end{array}$ & $\begin{array}{l}\text { Three new studies were added (Hanania 2011; Hoshino } 2011 \text {; } \\
\text { Jung 2012), increasing the number of participants contributing } \\
\text { data to the review from } 1021 \text { to } 1902 \text {. In this update, we found } \\
\text { that combined therapy tiotropium + LABA/ICS compared with } \\
\text { tiotropium plus placebo } \\
\text { In this update, we also included a synthesis of economic evi- } \\
\text { dence addressing the same question of interest for this review }\end{array}$ \\
\hline 10 April 2015 & New search has been performed & $\begin{array}{l}\text { This review was updated following a new literature search up to } \\
\text { April } 2015\end{array}$ \\
\hline 11 April 2013 & Amended & NIHR acknowledgement added \\
\hline
\end{tabular}

\section{CONTRIBUTIONS OF AUTHORS}

Charlotta Karner and Chris Cates wrote the first version of this review. Olga Milena García Morales, María Ximena Rojas-Reyes and Rodolfo J. Dennis drafted the update protocol and conducted the updating process. Olga Milena García Morales and Rodolfo J. Dennis conducted 
the screening search and data extraction; María Ximena Rojas-Reyes and Rodolfo J. Dennis conducted the screening search and extracted data from economic articles. The three review authors interpreted findings and wrote the review conclusions.

Charlotta Karner reviewed the document of the updated review, submitted it for editorial approval and accepted the final publication.

\section{DECLARATIONS OF INTEREST}

Dr. OM Garcia has received financial support to attend scientific meetings from pharmaceutical companies which manufacture tiotropium preparations. The remaining three authors were not aware of any conflict of interest that should be declared covering the past three years.

\section{SOURCES OF SUPPORT}

\section{Internal sources}

- The Department of Clinical Epidemiology and Biostatistics of the Faculty of Medicine of the Pontificia Universidad Javeriana, Bogotá, Colombia.

Supported the time dedicated by the review authors, Olga Milena García, María Ximena Rojas and Rodolfo Dennis, to update this review at the Cochrane Collaboration Center

\section{External sources}

- NIHR, UK.

National Institute for Health Research supported this work through funding for both authors who worked on the previous version of this review

\section{DIFFERENCES BETWEEN PROTOCOLANDREVIEW}

We included the comparison of treatment with tiotropium + LABA/ICS versus LABA/ICS. We narratively reported the percentage of participants with a clinically significant change in health-related quality of life as reported by study authors, although this was not specified in Measures of treatment effect.

In this update, we included a synthesis of economic evidence addressing the same question and performed sensitivity analyses that excluded studies that may have recruited large numbers of participants who would not be candidates for tiotropium + LABA/ICS according to current guidance.

\section{N DEX TERMS}

\section{Medical Subject Headings (MeSH)}

Administration, Inhalation; Adrenergic beta-2 Receptor Agonists [ ${ }^{*}$ administration \& dosage]; Bronchodilator Agents [ ${ }^{*}$ administration \& dosage]; Drug Therapy, Combination [methods]; Glucocorticoids [ ${ }^{*}$ administration \& dosage]; Pulmonary Disease, Chronic Obstructive [*drug therapy] [mortality]; Randomized Controlled Trials as Topic; Tiotropium Bromide [ ${ }^{\star}$ administration \& dosage]

\section{MeSH check words}

Humans 